\title{
RELATIVE EXPRESSION OF GERMINATION GENES SLEB, GERAC, AND GPR IN HEAT-TREATED BACILLUS LICHENIFORMIS AND BACILLUS SUBTILIS
}

\author{
A Thesis \\ Presented to \\ the Faculty of California Polytechnic State University, \\ San Luis Obispo \\ In Partial Fulfillment \\ of the Requirements for the Degree \\ Master of Sciences in Agriculture with Specialization in Dairy Products \\ Technology
}

By

Valerie Paige Arechiga

December 2014 
(C) 2014

Valerie Paige Arechiga

ALL RIGHTS RESERVED 
COMMITTEE MEMBERSHIP

TITLE:

Relative Expression of Germination Genes

SleB, GerAC, and gpr in Heat Treated Bacillus

licheniformis and Bacillus subtilis

AUTHOR:

Valerie Paige Arechiga

DATE SUBMITTED:

December 2014

COMMITTEE CHAIR:

Rafael Jimenez-Flores, Ph, D., Professor of Dairy Science

COMMITTEE MEMBER:

Chris Kitts, Ph. D., Professor of Biological Sciences

COMMITTEE MEMBER:

Ken Hillers, Ph. D., Associate Professor of Biological Sicences 


\author{
ABSTRACT \\ Relative Expression of Germination Genes SleB, GerAC, and gpr in Heat- \\ Treated Bacillus licheniformis and Bacillus subtilis \\ Valerie Paige Arechiga
}

Endospore-forming bacteria of the genus Bacillus are of significant importance to the food industry. Species from this genus exhibit the ability to form metabolically dormant endospores characterized by resistance to heat, UV, and chemical treatment. Spores have undetectable metabolic activity and remain impervious to the harsh conditions of their environment, but they can detect environmental cues signaling favorable growth conditions and begin the process of germination. Once germination and outgrowth are complete, the fully viable cell is capable of reproducing and forming colonies. The resistance of these endospores has been a topic of decades of research, particularly because of their impact on food processing. Only a few species of Bacillus are actually pathogenic, but many others present quality defects, particularly in milk and other dairy products.

This study involved the selection and use of primers specific for GerAC, gpr, and $S / e B$ genes to evaluate their relative expression and potential for indicators of lag phase in germination. Gene expression studies with qPCR were carried out during germination in Bacillus subtilis and Bacillus licheniformis spores that were given a heat shock in a tryptic soy broth at $80^{\circ} \mathrm{C}$ and subsequently incubated for $0,30,60$, and 120 minutes at their optimal growth temperatures. Expression ratios calculated relative to the samples incubated for $120 \mathrm{~min}(R=1)$ showed increased expression as germination and outgrowth progressed (GerAC gene on $B$. licheniformis and $B$. subtilis; $R_{30 \mathrm{~min}}=0.14$ and $0.14, R_{60 \mathrm{~min}}=0.76$ and 0.51 ). The different expression levels measured in this preliminary study suggest that the selected genes and methodology merit further optimization to verify the accuracy and significance of the assay as well as its application it to the milk powder process. 


\section{ACKNOWLEDGMENTS}

First, I would like to show my appreciation to my advisor, Dr. Jimenez for giving me the opportunity and support to see this degree through until its fulfillment. His positive outlook and faith in my abilities were instrumental in keeping my project on track and in perspective. I would also like to thank him for the experience in applications outside the scope of my thesis and of course for supporting my decision to start working before the completion of this degree. It has not been the easiest way to complete the thesis, but it had been a learning experience. I also extend this appreciation to my committee members, Dr. Kitts and Dr. Hillers, who were gracious and flexible with my scheduling. If not for a promise to them, I may not have finished this thesis.

Second, I would like to show my gratitude to Andrea Laubscher for being there to answer all of my many (and many of which were stupid) questions tirelessly and with the utmost patience. She brought order to chaos, and for this I cannot thank her enough. Of equal importance to the completion of research was Alma Islas-Trejo and Mariam of Dr. Juan Medrano's lab at the University of California, Davis. The integrity, efficiency, and accuracy of my research would be sorely lacking without the hours of patience they showed me. I would also like to thank Dr. Reaves for donating resources for my research when they were scarce. Without his generosity I would have spent a lot more time on a lot less satisfying results.

Of course I would like to tip my hat to my friends and peers at the Dairy Products Technology Center. Emily Kong, Lauren Collinsworth, Hadi Eshpari, 
Melissa Hsu, Tracy Nguyen, Stephanie Jacquez, Azucena Baracil, and Mariela Poveda were my colleagues and support crew throughout the almost two years at Cal Poly. The laughs and stories made the long hours of lab work and class time worth it. Corbin Kembel and Garrett Walsh, my career at Cal Poly would be incomplete without the two of you. You saw me through from the beginning and I am happy that you could see me through the end. From studying, brainstorming, complaining, and happy hours at Central Coast Brewery you guys helped me get through grad school by being there every step of the way. The same goes for Katy Lees, who allowed me to "help" milk her beloved Jersey cow and who saw me nearly everyday, whether at work or on a run.

Last, but certainly not least, I would like to thank my family. Thank you to my Mom, Dad and brother, for supporting me throughout my second time in the higher education system, even if they had no idea what I was doing my research on. I also can't overlook the subtle reminders of finishing my thesis even when I had spent too much time away from it. No matter how crazy I may seem, the love and support they showed me never waivers.

For all those who played a part in me finally making it through this journey, I cannot thank you enough. 


\section{TABLE OF CONTENTS}

Page

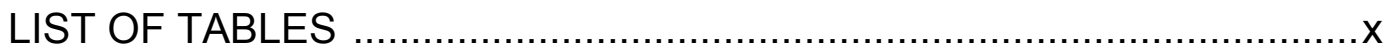

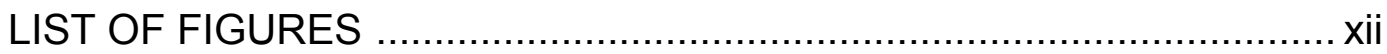

CHAPTER

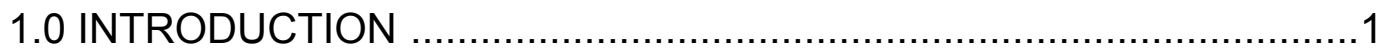

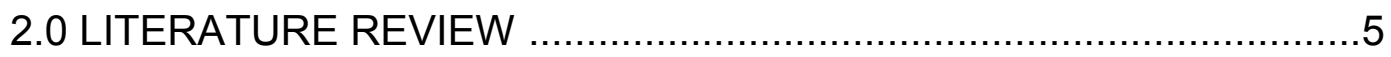

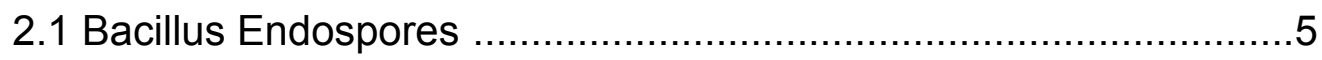

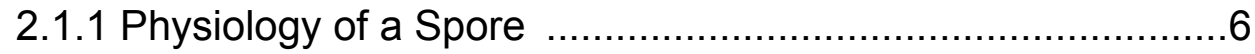

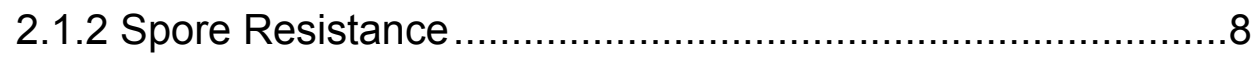

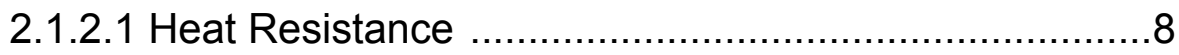

2.1.2.2 Radiation and Chemical Resistance ….....................

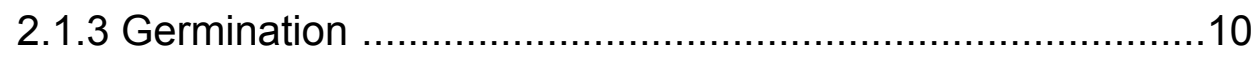

2.1.3.1 Germinant Receptors …....................................13

2.1.3.2 Ion/DPA Channels .............................................14

2.1.3.3 Cortex Lytic Enzymes …......................................16

2.1.3.4 Non-Nutrient Germination ......................................16

2.2 Occurrence of Spores in Dairy Products …..............................17

2.3 Relative Gene Expression Using qPCR …..............................21

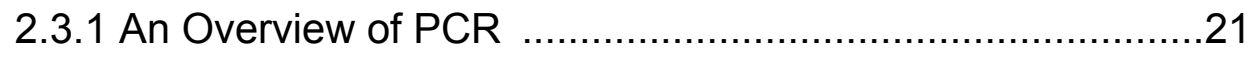

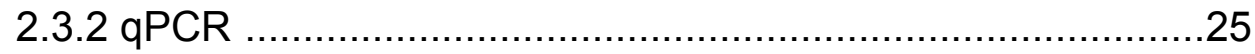

2.3.2.1 RNA extractions and quality requirements ...............25

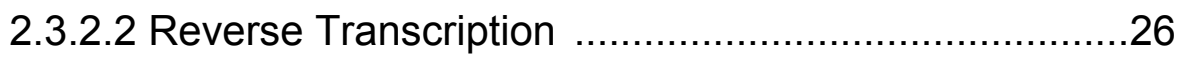


2.3.2.3 qPCR as an assay for relative gene expression

2.3.3 qPCR as a rapid method for identifying and enumerating endospores

3.0 MATERIALS AND METHODS .31

3.1 Spore Growth Curves and Germination Assays .31

3.1.1 Preparation of Endospore Stock Solution .31

3.1.2 Growth Curve Using BacT/Alert .33

3.1.3 Germination Assay .34

3.1.4 Statistical Analysis of Growth Curves and Lag Times .34

3.2 PCR .34

3.2.1 Purification of Genomic DNA .34

3.2.2 Selection of Target Genes .35

3.2.3 Primer Design .36

3.2.4 PCR Conditions for Pure Cultures .37

3.3 qPCR: Gene Expression Assay .37

3.3.1 Purification of Total RNA and cDNA Synthesis .37

3.3.1.1 Sample Preparation and Visual Inspection .37

3.3.1.2 Lysis of Spores and Vegetative Cells .38

3.3.1.3 Total RNA Purification from Lysate .39

3.3.1.4 Reverse Transcription .39

3.3.2 Validation Assay .40

3.3.3 Experimental Assay .41 
4.1 Growth and Germination Curves for $B$. subtilis and

B. licheniformis

4.1.1 Growth Curve Using BacT/Alert .....................................42

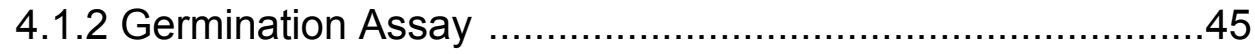

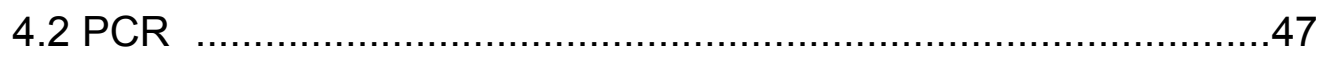

4.3 qPCR as a Gene Expression Assay .........................................51

4.3.1 Total RNA purification from Lysate .................................51

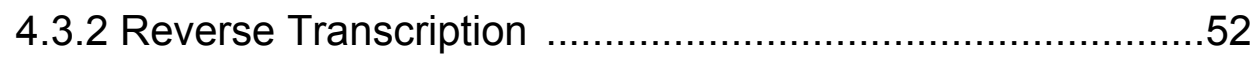

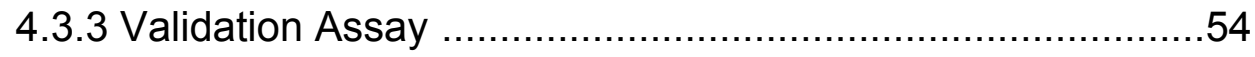

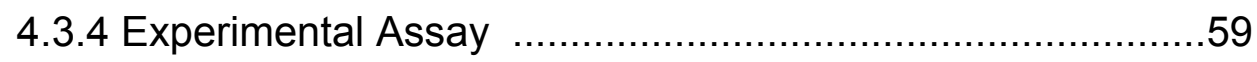

5.0 CONCLUSION AND FUTURE RESEARCH ..............................67

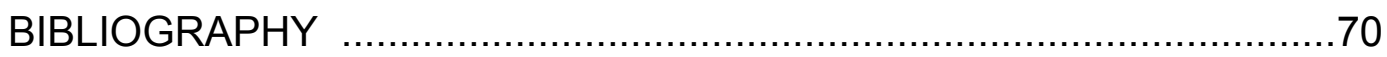

\section{APPENDICES}

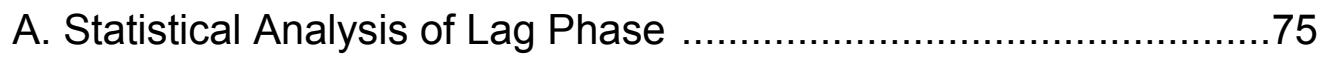

B. Additional Standard Curves and Dissociation Curves

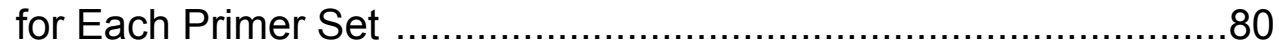

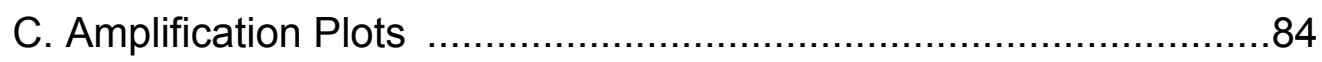




\section{LIST OF TABLES}

Table

Page

2.1 Natural occurrence of sporeformers reported in food with or without visible spoilage activity. Known sporeformers associated with specific food alterations are reported for late-blowing cheese, ropy bread, unstable canned foods, spoiled juice, and blown chilled meat packs. Taken from Postollec, et al, International Journal of Food Microbiology (2012)

3.1 Primers targeting genes specific for the species $B$. subtilis and $B$. licheniformis 36

3.2 Volumes and reagents used for Reverse Transcription.

First the sample and gDNA wipeout volumes were combined to complete the gDNA elimination step. That combined volume was mixed with RT Master Mix volume and RNase-Free water (to reach $20 \mu \mathrm{L}$ reaction volume) to complete the translation of RNA to cDNA

4.1 Lag phase values for $B$. subtilis and $B$. licheniformis (in minutes)

4.2 Lag time ratios for both species. These were calculated relative to the preceding concentration, which is why no value exists for the first concentration

4.3 Concentrations and purity of genomic DNA samples extracted using Rueckert et al method measured with a NanoDrop 2000c UV-Vis Spectrophotometer (Fisher Scientific), dilution factors, and final concentrations to be used in PCR

4.4 Concentration of RNA calculated from the $A_{260}$ readings given by a NanoDrop 2000c UV-Vis Spectrophotometer using $\varepsilon=25(\mu \mathrm{L} / \mu \mathrm{g}) \mathrm{cm}^{-1}$. Concentrations of cDNA were estimated assuming $100 \%$ efficiency of the RTase. Varying amounts of the RNA depending on the starting concentration, hence the incongruity between [RNA] and [cDNA]

4.5 E values for $r r n E$ and GerAC (B. subtilis and B. licheniformis), and $g p r$ and $S / e B$ (B. licheniformis). E values for the primers to amplify the gpr and SleB gene on B.subtilis were not calculated as the corresponding dissociation curves displayed non-specificity of the primers 
4.6 Mean $\mathrm{C}_{T}$ values and calculated Ratios for relative gene expression of the treatments of $B$. subtilis and $B$. licheniformis.

The ratio is a comparison to the control $(120 \mathrm{~min})$ treatment .............62 


\section{LIST OF FIGURES}

Figure

2.1 The general structure of a bacterial endospore

2.2 Events in spore germination

2.3 Spore structure (not to scale) and various components

involved in spore germination

2.4 Model for nutrient and non-nutrient spore germination in $B$. subtilis ..17

2.5 Schematic of polymerase chain reaction

4.1 Growth curves of $B$. subtilis $(A)$ and $B$. licheniformis $(B)$ in the BacT/Alert iAST media

4.2 Absorbance of spore solutions after heat-treatment at $80^{\circ} \mathrm{C}$ for

$12 \min$

4.3 Genomic DNA purification of $B$. subtilis and B. licheniformis .48

4.4 PCR product from varying annealing temperatures

$4.51 .5 \% \mathrm{w} / \mathrm{v}$ agarose gel on $1 \mathrm{x}$ TAE with ethidium bromide, run for $20 \mathrm{~min}$ at $90 \mathrm{~V}$ .50

4.6 RNA purification of $B$. licheniformis

4.7 PCR amplification using the primer set for the 16 s gene (reference gene)

4.8 Dissociation curve of 16 s primers (HKG) on template cDNA

for both species .55

4.9 Dissociation curve of $S / e B$ primers for $B$. subtilis template cDNA ......56

4.10 Standard curve using B. licheniformis template cDNA and $r$ rnE primers .58

4.11 Amplification plot showing all 5 PCR reactions-reference gene and GerAC for both B. licheniformis and B. subtilis, and gpr and SleB for $B$. licheniformis 
4.12 Ratio of the gene expression of the test treatment to the control treatment plotted according to test treatment

$4.13100 x--$ Spore differential staining using a $5 \%$ w/v malachite green solution

A Dissociation curve for primers targeting the gpr gene on B. licheniformis .80

B Dissociation curve for primers targeting the gpr gene on B. subtilis

C Dissociation curve for primers targeting the SleB gene on $B$. licheniformis

D Dissociation curve for primers targeting the GerAC gene on $B$. licheniformis (green and yellow curves) and on $B$. subtilis (blue and purple curves)

E Amplification plot for primers targeting the GerAC gene on B. licheniformis

F Amplification plot for primers targeting the GerAC gene on B. subtilis 


\section{CHAPTER 1 \\ INTRODUCTION}

Endospore-forming bacteria, particularly those species belonging to the genus Bacillus and Clostridium, have posed challenges throughout the history of food processing. First detected by Cohn in 1876 as 'strongly refracting bodies,' the survival of these organisms at $100^{\circ} \mathrm{C}$ came as a surprise and has become an extensive area of study ever since. Species of both Bacillus and Clostridium are associated with various food product quality defects and food-borne intoxication. Endospores created by species from these genera are metabolically dormant and resistant to heat, UV, and chemical treatments while maintaining environmental sensing that allows them to germinate and proliferate when a favorable environment is detected.

These endospores are capable of causing severe economic damage in addition to health and safety risks. In the dairy industry, they withstand most milk processing treatments in order to grow and reproduce in refrigerated environments. Furthermore, they survive in milk powder and pose problems in products of which milk powder is an ingredient. Of particular relevance to the dairy industry are the species belonging to the genus Bacillus. These species are Gram-positive aerobes or facultative aerobes that proliferate in a wide temperature range-different organisms of these species can be classified as psychrotrophs, mesophiles, or thermophiles. While only a few species are pathogens responsible for food-borne intoxications (e.g. Bacillus cereus and Bacillus anthracis), the rest can cause serious quality defects in milk and dairy 
products (and other food as well), which lead to economic loss and unnecessary waste.

Species of Bacillus are ubiquitous in the environment and are present in soil and the gastrointestinal tract of insects and animals. Spores enter the dairy processing environment through many different ways: studies have found up to hundreds of spores per gram of milk, but more typically around ten to twenty spores per gram (Christiansson et al., 1999). They are introduced into the dairy processing environment through the raw milk itself or from outside contamination. Once Bacillus spores have taken up residence in the processing plant, they have the ability to adhere to surfaces and create a biofilm. Both vegetative cells and spores reside in this film as micro colonies and release into the product, causing concentrations of the microbe to be much greater than in the fluid introduced.

The presence of a high number of spores $\left(>10^{4} \mathrm{cfu} / \mathrm{g}\right)$ in finished dairy products, specifically milk powder, is an indicator of poor hygiene and equates to a low quality product. In the United States, keeping the spore count low enough to meet the standards for high quality milk powder means increasing US exports of milk powder and economic growth for the dairy sector. Identifying and implementing technology and processes that manage spore counts in liquid and powdered milk products is an important step in the evolution of the dairy industry to higher quality functional food products and ingredients.

Methods to identify and enumerate bacilli in milk products are of great importance when dealing with milk powder. Thermophilic bacilli are particularly 
important, and pertinent methods include traditional plate count methods as well as rapid techniques. Of particular interest is the use of real-time quantitative polymerase chain reaction (qPCR) to amplify spore specific genes in order to identify and enumerate spores in dairy products. An assay developed by Rueckert et al (2006) amplifies DNA from the spoOA gene specific to thermophilic bacilli and other bacilli to measurable levels in less than one hour of lab time. Although this method is more rapid and more accurate than the plate counting method, it is more costly and requires a highly trained technician, and great attention to detail to execute appropriately.

Genes involved in germination are unique to these endospore-forming bacteria, and may also provide an effective way to identify species with these characteristics. In addition, the expression of these germination-related genes may give more insight to the lag phase of these species. The lag phase as applies to spores is the time in the bacteria's life cycle when it is germinating (losing its spore characteristics) and increasing in cell mass. This phase precedes the exponential phase in which the cells begin to double and increase geometrically in total number. Understanding the lag phase of spores can provide insight into their behavior in dairy processing environments. At some point in the lag phase, the germinating spore loses its heat resistance and will be susceptible to killing through wet or dry heat. Identifying when this loss in heat resistance occurs has critical implications in process adaptations that result in the decrease of spore counts in final products. 
A qPCR assay can be developed to determine relative gene expression of different germination specific genes at different times during the lag phase of selected Bacillus species. The level of expression of different genes can lend insight into the resistance of the spore. Genes associated with the later stages of germination (e.g. cortex lytic enzymes) will presumably be expressed at higher levels at a time when the spore has lost most of its chemical/thermal resistance and is no longer dormant. Once a relative gene expression assay has been optimized, it can be used to identify processing time-points in which spores have lost resistance and advise processing adjustments to decrease viable spore counts.

In summary, this study aimed to:

1. Compare the growth curves, particularly the lag phase, of $B$. licheniformis and B. subtilis.

2. Create an assay to determine relative gene expression using $\mathrm{qPCR}$

3. Analyze the feasibility of using the expression of select germination-specific genes to identify time-points during the lag phase that correlate to loss of spore resistance. 


\section{CHAPTER 2 \\ LITERATURE REVIEW}

\subsection{Bacillus Endospores}

Species belonging to the genera Bacillus and Clostridia are gram-positive rods that have the impressive quality of forming endospores when environmental stimuli indicate an unfavorable environment for cell growth. These endospores are inert, metabolically dormant "seeds" that maintain the ability to sense the environment. They resist heat, chemical, and UV treatments designed to decrease microbiological loads. Spore resistance and persistence enable their proliferation in food processing operations and in food products. The subsequent effect they have on quality have made bacterial endospores a topic of study for the past 138 years (Gould, 2005). While there has been no shortage of research on endospores and many discoveries characterizing their life cycles, there are still many unanswered questions about basic mechanisms involved in the sporulation and germination of these species. 


\subsubsection{Physiology of a Spore}

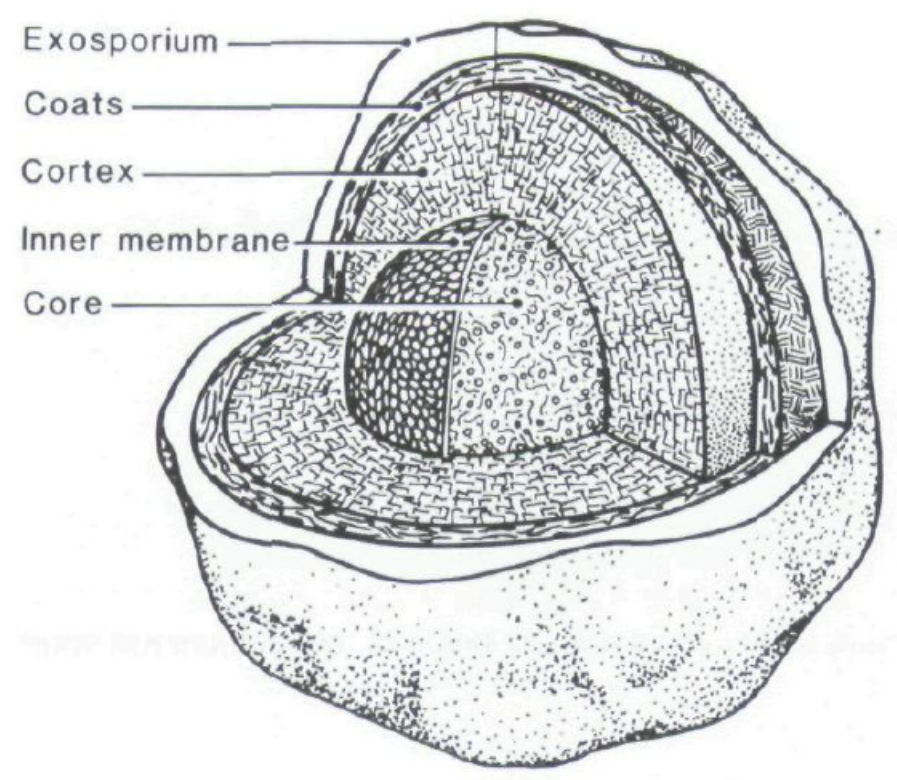

Figure 2.1 The general structure of a bacterial endospore. Not pictured: the outer membrane, which exists between the spore coats and cortex. Adapted from Foster and Johnstone

The spores of the Bacillus genus are metabolically dormant, meaning they exhibit no detectable metabolic activity. The spore's resistance and survival is attributed to this dormancy. Spores can withstand exposure to $\mathrm{pH}$ changes, radiation, heating and freezing, desiccation and humidity, as well as chemical agents and disinfectants (Setlow, 2003; Setlow, 2005; Burgess, 2010). This resistance is engendered by the anatomy of the spore. As shown in Figure 2.1, the innermost section of the spore is the core. The core houses the nucleic acids and all the genetic information required to form a functioning vegetative cell after germination and outgrowth. A lipid bilayer or inner membrane surrounds the core and a peptidoglycan cortex and cell wall surrounds the inner membrane and core as a protective barrier. Just outside of the cortex and cell wall is an outer 
membrane followed by a number of protein containing spore coats and possibly an exosporium, depending on the species (Foster et al., 1990).

The exosporium (if present) is composed mainly of proteins, lipids, and carbohydrates and as a result is quite hydrophobic. The spore coat resides underneath the exosporium, if present. Some species do not have an exosporium and the spore coat exists as the outer layer. The spore coats consist of proteins that are arranged via heavy disulfide bonds into thin protein layers. This structure is semi-permeable and allows smaller molecules (like germinants) through while excluding the larger molecules. The cortex and germ cell wall are both peptidoglycan structures (Setlow, 2003). Slight differences in composition of these two structures allow for the selective degradation of the cortex during germination, while keeping the germ cell wall intact to become the cell wall of the vegetative cell (Leggett et al., 2012). The inner membrane lines the inside of the germ cell wall, and is similar in composition to the cytoplasmic membrane of a vegetative cell. However it is different in critical ways, for instance a decreased mobility of membrane lipids to prevent the diffusion of any molecules to the spore's core (Leggett et al., 2012). The inner membrane houses the germinant receptors that bind to nutrient germinants and initiate the germination of the spore (Setlow, 2003). The core within the inner membrane contains the DNA, RNA, ribosomes, and most of the essential enzymes for the future cell. 


\subsubsection{Spore Resistance}

The dormancy and heat resistance of the spore is largely due to the dehydrated state of this core, along with the physical shielding of the spore's DNA to heat and harmful chemicals by small acid-soluble proteins (SASPs) (Setlow, 2005).

\subsubsection{Heat Resistance}

Wet heat resistance is a long noted characteristic of Bacillus endospores: spores are resistant up to $40^{\circ} \mathrm{C}$ higher than their vegetative counterparts (Setlo,. 2005; Wayne et al., 2000). Wet heat resistance is defined as a resistance to heat treatment when suspended in an aqueous environment. The biggest factor in the spore's wet heat resistance is the low water content of the spore's core (Setlow, 2005). Therefore, the lower the water content of the core, the greater wet heat resistance of the spore (Setlow, 2005). The environment of sporulation can dictate water content of the core; sporulation completed at a higher temperature will result in lower core water content and subsequent increase in wet heat resistance (Nicholson et al., 2000). Another factor is the spore's ability to synthesize dipicolinic acid (DPA). If a specific strain of spore cannot synthesize DPA, it will have higher core water content and lower wet heat resistance (Paidhungat et al., 2000).

Aside from water content, wet heat resistance is affected by mineralization of the core and the saturation of DNA with SASPs; the latter being a major factor in preventing DNA damage as the mechanism for spore killing with wet heat. 
Increased mineralization and increased SASP density increase the wet heat resistance of spores (Setlow, 2005). Although the wet heat resistance of spores has been studied extensively, it is still unclear what mechanism actually kills the spore with wet heat. Spore killing via wet heat is not done by DNA damage, as is the case with dry heat. It is associated with the rupturing of the inner membrane permeability barrier and inactivation of core enzymes (Warth, 1980; Setlow et al., 2002).

Spores also show an increase in dry heat resistance, up to $30^{\circ} \mathrm{C}$, compared to their vegetative counterparts (Nicholson et al., 2000). Because DNA damage is the resulting cause of spore death when dry heat is implemented, this resistance is largely attributed to the shielding of DNA with SASPs. Shielding by SASPs is also important to the spore's resistance to multiple rounds of desiccation and rehydration. As spore killing is caused by DNA damage, the ability of DNA repair by the spore during outgrowth is critical in its dry heat resistance (Weller et al., 2002).

\subsubsection{Radiation and Chemical Resistance}

Water content of the spore's core also contributes to the spore's ability to resist radiation treatments. Presumably, the lack of water limits the production of hydroxyl radicals by ionizing radiation, limiting the damage in the spore core (Setlow, 2005). The spore is also more resistant to UV-radiation than the vegetative cell. SASP shielding, low water content, and the presence of DPA limit 
the photosensitivity of the spore-core DNA to mutagenic UV at 254nm (Nicholson et al., 2000; Setlow, 2005). Spores possess at least 3 mechanisms to repair DNA that has been damaged by UV: recombinational repair, nucleotide exclusion repair, and spore photoproduct lyase (Nicholson et al., 2005). Furthermore, the rapid repair of spore photoproduct in the early stages of spore outgrowth also contributes to the increased resistance of the spore vis-a-vis vegetative cell. However, is important to remember that chemical resistance varies not only species to species (and strain to strain), but that sporulation conditions have an impact on the resistance of spores (Setlow, 2012). This is of particular importance when it comes identifying methods of eliminating spores from a food processing environment.

\subsubsection{Germination}

Germination is the initiation of spore degradation and the loss of spore-specific properties (Foster et al., 1990). It is completed solely with the apparatus already inherent in the spore (Moir, 2005). While the spores of Bacillus may be dormant and highly resistant, they retain the ability to sense their environment for favorable conditions. Germinants are agents responsible for initiating the germination process of a spore. These instigators can be both nutrient based and non-nutrient based. Non-nutrient germinants include lysozyme, salts, high

pressure, $\mathrm{Ca}^{2+}$, pyridine-2, 6-dicarboxylic acid (dipicolinc acid [DPA]) and cationic surfactants. Nutrient germinants include single amino acids, sugars, and purine nucleosides—often in combination. In vivo, nutrient germinants are responsible 
for triggering spore germination (Setlow, 2003). The germinants travel through the semi-permeable outer layers of the spore in order to interact with the germinant receptors located on the inner membrane. This initiates changes to the membrane and allows ion and DPA movement out of the spore. Furthermore, it allows initial hydration of the core and cortex while coat lytic enzymes are activated. This facilitates the complete hydration of the core, allowing for full metabolic activity, macromolecular synthesis and cell outgrowth (Moir et al., 2002).

Within seconds of contact with the nutrient germinants, the spore commits to germination. Germination cannot be reversed with the removal of the nutrients. At present, the mechanism behind the germination commitment has not been determined. Following this irreversible activation are the two stages of germination as shown in Figure 2.2. Stage I, the early stage, is comprised of three steps: first, the release of monovalent cations, $\mathrm{H}^{+}$and $\mathrm{Zn}^{2+}$, presumably from the core. The resulting increase in $\mathrm{pH}$ (from 6.5 to 7.7 ) is important for enzyme activity once the core has been hydrated and metabolism begins. Next, DPA is released with its associated divalent cations, predominantly $\mathrm{Ca}^{2+}$, the spore contains a large amount of DPA —approximately $10 \%$ of the spore's dry weight. The last step of stage I is the replacement of DPA with water. The hydration of the core is not enough for protein mobility, but is enough to decrease the spore's wet-heat resistance. Completion of the early stage is independent of cortex hydrolysis. Events in this stage I of germination may only take seconds in 
an individual spore. However, there may be a lag period of up to several minutes from when the germinant is introduced before the beginnings of stage I.

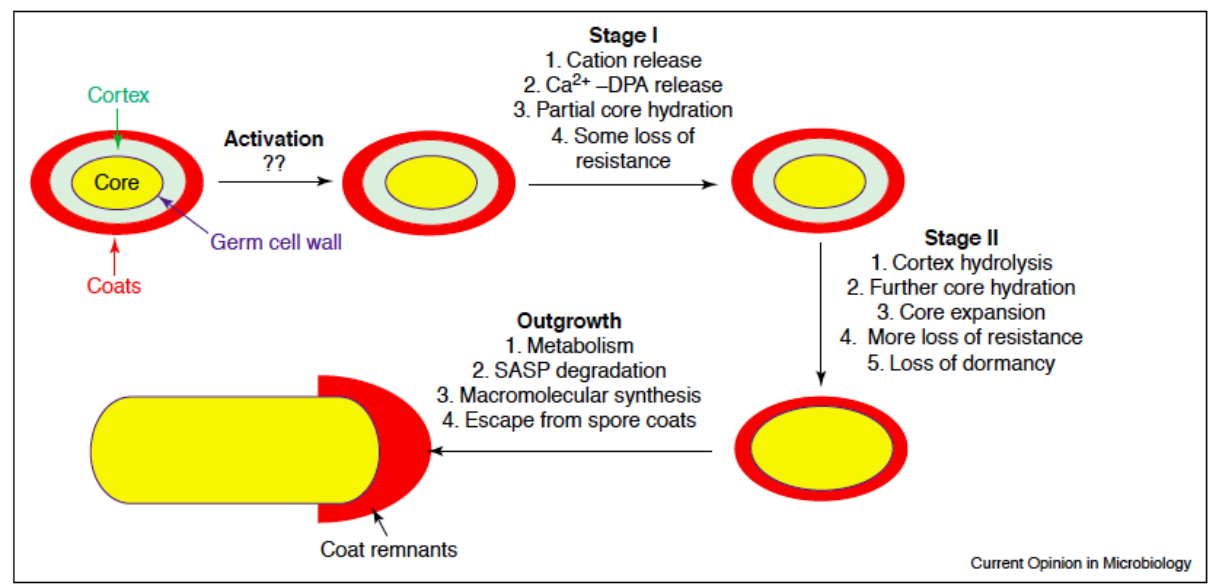

Figure 2.2 Events in spore germination. Spore germination is divided into two stages, as cortex hydrolysis is not required for stage I. SASP degradation denotes the hydrolysis of small, acidsoluble proteins (SASP) that make up to $10-20 \%$ of the protein in the spore core. Metabolism and SASP degradation (which require enzyme action in the spore core) are shown as taking place only after stage II is complete. However, these events may begin partway through stage II when the core water content has risen sufficiently for enzyme action. This figure shows the spore's germ cell wall expanding significantly to complete stage II of germination. The figure does not show the spore's inner and outer membranes.

Stage II, the later stage of germination, starts with the hydrolysis of the spore's peptidoglycan cortex. This degradation of the cortex may take several minutes for the individual spore (Setlow, 2003). The final step of stage II, the uptake of more water and the expansion of the germ cell wall further diminishes resistance and ends dormancy of the spore. After this final step, the core is hydrated enough for protein mobility and subsequent enzymatic activity (Paidhungat et al., 2002; Setlow B et a.l, 2001; Cowan et al., 2003). Germination of a population of spores may take many minutes due to the significant variation between the 
individual spores, particularly when it comes to the initiation of germination after introducing the germinant or germinants (Setlow, 2003).

\subsubsection{Germinant Receptors}

Nutrient induced germination is initiated by the binding of the nutrient to the receptor. Before interacting with the receptors on the inner membrane, the germinants must make their way through the spore coat. Spores of the gerP mutant were slow to germinate unless the spore coat was removed in a study conducted by Behravan et al (2000), suggesting that the proteins encoded by gerP are relevant in creating a permeable spore coat. Once the germinant makes it through the spore coats and cortex it will come into contact with one of the five germinant operons gerA, gerB, gerK, $y n d D E F, y f k Q R T$, all of which are homologous to the gerA operon (Kunst et al., 1997). Mutation phenotyping has been done for the gerA, gerB, and gerK operons, but research has shown the other two to be nonfunctional or responsive to unknown germinants (Paidhungat et al., 2000). The gerA, gerB, and gerK operons located on the inner membrane in the $B$. subtilis spore each recognize different nutrient germinants and code for three proteins.

Research has found that gerA mutants were unable to germinate the when Ialanine was the sole germinant present (Moir et al., 1979; Sammons et al., 1981). However, the same mutants germinated in the presence of amino acids combined with sugars (asparagine, glucose, fructose and KCl [AGFK]), 
suggesting that l-alanine is the germinant specific for the gerA operon. The gerB and gerK receptors require the combination of asparagine, glucose, fructose and KCl (AGFK) to induce germination (Moir et al., 1979; Corfe et al., 1994; Setlow, 2003). The gerA operon encodes three structural genes: the proteins GerAA, GerAB, and GerAC. Each of these genes inhibits germination with their deletion (Zuberi et al., 1987; Feavers et al., 1990). Sequencing of gerA suggests that the three proteins are membrane proteins (Feavers et al., 1985), supporting the presumption that the germinant receptors are located on the inner membrane of the spore. It has also been found that the germination genes present in the dormant spore are expressed, albeit in low levels, in the forespore (during sporulation), and localization of these genes in the forespore is consistent with localization on the spore's inner membrane.

\subsubsection{Ion/DPA Channels}

After the binding of a germinant to a receptor, a large amount of cations and $\mathrm{Ca}^{2+}$-DPA are released from the spore's core (Figure 2.3) to allow for the partial hydration of the core. In order for this to occur, it must be assumed that on the inner membrane of the spore exist one or more channels that are opened once a germinant has interacted with a receptor (Setlow, 2003). This is also hypothesized as the method for the uptake of DPA from the mother cell during sporulation. Although there are no known genes involved in the release of DPA from the core, there has been work to show that spoVA is responsible for the 
uptake of DPA in the developing spore (Tovar-Rojo et al., 2002). However, there is not sufficient evidence to associate the release of DPA with the same operon.

Other genes have been identified as possible candidates for the cation movement during germination. Among these are gerN, of which mutants exhibited a reduction in spore germination, but not the gerN homologues (Thackray et al., 2001). Also under scrutiny was the gerP operon, of which mutants also exhibited decreased spore germination (Behravan et al., 2000). The precise functions of these proteins are unclear, along with the mechanism of water uptake into the spore's core following germinant/receptor interaction.

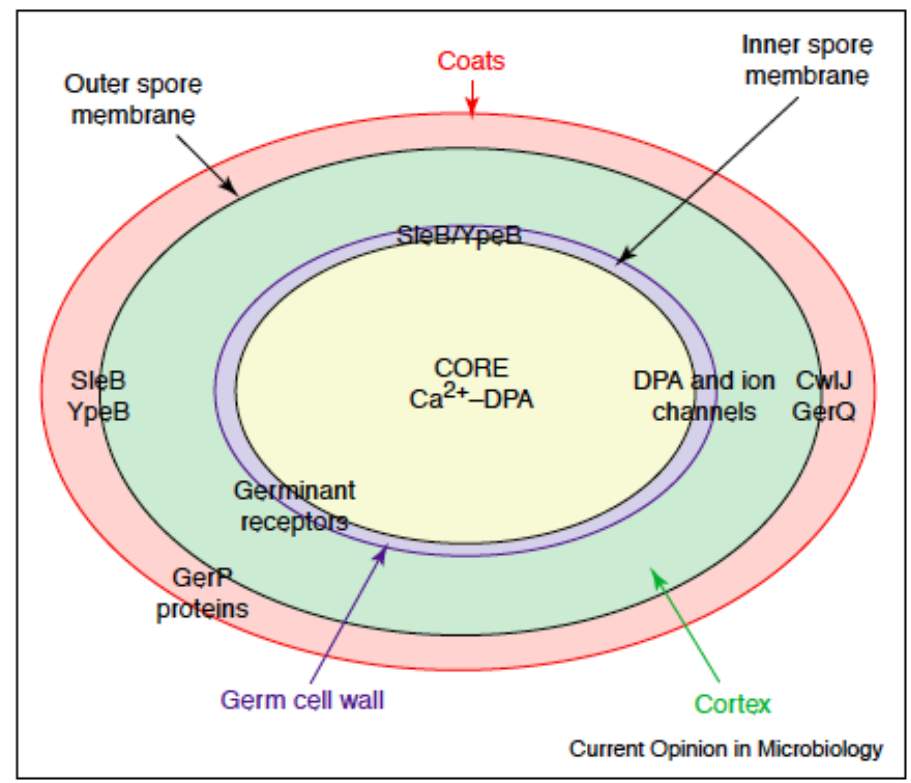

Figure 2.3 Spore structure (not to scale) and various components involved in spore germination. No exosporium is shown because as of current research it is irrelevant to germination. $\mathrm{Ca}^{2+}$-DPA is shown in the spore's core; germinant receptors, DPA and ion channels, and SleB/YpeB cortex lytic enzymes are shown on the inner membrane. GerP proteins are shown on the spore coat as they appear to be responsible for the permeability of the spore coat to germinants. The cortex lytic enzymes, SleB and CwlJ are shown adjacent to proteins that are required for their presence (YpeB and GerQ), however there is not sufficient evidence to show these proteins physically interact; their locations are in the cortex/coat boundary even though this may not be the precise location (Setlow, 2003). 


\subsubsection{Cortex Lytic Enzymes}

Stage II, the later stage of germination, includes the hydrolysis of the peptidoglycan cortex and the uptake of water to hydrate the spore's core and facilitate the mobility of proteins. Two redundant proteins are required for the hydrolysis of the cortex, SleB and Cw/J. Cw/J is activated by $\mathrm{Ca}^{2+}$-DPA (Paidhungat et al., 2002) and is present in the spore coat. Research on spores that have undergone a "decoating" procedure and are consequently lacking CWIJ supports the location of the protein as being in the spore coat (Chirakkal et al., 2002; Bagyan et al., 2002). SleB is a lytic transglycosylase located in the outer membrane and cortex as well as the spore coat (Chirakkal et al., 2002). Both proteins require muramic- $\delta$-lactam in order to degrade the spore cortex. This requirement differentiates between the cortex and the germ cell wall (also made of peptidoglycan), which lacks this modification and is subsequently left untouched by these enzymes (Popham, 2002).

\subsubsection{Non-Nutrient Germination}

Deletion of all the gerA-like operons resulted in extremely limited germination of spores; however, the spores were still able to germinate in the presence of $\mathrm{Ca}^{+}$DPA. This germination is labeled as a non-nutrient induced germination. Nonnutrient germinants include, but are not limited to, lysozyme, $\mathrm{Ca}^{2+}$-DPA, cationic surfactants and high pressure. Germination initiated by these non-nutrient germinants may not follow the spore's traditional nutrient germination pathway, as shown in Figure 2.4 . 


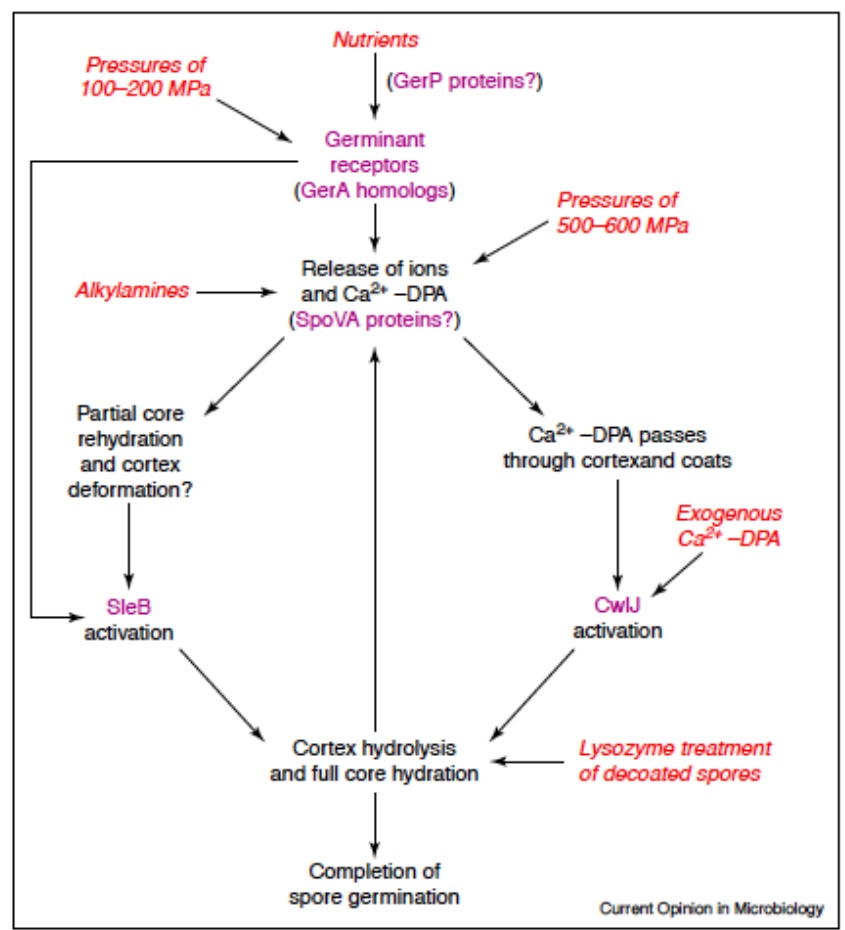

Figure 2.4 Model for nutrient and non-nutrient spore germination in $B$. subtilis. Nutrients activate the germinant receptors causing the release of ions including $\mathrm{Ca}^{2+}$-DPA from the spore core. This triggers Cw/J action and subsequent hydrolysis of the spore's cortex. SleB action may be triggered by germinant receptor activation upon nutrient binding, and/or by changes in the stress upon the spore cortex due to the partial hydartion of the spore's core in stage I of germination. SleB and/or $C W / J$ then catalyze cortex hydrolysis. High pressures either activate the germinant receptors (100-200 MPa) or $\mathrm{Ca}^{2+}$-DPA release (500-600 MPa), whereas alkylamines activate $\mathrm{Ca}^{2+}$-DPA release either directly or indirectly by effects at the spore's inner membrane. External $\mathrm{Ca}^{2+}$-DPA activates $C W / J$, which then causes cortex hydrolysis. Lysozyme treatment also causes cortex hydrolysis which somehow causes $\mathrm{Ca}^{2+}$-DPA release. (Setlow, 2003)

\subsection{Occurrence of Spores in Dairy Products}

Species of the genus Bacillus are spore-forming bacteria, naturally occurring inhabitants of soil and the gastrointestinal tract of insects and animals. Large numbers of Bacillus spores were found in both the soil and in human feces in a study by Hong et al., (2009), which suggest that they are common residents in the gut. The impressive variety in phenotypic characteristics shown by species of the spore-forming genera, make them a formidable force when it comes to the 
food industry. These spore-forming bacteria are the root cause of food spoilage and food-borne illnesses_-both result in large economic losses as well as posing a health threat to consumers. Some spores can survive food processing, be triggered to germinate by inadequate handling conditions and even grow in a refrigerated environment. The ubiquitous nature prevents the removal of spores from raw ingredients. A study by Postollec et al., (2012) found diverse and numerous groups of naturally occurring spore formers in products ranging from meat and dairy products to canned food and ingredients. Their results are compiled with other studies and listed in Table 2.1. 
Table 2.1 Natural occurrence of sporeformers reported in food with or without visible spoilage activity. Known sporeformers associated with specific food alterations are reported for lateblowing in cheese, ropy bread, unstable canned foods, spoiled juice, and blown chilled meat packs. Taken from Postollec, et al, International Journal of Food Microbiology (2012).

\begin{tabular}{|c|c|c|}
\hline Food matrices & Encountered sporeformers ${ }^{a}$ & Reference \\
\hline Silage & $\begin{array}{l}\text { Bacillus cereus, Bacillus firmus, Bacillus lentus, Bacillus licheniformis, Clostridium bifermentans, Clostridium butyricum, } \\
\text { Costridium disporicum, Clostridium putrificum, Clostridium sphenoides, Clostridium sporogenes, Clostridium } \\
\text { tyrobutyricum, Lysinibacillus sphaericus, Paenibacillus macerans, Paenibacillus polymyxa }\end{array}$ & $\begin{array}{l}\text { Te Giffel et al. (2002) } \\
\text { Jonsson (1991) } \\
\text { Julien et al. (2008) }\end{array}$ \\
\hline Raw milk & $\begin{array}{l}\text { Bacillus circulans, Bacillus licheniformis, Bacillus pumilus, Bacillus subtilis, Bacillus cereus group, Brevibacillus brevis, } \\
\text { Ureibacillus thermosphaericus }\end{array}$ & $\begin{array}{l}\text { De Jonghe et al. (2008) } \\
\text { Coorevits et al. (2008) }\end{array}$ \\
\hline Egg-based products & Costridium spp., Bacillus cereus group, Bacillus licheniformis, Bacillus subtilis, Lysinibacillus fusiformis & This study \\
\hline Honey & $\begin{array}{l}\text { Bacillus cereus group, Bacillus licheniformis, Bacillus megaterium, Bacillus pumilus, Brevibacillus laterosporus, } \\
\text { Paenibacillus larvae }\end{array}$ & Lurlina et al. (2005) \\
\hline $\begin{array}{l}\text { Dairy and } \\
\text { fermented products }\end{array}$ & $\begin{array}{l}\text { Bacillus cereus group, Bacillus coagulans, Bacillus licheniformis, Bacillus pumilus, Bacillus subtilis, Bacillus } \\
\text { sporothermodurans, Costridium spp., Lysinibacillus spp. }\end{array}$ & This study \\
\hline Milk powder & $\begin{array}{l}\text { Aneurinibacillus thermoaerophilus, Anoxy bacillus flavithermus, Bacillus circulans, Bacillus coagulans, Bacillus } \\
\text { licheniformis, B pumilus, Bacillus subtilis, Geobacillus stearothermophilus, Geobacillus thermoleovorans, Lysinibacillus } \\
\text { fusiformis, Ureibacillus themosphaericus }\end{array}$ & $\begin{array}{l}\text { Rückert et al. (2004) } \\
\text { Scott et al. (2007) } \\
\text { This study }\end{array}$ \\
\hline $\begin{array}{l}\text { Dehydrated } \\
\text { ingredients }\end{array}$ & $\begin{array}{l}\text { Anoxybacillus nupiensis, Bacillus cereus group, Bacillus amylovorans, Bacillus coagulans, Bacillus licheniformis, Bacillus } \\
\text { simplex, Bacillus smithii, Bacillus subtilis, Brevibacillus themonuber, Lysinibacillus fusiformis, Paenibacillus pabuli, } \\
\text { Paenibacillus polymyxa, Geobacillus pallidus, Geobacillus stearothermophilus, Geobacillus spp., Thermoanaerobacterium } \\
\text { thermosaccharolyticum, uncultured bacterium }\end{array}$ & This study \\
\hline Gelatin & $\begin{array}{l}\text { Alicyclobacillus acidocaldarius, Anoxybacillus contaminans, Anoxybacillus flavithermus, Bacillus amyloliquefaciens, } \\
\text { Bacillus cereus group, Bacillus badius, Bacillus coagulans, Bacillus fumarioli, Bacillus gelatini, Bacillus licheniformis, } \\
\text { Bacillus pumilus, Bacillus sonorensis, Bacillus subtilis, Bacillus thermoamylovorans, Brevibacillus agri, Brevibacillus } \\
\text { borstelensis, Geobacillus stearothemophilus, Paenibacillus spp. }\end{array}$ & $\begin{array}{l}\text { De Clerck et al. (2004) } \\
\text { De Clerck and De Vos (2002) }\end{array}$ \\
\hline $\begin{array}{l}\text { Ethnical fermented } \\
\text { food }\end{array}$ & $\begin{array}{l}\text { Bacillus badius, Bacillus cereus group, Bacillus jeotgali, Bacillus licheniformis, Bacillus pumilus, Bacillus subtilis, } \\
\text { Brevibacillus brevis, Brevibacillus bortelensis, Brevibacillus laterosponis, Lysinibacillus fusiformis, Lysinibacillus } \\
\text { sphaericus, Paenibacillus macerans }\end{array}$ & $\begin{array}{l}\text { Ogbadu et al. (1990) } \\
\text { Yoon et al. (2001) } \\
\text { Achi et al. (2007) } \\
\text { Ouoba et al. (2008) }\end{array}$ \\
\hline $\begin{array}{l}\text { Traditional cacao } \\
\text { fermentation }\end{array}$ & $\begin{array}{l}\text { Bacillus circulans, Bacillus coagulans, Bacillus firmus, Bacillus licheniformis, Bacillus megaterium, Bacillus pumilus, } \\
\text { Bacillus subtilis, Brevibacillus brevis, Brevibacillus laterosporus, Geobacillus stearothermophilus, Paenibacillus polymyxa, } \\
\text { Paenibacillus macerans, Sporosarcina pasteurii }\end{array}$ & Schwan et al. (2006) \\
\hline Late blowing cheese & $\begin{array}{l}\text { Bacillus polymyxa, Costridium beijerinckii, Clostridium butyricum, Clostridium pasteurianum, Clostridium sporogenes, } \\
\text { Costridium tertium, Clostridium tetanomorphum, Clostridium tyrobutyricum, Paenibacillus macerans }\end{array}$ & $\begin{array}{l}\text { Klijn et al. (1995) } \\
\text { Le Bourhis et al. (2005) } \\
\text { Quiberoni et al. (2008) }\end{array}$ \\
\hline Ropy bread & Bacillus cereus group, Bacillus clausii, Bacillus firmus, Bacillus licheniformis, Bacillus pumilus, Bacillus subtilis & $\begin{array}{l}\text { Rosenkvist and Hansen (1995) } \\
\text { Pepe et al. (2003) }\end{array}$ \\
\hline Unstable canned food & $\begin{array}{l}\text { Bacillus cereus group, Bacillus coagulans, Bacillus subtilis, B. licheniformis, Clostridium thermosaccharolyticum, } \\
\text { Desulfotomaculum nigrificans, Geobacillus stearothermophilus, Moorella thermoacetica, Moorella thermoautotrophica }\end{array}$ & $\begin{array}{l}\text { Carlier and Bedora-Faure (2006) } \\
\text { This study }\end{array}$ \\
\hline $\begin{array}{l}\text { Spoiled juice and soft } \\
\text { drinks }\end{array}$ & $\begin{array}{l}\text { Alicyclobacillus acidoterrestris, Alicyclobacillus acidiphilus, Alicyclobacillus acidocaldarius, Alicyclobacillus hesperidum, } \\
\text { Alicyclobacillus mali }\end{array}$ & $\begin{array}{l}\text { Takahashi et al. (2007) } \\
\text { Tokuda (2007) }\end{array}$ \\
\hline $\begin{array}{l}\text { Blown-pack meat } \\
\text { spoilage }\end{array}$ & $\begin{array}{l}\text { Costridium algidicarnis, Clostridium estertheticum, Clostridium frigidicamis, Clostridium gasigenes, Clostridium } \\
\text { laramiense }\end{array}$ & $\begin{array}{l}\text { Broda et al. }(1999) \\
\text { Broda et al. }(2000)\end{array}$ \\
\hline
\end{tabular}

As shown in Table 2.1, a significant portion of affected food types are dairy foods. The presence of endospores in raw milk, dairy processing facilities, and in the final product are significant challenges that the industry experiences. The overwhelming presence that endospores have assumed in the dairy industry is based largely on two contributing factors. First, there is the omnipresence of spores in the raw product, which is the process by which many believe the endospore contaminants enter the milk processing environment. Low numbers of spores can be found in the raw milk of individual cows as well as in the bulk tanks of Californian dairies (Arechiga 2013 unpublished data). The presence of 
spores in the cows' milk is most likely attributed to the high number and large diversity of spores that are found in the pasture soil, as well as in the hay and feed concentrate of dairy cows (Christiansson et al.,1998; Vaerewijck et al., 2001).

Although it is rare to source raw milk that is free from endospore contamination, the introduction of spores to the processing environment does not explain the resulting high numbers $\left(>10^{4} \mathrm{cfu} / \mathrm{g}\right)$ of spores that end up in the final product. This phenomenon is specific to powdered milk, which not only experiences a non sequitur increase in spore counts as compared to the raw milk, but also a switch in the species profiles of the spore formers (Burgess et al., 2010). This preponderance of spores in milk powder and not in the raw milk is explained by the growth and sporulation of these bacteria the manufacturing plant itself. The ability of Bacillus cells and spores to adhere to processing equipment and form biofilms is responsible for the growth of these cells within the manufacturing plant. First cells attach, then once irreversibly attached the cells form micro colonies and produce a matrix of extracellular polymeric substances (EPS). From there the cells continue to grow and the micro colonies expand within the matrix while pulling nutrients from it (Johnston, 2004; Stoodley et al., 2002). 


\subsection{Relative gene expression using qPCR}

\subsubsection{An Overview of PCR}

The polymerase chain reaction (PCR) is an amplification technique using thermal cycling that can synthesize millions of copies of selected DNA sequences in vitro. As shown in Figure 2.5, PCR cycles have 3 steps: Denaturation, annealing, and extensions. Denaturation is conducted at a high temperature, $94^{\circ} \mathrm{C}$, and functions to separate the DNA into single strands. From there, the temperature is lowered to facilitate the annealing of primers to the separate strands. Primers are oligonucleotides that are complimentary to a small segment of the DNA strand, typically about $12-30$ nucleotides. The annealing temperature of the reaction is

dictated by the composition (frequency of the different nucleotides) and length of the primers. Once the primers have annealed, the temperature is increased to $72^{\circ} \mathrm{C}$ to allow for the enzyme, DNA polymerase, to extend from the $3^{\prime}$ end of the primer all the way down. When the cycle is repeated, the two products will become the templates and denaturation will commence again to create single stranded DNA, the complimentary primers will anneal to these templates and polymerase will extend from the 3 ' end of the primers until it falls of the end of the template. Since the product becomes the template in each subsequent cycle of PCR, the amount of product doubles with each cycle-after 20 cycles of PCR, assuming $100 \%$ efficiency, PCR produces a million-fold $\left(2^{20}\right)$ amplification (Erlich, 1989). 


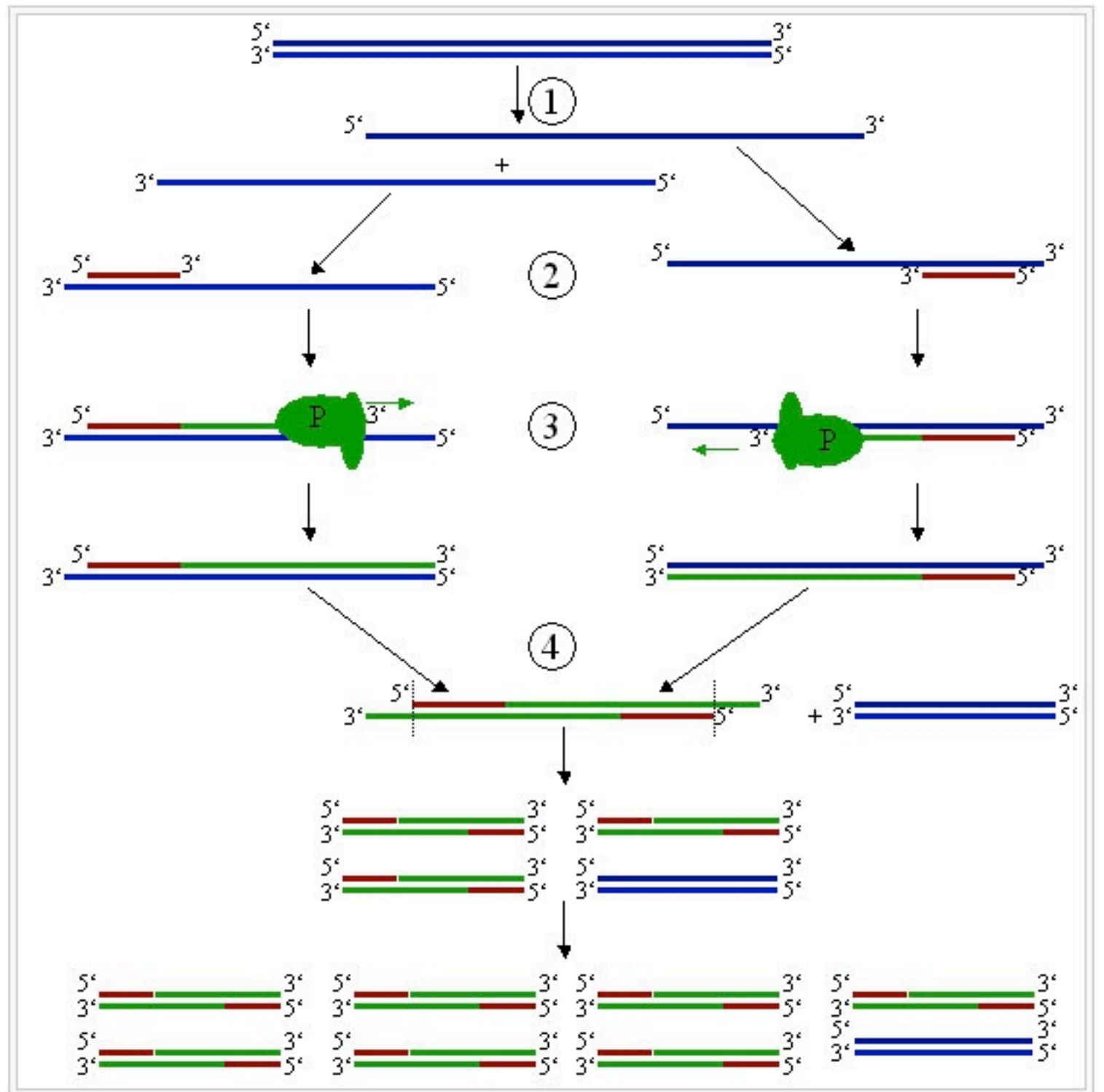

Figure 2.5 Schematic of Polymerase chain reaction. 1. Denaturation 2. Annealing of primers 3 . Extension of primers by DNA polymerase (P) 4. The final products. The cycles will repeat using the resulting DNA strands as templates. Courtesy of Bruce Fouke's Lab, University of Illinois.

Once the PCR cycles are complete, the resulting PCR product is analyzed using gel electrophoresis and viewed with UV light. Since larger concentrations of DNA are needed to be visible on the gel, the amplified DNA fragment should show up as a thick fluorescent band at the appropriate length of a molecular ruler. This not only assists in confirming that amplification occurred, but can show if one or more 
DNA fragments were amplified in the reaction. The number of amplicons from one reaction dictates the specificity and stringency of the reaction.

DNA polymerases are enzymes that synthesize DNA strands using deoxyribonucleotide triphosphates and a template DNA strand when prompted by oligonucleotide primers. The original DNA polymerase used was the Klenow fragment of Escherichia coli DNA polymerase (Erlich, 1989). This polymerase had an optimal reaction temperature of $37^{\circ} \mathrm{C}$, and would be denatured during the denaturation step of the cycle. As a result, a new aliquot of DNA polymerase would need to be added to the beginning of each cycle. The discovery of the thermostable "Taq" DNA polymerase from the thermophilic bacterium Thermus aquaticus, meant that the polymerase would survive the denaturation step and the assay could be automated. The optimal temperature of Taq polymerase is $75^{\circ} \mathrm{C}$, which not only allowed for automation but increased the stringency of the reaction.

Stringency references the specificity of the PCR, or the number of non-target products amplified, and can be validated by viewing the number of amplicons that result with gel electrophoresis. One amplicon alludes to a stringent reaction, while increasing PCR products indicate a decreasing stringency. As PCR is often used for the isolation of a particular target sequence, for detection purposes or other down-stream applications, stringency is a desired characteristic of a robust PCR assay. Another desirable quality is that of fidelity, or the frequency of errors 
the polymerase makes when synthesizing the strand of DNA. Some polymerases have a 5' "proofreading" quality that allows them to correct such errors and result in a higher fidelity. Taq does not have this capability and has an error rate of $\sim 2 \times 10^{-4}$ nucleotides per cycle (Erlich, 1989).

Although the theory of PCR is elegant and straightforward, accurate implementation relies on the optimization of certain factors. A stringent PCR reaction can be created through primer design. The length and percent of guanine and cytosine (\%GC) present in the primers dictates their melting temperatures and subsequently, their annealing temperatures. A higher annealing temperature means a more specific PCR reaction with higher fidelity. The higher extension temperature of Taq polymerase also contributes to stringency by decreasing the extension of mismatched primers. Also, there is an indirect correlation between specificity of a reaction and the concentration of $\mathrm{Mg}^{2+}$. Every PCR can be optimized, but there is no one set of conditions that are optimal for all reactions. Each assay requires preliminary experiments to determine optimal reagent concentrations and cycling conditions.

Traditional end-point PCR has its limitations, but more sophisticated techniques have become commonplace to cover a broader range of applications. The addition of reverse transcription to the PCR process allows for gene expression assays by using cDNA as the template. The creation of a real-time quantitative PCR (qPCR) assay that uses fluorescent reporters to monitor amplification gives 
quantitative results that provide utilitarian data for further analysis. Although multiple PCR methods exist, this review will focus on reverse transcription and qPCR as it was the method utilized in this study.

\subsection{2 qPCR}

Real-Time PCR (qPCR) uses fluorescent reporter molecules to monitor amplification with each cycle, and is used in conjunction with Reverse Transcription PCR (RT-PCR). These two reactions allow for a simple, specific, and sensitive method to detect and/or compare RNA levels (Bustin et al., 2005). The inclusion of fluorescent reporter molecules in the reaction eliminates the need for visualization using gel electrophoresis, and also realizes the quantitative abilities of PCR. Last, the assay is able to handle a wide dynamic range of RNA concentrations, enabling the comparison of different genes that have significant differences in expression levels. However, this progressive technique still has many limitations when it comes to accurate and consistent deliveries of scientific data and research. Certain aspects of the qPCR assay are subjective and determined by the manufacturer and can lead to inaccurate results if not reined in by strict guidelines for interpretation and reporting (Bustin et al., 2005).

\subsubsection{RNA Extractions and Quality Requirements}

Reverse transcription is the process in which mRNA is translated into cDNA. In the cell, the following step of transcription creates a new DNA strand. As a gene is expressed in a cell, the level of mRNA will increase. Using PCR to determine 
the amount of mRNA in a cell lends insight into the level of expression of the gene. In order for a real-time RT-PCR reaction to be successful and reliable, it must have high quality, intact total RNA or pure mRNA that is free from contamination by genomic DNA. RNase cleaves RNA, and is the major source of RNA degradation; in order to eliminate damage caused by this ubiquitous enzyme, sampling and isolation techniques must be done with RNase-free tools and techniques. Samples of RNA are very unstable; it is critical to store samples in RNase free water at $-20^{\circ} \mathrm{C}$ to prevent degradation.

Contamination by genomic DNA is common, and even commercially obtained RNA samples will contain detectable amounts of DNA. It is critical that a control be included in the assay to confirm that amplification is not due to the presence of contaminating DNA. This is often done by treating RNA samples with RNase free DNase, and including a No-RT (No Reverse Transcriptase) and water

control. If sampling with cells that contain introns, it is good to design primers in a way that amplicons derived from contaminating DNA will contain both introns and exons; as a result, they are distinguishable from product amplified from cDNA using gel electrophoresis.

\subsubsection{Reverse Transcription}

In reverse transcription, mRNA is translated to single-stranded complimentary DNA (cDNA) by the enzyme reverse transcriptase. The sensitivity and specificity of this reaction has made it a crucial step in real-time RT-PCR (Pfaffl, 2004). RT 
is sensitive to alcohol, salts, phenol, and other inhibiting contaminants that may be carried over from isolation of RNA—all of which affect the efficiency of the reaction. Other contributors to variability in this step are choices in enzyme (MMIV ${ }^{\mathrm{H}-} \mathrm{RT}, \mathrm{AMV}$, and $\mathrm{RNase} \mathrm{H}^{-} \mathrm{RT}$ ) and primer design. There are specific and non-specific primers that can be used for reverse transcription. Specific primers are designed for a target gene and its corresponding mRNA, so new primers must be designed for each target gene. However, nonspecific primers can be used to translate many genes from a single pool of cDNA (Pfaffl, 2004). This maximizes the number of genes that can be assayed from a limited sample of mRNA, and also makes the assays between different genes comparable. Since the quality of mRNA also has a large impact on the quality of cDNA, it is important to have positive controls for the qPCR assay, referred to as reference genes or house keeping genes. These reference genes, often ribosomal RNA, are expressed all the time and are used to measure the relative expression level of the target genes.

\subsubsection{3 qPCR as an Assay for Relative Gene Expression}

The kinetics of qPCR can be broken down in to 4 phases: in the first phase the exponential amplification is hidden beneath the background fluorescence of the reporter, in the second the exponential phase is detected and the amount of output is proportional to the amount of input; in the third there is linear amplification accompanied by a sharp increase in fluorescence; the last is the plateau where the reaction has attenuated due to the consumption of reagents 
and exhaustion of the enzyme (Pfaffl, 2004). In order for qPCR to be an accurate assay, the product of the target gene needs to be measured during the second phase, when it is proportional to input and also detectable. Detection of the exponential phase of the reaction can be completed using two different types of reporter dyes. The first uses Fluorescence Resonance Energy Transfer (FRET) by means of gene specific reporters. Taqman probes $(A B I)$ are examples of this; the probes take advantage of the 5'-3' exonuclease activity of Taq polymerase to fluoresce when extension of the PCR product occurs. The second method of detection uses a dye like SYBR Green to intercalate with the double stranded DNA. This detection method is not gene specific, but when coupled with welldesigned primers produces a dynamic range and sensitivity comparable to Taqman, and has the potential to be more precise (Schmittgen et al., 2000).

When quantifying using qPCR, there are two approaches: absolute and relative quantification. Absolute quantification uses a calibration curve to determine the concentrations of the unknown mRNA amount from known DNA or RNA samples. Relative quantification compares the expression level of a target gene with a reference gene, and can identify physiological changes (Pfaffl, 2006). Different mathematical models are available when comparing the expression of a target gene to a reference gene; some which account for the differences in efficiency and other which do not. Efficiency is a reflection of the exponential phase of the reaction and trend of fluorescence that results. This varies between 
each sample tube, and can affect the relative expression calculations if not considered in the mathematical model (Pfaffl, 2006)

\subsection{3 qPCR as a Rapid Method for Identifying and Enumerating Endospores}

Plate count methods to enumerate thermophilic spores were described by Burgess et al (2010). In this method, spores are heat-treated for $30 \mathrm{~min}$ at $100^{\circ} \mathrm{C}$ and then pour plated in milk plate count agar (MPCA) with $0.2 \%$ starch and then incubated at $55^{\circ} \mathrm{C}$ for 48 hours. The heat-treatment serves to inactivate the vegetative cells while simultaneously activating germination of the spores. An adapted protocol was applied to mesophilic endospores at the California State Polytechnic University in San Luis Obispo, California. In this method, spore solutions are heat shocked at $80^{\circ} \mathrm{C}$ to inactivate the vegetative cells and induce germination, then pour plated in Tryptic Soy Agar (TSA) with $0.2 \%$ starch and incubated at $32^{\circ} \mathrm{C}$ for up to 48 hours. These plate count methods are both time consuming and labor intensive. As a result, research has identified rapid methods for enumeration critical for reducing labor costs, releasing product more quickly, and having more control over the process (Burgess et al., 2010).

One of the rapid methods uses the BactiFlow ${ }^{\mathrm{TM}}$ flow cytometer and enumerates total viable cells in addition to spores. A method specific for thermophiles was created, but limitations still persist (Flint et al., 2006; Flint et al., 2007). A realtime PCR assay for the enumeration of thermophilic endospores and vegetative cells was developed using a small amplicon of the 16s rRNA gene (Rueckert et 
al., 2005a and 2005b). Later research improved the specificity and efficiency of the $\mathrm{qPCR}$ assay by targeting the spoOA genes, and accomplishing the assay in an hour of lab time (Rueckert et al., 2006). This assay was successful in amplifying DNA from a multitude of thermophilic endospores and their vegetative counterparts. Despite the accuracy and efficiency that real-time PCR delivers relative to the traditional plate count methods, it requires expensive equipment and a trained, skilled technician. Such requirements are not always an economic or feasible solution in industry applications. Real-time PCR has the potential to provide critical biological information about spore formers and their life cycle within the dairy processing environment. 


\section{CHAPTER 3 \\ MATERIALS AND METHODS}

\subsection{Spore Growth Curves and Germination Assays}

\subsubsection{Preparation of Endospore Stock Solution}

Freeze-dried cultures of Bacillus licheniformis ATCC\#14580 and Bacillus subtilis ATCC\#23857 (corresponding to Bacillus subtilis subsp. subtilis str. 168) were used in the preparation of stock solutions of $10^{9}$ spores per $\mathrm{mL}$. Using sterile, single-use $10 \mu \mathrm{l}$ loops, a loopful of freeze-dried culture was transferred aseptically to sterile Tryptic Soy Agar (TSB) tubes. Samples were vortexed to mix and incubated at $37^{\circ} \mathrm{C}$ and $32^{\circ} \mathrm{C}$ until turbid (up to $24 \mathrm{hrs}$ ). Using a sterile loop and aseptic technique, a loopful of each tube was streaked for growth and isolation on Tryptic Soy Agar(TSA) with $0.1 \%$ starch in duplicate. Plates were incubated at $37^{\circ} \mathrm{C}$ and $32^{\circ} \mathrm{C}$ for $12 \mathrm{hrs}$ and visually checked for contamination. Single colonies from the plates were selected and removed from the plates with sterile, singleuse $1 \mathrm{~mL}$ loops and transferred aseptically to sterile TSB tubes. Samples were vortexed to mix and incubated at $37^{\circ} \mathrm{C}$ and $32^{\circ} \mathrm{C}$ until turbid (up to $24 \mathrm{hrs}$ ). Once again, each tube was used to streak for isolation using a sterile loop and aseptic technique onto TSA with $0.1 \%$ starch in duplicate. Plates were incubated at $37^{\circ} \mathrm{C}$ and $32^{\circ} \mathrm{C}$ for $12 \mathrm{hrs}$ and checked for contamination. After confirmation that no contamination had occurred, single colonies were selected and streaked in quadruplicate for heavy growth using aseptic technique. B. subtilis was incubated at $32^{\circ} \mathrm{C}$ for 7 days, and $B$. licheniformis was incubated $37^{\circ} \mathrm{C}$ for 9.5 days to achieve $90 \%$ sporulation. Sporulation was assessed using differential staining with malachite green for spore-formers. Samples were heat-fixed onto pre- 
cleaned microscope slides. The slides were soaked with $5 \% \mathrm{w} / \mathrm{v}$ malachite green over steam for 5 minutes. Slides were rinsed with cool tap water before flooded with safranin for $2 \mathrm{~min}$. After a final rinse with cool tap water, the slides were patted dry before viewing with a microscope. Once $90 \%$ sporulation was confirmed, corresponding plates were moved to $4^{\circ} \mathrm{C}$ for 12 hours to induce further sporulation. Spores were scraped from the agar surface into sterile $50 \mathrm{~mL}$ falcon tubes using a sterile hockey stick and rinsing with sterile dl water. Spores and cells were pelleted at 4,000xg for 20 min (Eppendorf 5810R) and the supernatant was decanted before heat shocking at $70^{\circ} \mathrm{C}$ for 3 min to kill vegetative cells. Enzymatic digestion was completed by adding $9 \mathrm{~mL}$ of filter sterilized lysozyme solution $\left(0.9 \mathrm{mg} / \mathrm{ml}\right.$ lysozyme, $15 \mathrm{mM} \mathrm{MgCl}_{2}, 0.1 \mathrm{M} \mathrm{K}-$ phosphate buffer, $\mathrm{pH}$ 7.0) to each tube, vortexing, and incubating at room temperature for 1 hour. After incubation, spores were pelleted at 4,000xg and the supernatant was decanted and the pellet was heat shocked at $60^{\circ} \mathrm{C}$ to inactivate the lysozyme. Pellets were washed by adding $30 \mathrm{~mL}$ sterile $\mathrm{dl}$ water, vortexing, centrifuging at $10,000 x g$ and decanting supernatant. The washing was completed three times before adding a final volume of $30 \mathrm{~mL}$ of sterile dl water to the spore pellet. Concentration was determined using direct microscopic counts and was recorded on each tube along with the culture information. Spore solutions were stored at $4^{\circ} \mathrm{C}$. 


\subsubsection{Growth Curve using BacT/ Alert}

The BacT/Alert-3D from Biomerieux (Durham, NC) is an automated microbial detection system that is used to detect the presence or absence of microbes, in this case spores, in aseptic food products. It also provides a growth curve of the microorganisms based on a color change induced by the metabolites produced by the germinated spores and replicating viable cells. The incubation temperature of the instrument was set a day before the performed experiment to allow time for calibration and equilibration. The incubation temperatures were set at $37^{\circ} \mathrm{C}$ for the growth of $B$. licheniformis and $32^{\circ} \mathrm{C}$ for the growth of $B$. subtilis. Serial dilutions of each spore type were made from the stock spore solution, vortexing to mix between each dilution. The following concentrations of spores were heat shocked for $12 \mathrm{~min}$ at $80^{\circ} \mathrm{C}$ (timing began when samples reached $80^{\circ} \mathrm{C}$ ): $10^{2}$ spores $/ \mathrm{ml}, 10^{3}$ spores $/ \mathrm{ml}, 10^{4}$ spores $/ \mathrm{ml}, 10^{5}$ spores $/ \mathrm{ml}$, and $10^{6} \mathrm{spores} / \mathrm{ml}$. Samples were immediately placed in an ice bath for $15 \mathrm{~min}$ following the heat shock. Biomerieux IAST media bottles were inoculated with $1 \mathrm{~mL}$ of each corresponding dilution using a $21 \mathrm{ga}$ syringe and alcohol swab for sterile technique. The final bottle concentrations were: $10^{0}$ spores $/ \mathrm{ml}$, $10^{1} \mathrm{spores} / \mathrm{ml}, 10^{2} \mathrm{spores} / \mathrm{ml}, 10^{3} \mathrm{spores} / \mathrm{ml}$, and $10^{4} \mathrm{spores} / \mathrm{ml}$. Bottles and bottle data were loaded into the BacT/Alert and incubated for $24 \mathrm{hrs}$. Once incubation was complete, bottles were unloaded and data was downloaded into Microsoft Excel. 


\subsubsection{Germination Assay}

Serial dilutions to $10^{-8}$ were made of spore stock solution in sterile TSB tubes. Tubes were heat shocked for $12 \mathrm{~min}$ at $80^{\circ} \mathrm{C}$ (timing began when samples reached $80^{\circ} \mathrm{C}$ ), and then immediately placed in an ice bath for $15 \mathrm{~min} .250 \mu \mathrm{L}$ of each sample were loaded into a 96 -well plate in triplicate with blanks $(250 \mu \mathrm{L}$ TSB) at the beginning at end of each sample row. Samples were arranged in ascending order of concentration, starting with $10^{\circ}$ spores $/ \mathrm{mL}$ in row A. The plate was covered and incubated at $32^{\circ} \mathrm{C}$ for $B$. subtilis and $37^{\circ} \mathrm{C}$ for $B$. licheniformis, with absorbance readings taken at 580nm every 10 minutes for 12 hours with 3 seconds of mixing before each reading. Data was exported into Microsoft Excel for analysis.

\subsubsection{Statistical Analysis of Growth Curves and Lag Times}

To analyze the growth curves of the two different species, lag times of each run were found by the intersection of the tangent line to the inflection point $\left(f^{\prime \prime}(x)=\right.$ $0)$. This was conducted manually with Microsoft Excel. The calculated inflection points of both $B$. subtilis and $B$. licheniformis were compared using a one-way ANOVA.

\subsection{PCR}

\subsubsection{Purification of Genomic DNA}

Purification from spores and vegetative cells followed the method used by Rueckert et al (2005). $10 \mathrm{~mL}$ of spore solution or cell cultures were pelleted at 
4,000xg and $4^{\circ} \mathrm{C}$ (Eppendorf 5810R). Supernatant was decanted and the pellet was resuspended in $1 \mathrm{~mL}$ of $50 \mathrm{mM}$ Tris- $\mathrm{HCl}(\mathrm{pH} 8.0), 100 \mathrm{mM} \mathrm{NaCl}$, and $20 \mathrm{mM}$ EDTA. The first step of digestion was carried out with $2 \mathrm{mg} / \mathrm{mL}$ of lysozyme and incubated at $37^{\circ} \mathrm{C}$ for $45 \mathrm{~min}$. SDS was added at $1 \% \mathrm{w} / \mathrm{v}$ and proteinase $\mathrm{K}$ was added at $200 \mu \mathrm{g} / \mathrm{mL}$ and the second step of digestion was completed at $55^{\circ} \mathrm{C}$ for $1 \mathrm{hr}$. Two extractions followed: the first with an equal volume of phenol: chloroform (1:1) and the second with an equal volume of chloroform: isoamyl alcohol (24:1). Both extractions were mixed with gentle up and down pipetting, centrifuged at $14000 \mathrm{rpm}$ for $5 \mathrm{~min}$ (Eppendorf 5417C), and the top aqueous layer was removed and placed into a clean microfuge tube. DNA was precipitated with a $1 / 10$ volume of $3 \mathrm{M}$ sodium acetate and a 0.6 volume of ice-cold isopropanol. The samples were pelleted and the supernatant decanted before the pellets were washed with ice-cold $80 \%$ Ethanol. After the second washing, the pellet was allowed to air dry before resuspension in $100 \mu \mathrm{L}$ of $1 \mathrm{x}$ TE. Samples were stored at $-20^{\circ} \mathrm{C}$ for downstream applications.

\subsubsection{Selection of Target Genes}

Past research focused on $B$. subtilis found genes directly involved in spore germination, in the hydrolysis of the spore cortex and spore core proteins. In order to associate the lag phase with germination, a gene from each of these groups was selected for primer design. The final selections were GerAC, SleB, and gpr: GerAC is a protein encoded in the tricistronic operon of gerA which codes for the three proteins (GerAA, GerAB, and GerAC) that create the 
germinant receptor; research has shown that the receptor plays an important role in germination with I-alanine. SleB is a cortex lytic transglycosylase located in the outer surface of the spore cortex and possibly in the inner membrane of the spore. SleB is involved in the second half of germination while GerAC is presumably expressed in the first stages of germination. Gpr is an endoprotease located in the spore core (Soneshein, 2002). Genes coding for ribosomal proteins have been used in the past as constitutive references (rpsE and rpsJ) for Bacillus bacteria grown under optimal conditions and had exhibited constant expression (Jordan et al., 2006). This study followed suit and used the rrnE gene for $16 \mathrm{~S}$ ribosomal RNA as a reference, or housekeeping gene (HKG).

\subsubsection{Primer Design}

Primer design and analysis of primer and amplicon secondary products were conducted following the protocol by Thornton and Basu (2011). The results are displayed in Table 3.1.

Table 3.1 Primers targeting genes specific for the species $B$. subtilis and $B$. licheniformis

\begin{tabular}{|l|l|l|l|}
\hline Target Gene & Target Species & Forward Primer (5'-3') & Reverse Primer (5'-3') \\
\hline$r r n E(H K G)$ & $\begin{array}{l}\text { B. subtilis \& } B . \\
\text { licheniformis }\end{array}$ & $\begin{array}{l}\text { GCTCGTGTCGTGAGAT } \\
\text { GTTGGGTTA }\end{array}$ & $\begin{array}{l}\text { GGTTTCGCTGCCCTTTGT } \\
\text { TCTGTCC }\end{array}$ \\
\hline GerAC & B. subtilis & $\begin{array}{l}\text { CATTGCGTCTCATTCT } \\
\text { GCTTTCCA }\end{array}$ & $\begin{array}{l}\text { AACTCCTCTTGTTCCGT } \\
\text { TGTCTCT }\end{array}$ \\
\hline$g p r$ & B. subtilis & $\begin{array}{l}\text { TTGAGCACAGGTCAG } \\
\text { GGAGA }\end{array}$ & $\begin{array}{l}\text { CAAGCTGCCATCGGTC } \\
\text { CAAGCG }\end{array}$ \\
\hline SleB & B. subtilis & $\begin{array}{l}\text { GATGAAACGGCACGA } \\
\text { GAACAATACCAAGCACGGC } \\
\text { GATTA }\end{array}$ \\
\hline GerAC & B. licheniformis & $\begin{array}{l}\text { CAACCATCCGTTCCAC } \\
\text { CGCTTT }\end{array}$ & $\begin{array}{l}\text { ATAGACCTCGCTCCTTCT } \\
\text { GAT }\end{array}$ \\
\hline Gpr & B. licheniformis & $\begin{array}{l}\text { CTCGGCAACTGGAATGT } \\
\text { CACGC }\end{array}$ & $\begin{array}{l}\text { CCCTTGGATAATGTCGCT } \\
\text { CGTTTCA }\end{array}$ \\
\hline SleB & B. licheniformis & $\begin{array}{l}\text { AAGATGAAACAGAAAGG } \\
\text { AAAGCGTG }\end{array}$ & $\begin{array}{l}\text { TGACTGAATGGAAGTGAA } \\
\text { AGACTGG }\end{array}$ \\
\hline
\end{tabular}




\subsubsection{PCR conditions for pure cultures}

Using the primers specific to each species, PCR conditions were: 1-10ng of template DNA, 10x PCR Buffer (Life Technologies, Carlsbad, CA), $0.6 \mathrm{mM}$ dNTPs, $0.8 \mu \mathrm{g} / \mathrm{mL}$ Bovine Serum Albumin (BSA), $3.5 \mathrm{mM} \mathrm{MgCl}_{2}$ (Life technologies), $0.6 \mathrm{mM}$ of each primer (Integrated DNA Technologies, Coralville. IA), 0.6U of Taq Polymerase (Amplitaq Gold-Life Technologies), and sterile dl water to bring the volume to $20 \mu \mathrm{L}$. Amplification was completed on a Techne Touchgene Gradient Thermal Cycler (Bibby Scientific Limited, Staffordshire, UK) with the following conditions: initial denaturation for $10 \mathrm{~min}$ at $94^{\circ} \mathrm{C}, 25$ cycles of $1 \mathrm{~min}$ at $94^{\circ} \mathrm{C}, 1 \mathrm{~min}$ at $56^{\circ} \mathrm{C}, 1 \mathrm{~min}$ at $72^{\circ} \mathrm{C}$, and a final extension of $10 \mathrm{~min}$ at $72^{\circ} \mathrm{C}$ with a final hold at $10^{\circ} \mathrm{C}$.

\section{3 qPCR: Gene Expression Assay}

\subsubsection{Purification of Total RNA and cDNA Synthesis}

\subsubsection{Sample Preparation and Visual Inspection}

For each species (B. subtilis and B. licheniformis) $1 \mathrm{~mL}$ of pure culture was added to tubes of $9 \mathrm{~mL}$ of sterile TSB-1 sample with a final concentration of $10^{7}$ spores $/ \mathrm{mL}\left(0 \mathrm{~min}\right.$ ) and 3 samples with final concentrations of $10^{4}$ spores $/ \mathrm{mL}$-in duplicate. Samples were vortexed to mix, heat shocked at $80^{\circ} \mathrm{C}$ for $12 \mathrm{~min}$, and immediately placed in an iced bath to cool for $15 \mathrm{~min}$. B. subtilis was incubated at $32^{\circ} \mathrm{C}$ and $\mathrm{B}$. licheniformis at $37^{\circ} \mathrm{C}$ for $0,30,60$, and $120 \mathrm{~min}$. When each sample reached its incubation time, both duplicates were pelleted at $4000 \times \mathrm{xg}$ and $7^{\circ} \mathrm{C}$ for $20 \mathrm{~min}$ and the supernatant was decanted. $500 \mu \mathrm{L}$ of one duplicate was added to 
a sterile, RNase-free microfuge tube with $1 \mathrm{~mL}$ of Bacteria Protect (Qiagen, Venlo, Limburg) and was stabilized following the protocols for enzymatic lysis and proteinase $\mathrm{K}$ digestion of bacteria with and without mechanical disruption as stated in the RNAprotect Bacteria Reagent Handbook (Qiagen 2005). Once the formation of the pellet was complete, the samples were stored at $-20^{\circ} \mathrm{C}$. The other duplicate of spore culture was diluted in sterile dl water if necessary and prepared on a pre-cleaned microscope slide with differential staining by malachite green and safranin for spore differentiation. Visual observations of sporulation and number of vegetative cells were documented.

\subsubsection{Lysis of Spores and Vegetative Cells}

The 0 min and 30 min incubation samples for both $B$. subtilis and $B$. licheniformis followed the protocol for enzymatic lysis, proteinase $\mathrm{K}$ digestion, and mechanical disruption of bacteria in the RNAprotect Bacteria Reagent Handbook (Qiagen, 2005 ) with $20 \mathrm{~min}$ of incubation for enzymatic lysis. The $60 \mathrm{~min}$ and $120 \mathrm{~min}$ incubation samples for $B$. subtilis followed protocol for enzymatic lysis, proteinase $\mathrm{K}$ digestion, and mechanical disruption of bacteria in the RNAprotect Bacteria Reagent Handbook (Qiagen, 2005) with 15min of incubation for enzymatic lysis. The $60 \mathrm{~min}$ and $120 \mathrm{~min}$ incubated samples for $B$. licheniformis followed the protocol for enzymatic lysis and proteinase $\mathrm{K}$ digestion of bacteria (Qiagen, 2005) with 20min of incubation for enzymatic lysis. Mechanical disruption was completed using a mini bead beater from BioSpec Products (Bartlesville, OK). 


\subsubsection{Total RNA purification from Lysate}

Once spore and cell lysis was complete, total RNA was obtained by following the purification of total RNA from bacterial lysate in the RNAprotect Bacteria Reagent Handbook using the RNeasy mini kit (Qiagen). $6 \mu \mathrm{L}$ of the RNA samples were run for $25 \mathrm{~min}$ at $90 \mathrm{~V}$ in a $1.5 \% \mathrm{w} / \mathrm{v}$ agarose in $1 \mathrm{x}$ TAE with $3 \mu \mathrm{L}$ of ethidium bromide (Fisher Scientific) to check for degradation. Concentration and purity were estimated using a NanoDrop 2000c Spectrophotometer from Thermo Scientific (Waltham, MA).

\subsubsection{Reverse Transcription}

Reverse transcription (translation of mRNA to CDNA) was completed using the QuantiTect Reverse Transcription Kit (Qiagen). The protocol in the QuantiTect Reverse Transcription Handbook (p.11-13, 2009) called for the completion of two steps: genomic DNA elimination followed by reverse transcription. The volumes of the RNA sample, DNase, and RTase used are shown in Table 3.2. Once translation was complete, $\mathrm{CDNA}$ samples were stored at $-20^{\circ} \mathrm{C}$ for use in $\mathrm{qPCR}$. 
Table 3.2 Volumes and reagents used for Reverse Transcription. First the sample and gDNA wipeout volumes were combined to complete the gDNA elimination step. That combined volume was mixed with the RT Master Mix volume and RNase-Free water (to reach a $20 \mu \mathrm{L}$ reaction volume) to complete the translation of RNA to cDNA.

\begin{tabular}{|l|l|l|l|l|l|}
\hline Species & Sample & $\begin{array}{l}\text { Sample } \\
\text { Vol. }(\boldsymbol{\mu L})\end{array}$ & $\begin{array}{l}\text { gDNA } \\
\text { Wipeout } \\
\text { Vol. }(\boldsymbol{\mu L})\end{array}$ & $\begin{array}{l}\text { RNase-Free } \\
\text { Water Vol. } \\
(\boldsymbol{\mu L})\end{array}$ & $\begin{array}{l}\text { RT Master } \\
\text { Mix Vol. } \\
(\boldsymbol{\mu L})^{*}\end{array}$ \\
\hline B.subtilis & Omin & 32 & 6 & 4 & 18 \\
\hline B.licheniformis & Omin & 28 & 6 & 8 & 18 \\
\hline B.subtilis & $30 \mathrm{~min}$ & 24 & 6 & 12 & 18 \\
\hline B.licheniformis & $30 \mathrm{~min}$ & 28 & 6 & 8 & 18 \\
\hline B.subtilis & $60 \mathrm{~min}$ & 31 & 6 & 5 & 18 \\
\hline B.licheniformis & $60 \mathrm{~min}$ & 36 & 6 & 0 & 18 \\
\hline B.subtilis & $120 \mathrm{~min}$ & 32 & 6 & 4 & 18 \\
\hline B.licheniformis & $120 \mathrm{~min}$ & 18 & 6 & 18 & 18 \\
\hline B.subtilis & No RT & 24 & 4 & 0 & 0 \\
\hline B.licheniformis & No RT & 24 & 4 & 0 & 0 \\
\hline
\end{tabular}

*Volume was added once elimination of gDNA was complete

\subsubsection{Validation Assay}

To test the efficiency of the reaction, as well as the performance of the primers, a validation plate was run. A twenty-fold dilution was made using cDNA from 0min, $30 \mathrm{~min}$, and $120 \mathrm{~min}$ samples; diluting the $60 \mathrm{~min}$ samples was not required due to their low concentration and subsequent low amount of cDNA. These dilutions were pooled $(20 \mu \mathrm{L}$ of each) based on species and four, five-fold serial dilutions were made using sterile $\mathrm{dl}$ water. The undiluted pooled sample for each species had cDNA concentrations of approximately $1.2 \mathrm{ng} / \mu \mathrm{L}$. Quantitative PCR with each primer set and template dilution were done in triplicate with $0.2 \mathrm{mM}$ of total primers, $2.5 \mu \mathrm{L}$ of cDNA, $10 \mu \mathrm{L}$ of Fast SYBR Green Master Mix (Applied Biosystems), and sterile dl water to bring the final reaction volume to $20 \mu \mathrm{L}$. The assay was carried out at an annealing temperature of $59^{\circ} \mathrm{C}$ on a 7500 Fast RealTime PCR System from Applied Biosystems (Life Technologies). 


\subsubsection{Experimental Assay}

To run the experimental assays, the primers targeting the $r r n E-16$ s ribosomal RNA (reference), GerAC on both B. subtilis and B. licheniformis, and gpr and SleB on $B$. licheniformis were used. The conditions for the reactions were: approximately $3 \mathrm{ng}$ of template cDNA, $0.2 \mathrm{mM}$ of total primers, $10 \mu \mathrm{L}$ of Fast SYBR Green Master Mix, and sterile water to bring the reaction volume to $20 \mu \mathrm{L}$. Reactions were done in triplicate and carried out at an annealing temperature of $59^{\circ} \mathrm{C}$ on a 7500 Fast Real-Time PCR System from Applied Biosystems. 


\section{CHAPTER 4 RESULTS AND DISCUSSION}

\subsection{Growth and Germination Curves for B. subtilis and B. licheniformis}

\subsubsection{Growth Curve using BacT/ Alert}

After a 24-hour incubation period for both species, the curves shown in Figure 4.1 were generated. The color values were normalized to the color reading of both an "open" and "closed" blank so that 0 color corresponded to no color change (which correlates to no outgrowth or metabolic activity from vegetative cells). From these curves, a lag time could be estimated. 


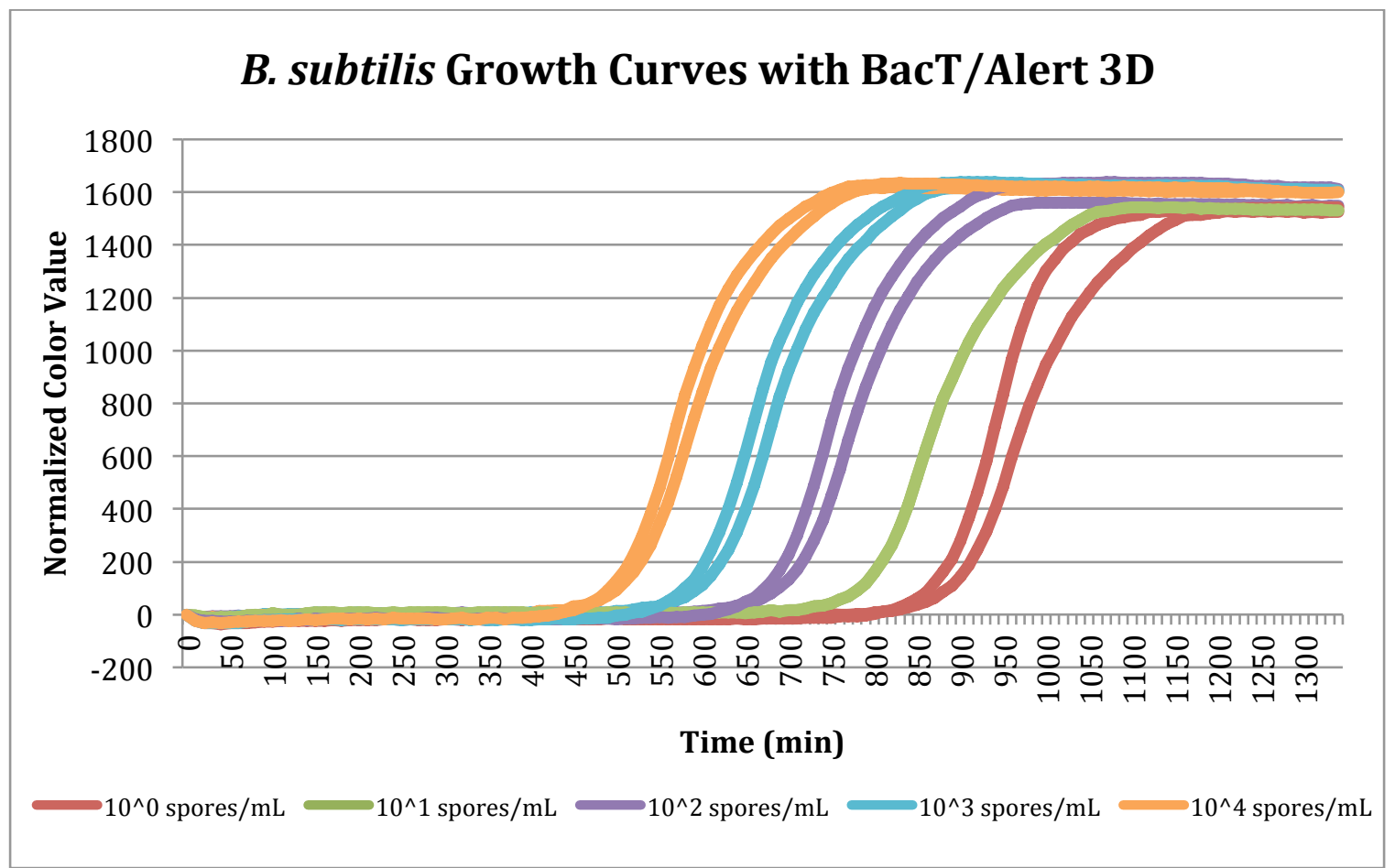

(A)

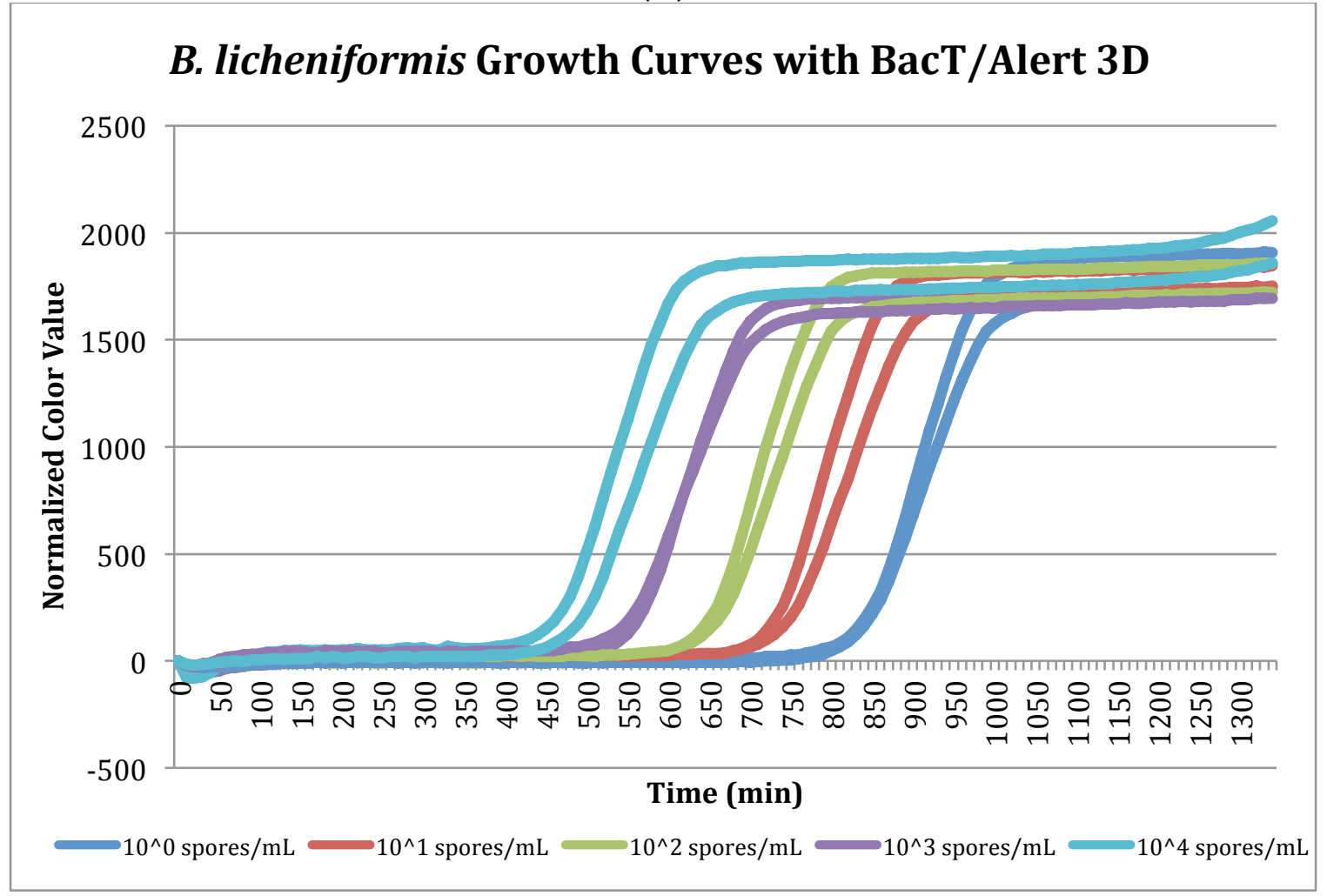

(B)

Figure 4.1 Growth curves of $B$. subtilis (A) and $B$. licheniformis $(B)$ in the BacT/Alert iAST media. Varying dilutions of $B$. subtilis were incubated at $32^{\circ} \mathrm{C}, B$. licheniformis samples were incubated at $37^{\circ} \mathrm{C}$. The BacT/Alert measures growth via color change of the bottom of the bottle. A higher color value corresponds to a higher concentration of viable Bacillus cells. 
Lag time in the life cycle of a bacteria refers to the stage when bacterial cells are increasing in mass, but not in number. This time will vary between species, as well as between cultures of the same species, but of different stages in life cycles. The lag phase for spore formers is more complex as it also includes the transformation from a spore to a vegetative cell. As the lag phase for activated spores also includes germination, it is important to note that the lag phase for a spore population may take longer than other, non spore-forming bacteria when using a machine like the BacT/Alert. Figure 4.1 displays the growth curves for both $B$. subtilis and $B$. licheniformis. The lag time is determined by the value (time) when the line tangent to the inflection point $\left(f^{\prime \prime}(x)=0\right)$ intercepts the $x$ axis. The lag phase values for each species is shown in Table 4.1.

Table 4.1 Lag phase values for $B$. subtilis and B. licheniformis (in minutes)

\begin{tabular}{|c|c|c|c|c|c|}
\hline & \multicolumn{5}{|c|}{ Concentration (spores/mL) } \\
\hline & $10^{\wedge} 0$ & $10^{\wedge} 1$ & $10^{\wedge} 2$ & $10^{\wedge} 3$ & $10^{\wedge} 4$ \\
\hline B. licheniformis & 834.73 & 720.30 & 640.99 & 548.66 & 453.96 \\
\hline B. licheniformis & 831.75 & 735.88 & 647.62 & 535.41 & 477.23 \\
\hline Average & 833.24 & 728.09 & 644.30 & 542.04 & 465.60 \\
\hline Standard Dev. & 2.11 & 11.02 & 4.68 & 9.37 & 16.45 \\
\hline B. subtilis & 896.63 & 795.12 & 701.90 & 610.98 & 513.54 \\
\hline B. subtilis & 878.38 & 790.24 & 679.67 & 590.78 & 502.34 \\
\hline Average & 887.51 & 792.68 & 690.78 & 600.88 & 507.94 \\
\hline Standard Dev. & 12.91 & 3.45 & 15.72 & 14.28 & 7.92 \\
\hline
\end{tabular}

Analysis of variance looking at the lag times between the species as well as between the concentrations found there to be significant differences $(p<0.0001)$ with both factors (species and concentrations)--the averages for $B$. subtilis at every concentration being higher than $B$. licheniformis. The differences between the lag times were looked at as a percentage of the more concentrated in serial. 
It was found that there was a decrease in lag times by $13 \%$, on average, with each ten-fold increase in concentration as shown in Table 4.2.

Table 4.2 Lag time ratios for both species. These were calculated relative to the preceding concentration, which is why no value exists for the first concentration.

\begin{tabular}{|l|c|c|c|c|c|}
\hline \multirow{2}{*}{$\begin{array}{c}\text { Average lag } \\
\text { times }\end{array}$} & \multicolumn{5}{|c|}{ Concentration (spores/mL) } \\
\cline { 2 - 6 } & $\mathbf{1 0 \wedge 0}$ & $\mathbf{1 0 \wedge 1}$ & $\mathbf{1 0 \wedge 2}$ & $\mathbf{1 0 \wedge 3}$ & $\mathbf{1 0 \wedge 4}$ \\
\hline B. licheniformis & - & 0.87 & 0.88 & 0.84 & 0.86 \\
\hline B. subtilis & - & 0.89 & 0.87 & 0.87 & 0.85 \\
\hline
\end{tabular}

Analysis of variance was conducted on the ratios by both species $(p=0.5195)$ and concentration $(p=0.2295)$ and found neither factor to be significant in this lagtime decrease. It may be the mechanics of the BacT/Alert 3D detection system that decreases lagtime with a ten-fold increase in concentration.

\subsubsection{Germination Assay}

For the germination curves pictured in Figure 4.2 the starting concentrations were $10^{4}$ spores $/ \mathrm{mL}$, and each color represents one triplicate. Although the germination assays were carried out five times, the expected results were never achieved. When germination occurs in a spectrophotometer, the absorbance measured at $610 \mathrm{~nm}$ typically decreases as the refractivity of the spores is lost during the degradation of the spore coats and peptidoglycan cortex. This was not the case in the experiments carried out with both species of spore. In fact, every experimental run yielded different results, none of which showed the steady decrease in absorbance that corresponds to germination of the spore solution. Figure 4.2 shows germination curves that did not have cross contamination in their blanks when following the protocol described in the Methods and Materials. 
In the runs that did experience cross contamination, the wells with uninnoculated TSB became turbid from bacterial growth. This made the results from those experiments inaccurate. No initial decrease was seen, and the germination curves of the two spore-formers do not match those observed in other research (Rode et al., 1961).

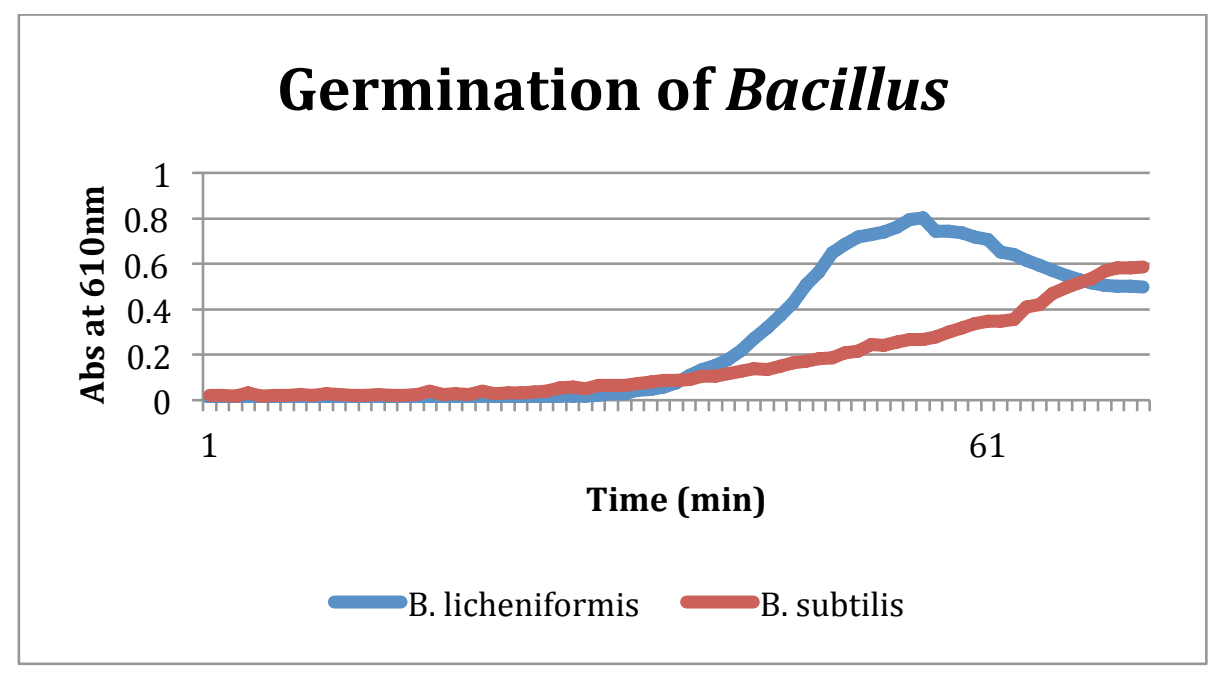

Figure 4.2 Absorbance of spore solutions after heat treatment at $80^{\circ} \mathrm{C}$ for $12 \mathrm{~min}$. As spores are 'refractile bodies' absorbance should have decreased during the first 2 hours of the assay in representation of germination and the loss of the refractile spore coat. A sufficient decrease in absorbance was not observed and the assay gave results of a standard growth curve despite multiple replications.

Possible reasons for the lack of success in this assay may have been due to the contamination of the blank on the 96-well plate. Once the blanks become contaminated the spectrophotometer is no longer accurately reading the wavelengths of the unknown samples. Another explanation may have to do with the starting concentration of spores in the solution. The starting concentration for this assay was approximately $10^{4}$ spores $/ \mathrm{mL}$ of tryptic soy broth, while previous experiments were greater than $10^{7}$ spores $/ \mathrm{mL}$ per germinant rich solution (which 
varied in concentration of sugars and amino acids given the study being conducted). The lower concentration of spores was used in order to mimic high counts that would be found in a powder milk product. It is possible that this low of a concentration of spores was below the threshold of detection for the spectrophotometer and so accurate absorbance measures could not be taken.

\subsection{PCR}

Genomic DNA was purified using the DNA purification protocol adapted from Reukert et al (2006). To check for quality, $10 \mu \mathrm{L}$ were loaded with $1 \mu \mathrm{L}$ of gel loading buffer (BioRad) into a 1\% w/v agarose gel prepared with ethidium bromide to allow immediate viewing of the DNA on a Universal Hood II (BioRad) under UV light. Figure 4.3 shows the genomic DNA results--the thick, bright bands at the top of the gel represent genomic DNA that has not been degraded. The less intense bands of less than $1000 \mathrm{bp}$, correspond to RNA and degraded DNA. The minimal streaking in lanes 5 and 6 qualified those DNA samples for use in endpoint PCR. Once quality was confirmed, concentration of each sample was measured on a NanoDrop 2000c UV-Vis Spectrophotometer by Fisher Scientific. Concentrations and purity of the genomic DNA isolated from the spore suspensions are listed in Table 4.3. For a DNA sample to be of high enough quality for use in PCR, samples were only selected for downstream use if their purity ratio $\left(A_{260} / A_{280}\right)$ was greater than 1.5 . 


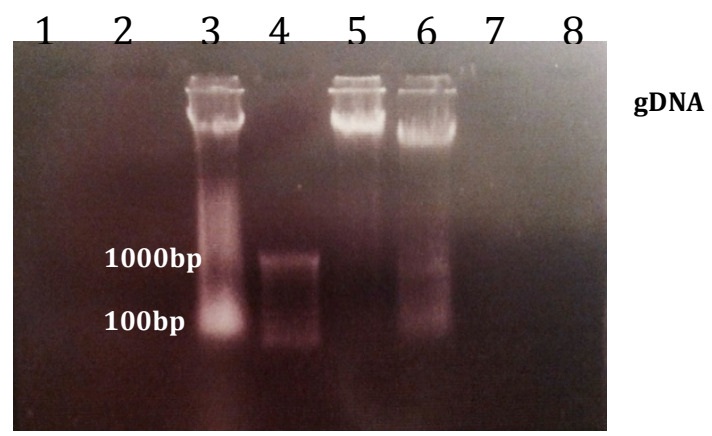

Figure 4.3 Genomic DNA purification of B.subtilis and B.licheniformis. $1 \% \mathrm{w} / \mathrm{v}$ agarose gel in $1 \times T A E$ run at $90 \mathrm{~V}$ for $20 \mathrm{~min}$. Lanes 2 and 5 contain a samples of $B$.licheniformis gDoNA; lanes 3 and 6 contain samples of $B$. subtilis gDNA; and lane 4 is a 100bp ladder (BioRad)

Table 4.3 Concentrations and purity of genomic DNA samples extracted using the Reuckert et al method measured with a NanoDrop 2000c UV-Vis Spectrophotometer (Fisher Scientific), dilution factors, and final concentrations to be used in PCR.

\begin{tabular}{|c|c|c|c|c|c|}
\hline $\begin{array}{c}\text { Lane } \\
\text { No. }\end{array}$ & $\begin{array}{c}\text { Bacillus } \\
\text { Species }\end{array}$ & $\begin{array}{c}{[\mathbf{g D N A}]_{\mathbf{i}}} \\
(\mathbf{n g} / \boldsymbol{\mu L})\end{array}$ & $\begin{array}{c}\text { Purity } \\
\left(\mathbf{A}_{\mathbf{2 6 0}} / \mathbf{A}_{\mathbf{2 8 0}}\right)\end{array}$ & DF & $\begin{array}{c}{[\mathbf{g D N A}]_{\mathbf{f}}} \\
(\mathbf{n g} / \boldsymbol{\mu L} \mathbf{L})\end{array}$ \\
\hline 2 & licheniformis & 6.0 & 1.57 & 0 & 6.0 \\
\hline 3 & subtilis & 236.7 & 2.03 & 100 & 2.37 \\
\hline 5 & licheniformis & 130.9 & 1.82 & 100 & 1.31 \\
\hline 6 & subtilis & 48.5 & 2.10 & 10 & 4.85 \\
\hline
\end{tabular}

PCR amplification was done with primer sets that targeted 3 germination related genes on both species (GerAC, sleB, and gpr) as well as the 16 s gene, following the temperatures and reagent concentration listed in the Materials and Methods. What resulted was amplification of 100-250bp products depending on the primer set used. Figure 4.4 shows amplicons from two of the primer sets-those for the GerAC gene on $B$. subtilis (102bp) and those for the SleB gene on $B$. licheniformis (165bp). Endpoint PCR was used as a confirmation of the efficacy of the primers before they could be utilized for real-time PCR. 


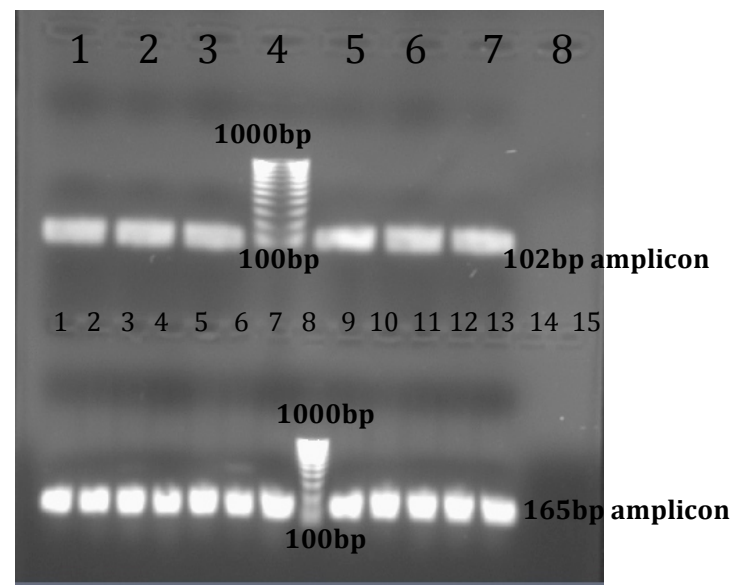

Figure 4.4 PCR product from varying annealing temperatures. $1 \% \mathrm{w} / \mathrm{v}$ agarose gel in $0.5 \times T B E$ run at $95 \mathrm{~V}$ for $20 \mathrm{~min}$ with $3 \mu \mathrm{L}$ of EtBr. Temperatures increase approx. $0.5^{\circ} \mathrm{C}$ going from left to right starting at $59.2^{\circ} \mathrm{C}$ for the top row and $56.5 \mathrm{C}$ for the bottom row. Top Row: Lanes 1-3 and 5-7 contain PCR product (102bp) from primers targeting GerAC on B. subtilis; lane 4 contains $100 \mathrm{bp}$ ladder (BioRad). Bottom Row: Lanes 1-7 and 9-13 contain PCR product (165bp) from primers targeting the SleB gene on $B$. licheniformis; lane 8 is the 100bp ladder (BioRad).

To verify the specificity of the primers selected for $\mathrm{qPCR}$, the primers were tested on Lactic Acid Bacteria and E. coli as well. These bacteria are commonly found in dairy products and are plausible sources of contamination during DNA purification of milk products. The specificity of the primers was confirmed after a reaction with the DNA from lactic acid bacteria, E.coli, Bacillus subtilis, and bacillus licheniformis. The results were visualized using gel electrophoresis and shown in Figure 4.5. 


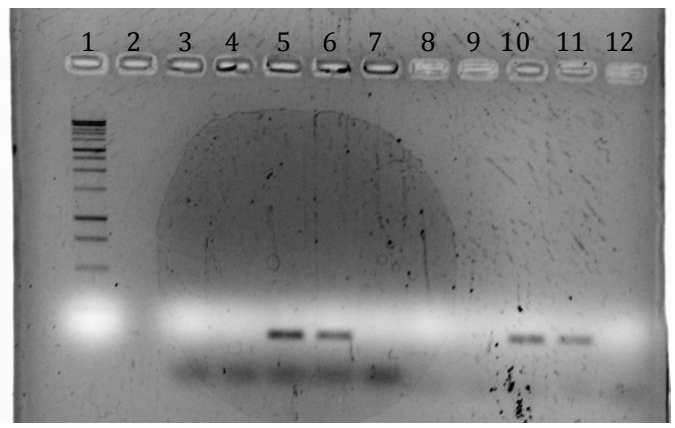

(A)

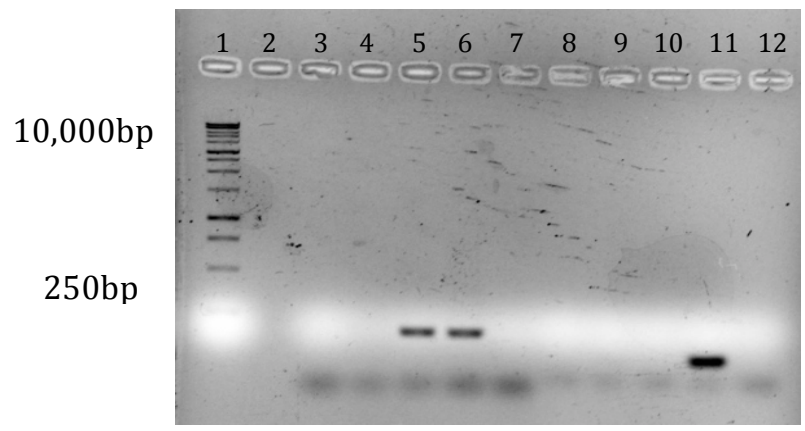

(B)

Figure $4.51 .5 \% \mathrm{w} / \mathrm{v}$ agarose gel in $1 \mathrm{x}$ TAE with ethidium bromide, run for $20 \mathrm{~min}$ at $90 \mathrm{~V}$. (A) GerAC and SleB primers designed for $B$. licheniformis. The lane contents starting with lane 1 on the left: 1. Molecular ruler (Promega) 2. empty 3. E.coli DNA GerAC L1 primers 4. Lactobacillus DNA and GerAC L1 primers 5. B. licheniformis DNA and GerAC L1 primers 6. B. subtilis DNA and GerAC L1 primers 7. No DNA and GerAC L1 primers 8. E. coli DNA and SleB L1 primers 9. lactobacillus DNA and SleB L1 primers 10. B. licheniformis DNA and SleB L1 primers 11. $B$. subtilis DNA and SleB L1 primers 12. No DNA and SleB L1 primers. (B) gpr and primers designed for $B$. licheniformis and GerAC primers designed for $B$. subtilis. The lane contents starting with lane 1 on left : 1 . Molecular ruler 2. empty 3. e. coli DNA and gpr L1 primers 4. lactobacillus DNA and gpr L1 primers 5. B. licheniformis DNA and gpr L1 primers 6. B. subtilis DNA and gpr L1 primers 7. No DNA and gpr L1 primers 8. e.coli DNA and GerAC S1 primers 9. Lactobacillus DNA and GerAC S1 primers 10. B. licheniformis DNA and GerAC S1 primers 11. B. subtilis DNA and GerAC S1 primers 12. No DNA and GerAC S1 primers.

Figure 4.5 shows amplicons around 100bp for lanes 5, 6, 10, and 11 in gel (A) and lanes 5, 6, and 11 in (B). These lanes contained the DNA of endospore formers $B$. licheniformis and subtilis. The empty lanes containing no DNA and DNA from other bacteria verify that the designed primers do not amplify contaminating DNA and are specific to the species of endospore former. It is interesting to note, however, that the primers designed for $B$. licheniformis also amplify the same size product from $B$. subtilis DNA. This suggests a possible optimized assay that only requires one set of primers to identify a majority of the endospore formers found in milk powders without worry of false positives by lactic acid bacteria and E. coli. 


\section{3 qPCR as a Gene Expression Assay}

\subsubsection{Total RNA Purification from Lysate}

Total RNA purification was completed with the RNeasy Mini Kit and Bacteria Protect from Qiagen. $6 \mu \mathrm{L}$ of sample RNA was loaded with $1 \mu \mathrm{L}$ of $10 x$ loading buffer (BioRad) onto a $1.5 \% \mathrm{w} / \mathrm{v}$ agarose gel. Ethidium bromide was added to the gel to allow for immediate viewing under UV light with a Universal Hood II (BioRad).

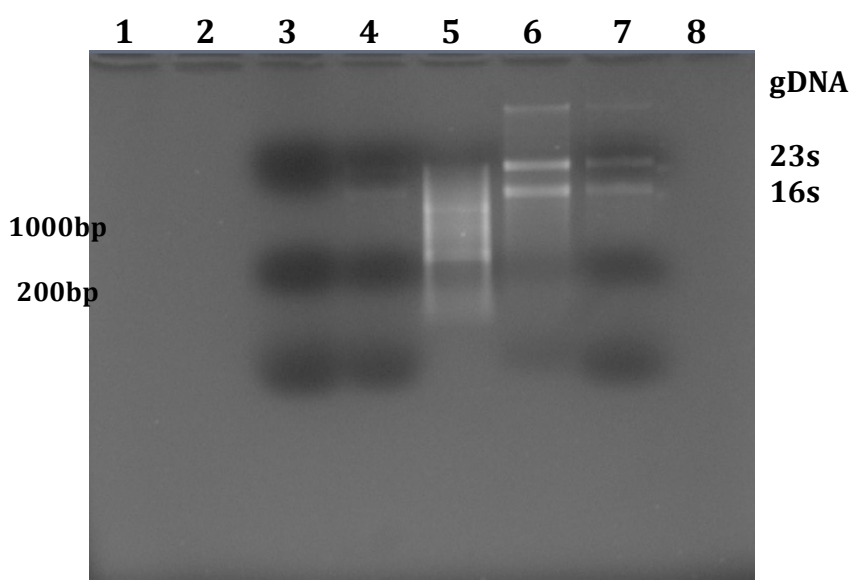

Figure 4.6 RNA purification of $\boldsymbol{B}$. licheniformis. $1.5 \% \mathrm{w} / \mathrm{v}$ agarose gel in $1 \mathrm{XTAE}$ with $3 \mu \mathrm{L}$ ethidium bromide, run at $90 \mathrm{~V}$ for $20 \mathrm{~min}$. Lanes 3 is $B$. licheniformis spores at $0 \mathrm{~min}$ incubation, lane 4 is $30 \mathrm{~min}$, lane 5 is EZ Load ${ }^{\text {TM }} 20 \mathrm{bp}$ Molecular Ruler (BioRad) of incubation, lane 6 is $60 \mathrm{~min}$ of incubation, and lane 7 is $120 \mathrm{~min}$ of incubation.

Intact bands with minimal streaking indicate high quality RNA that has not degraded due to RNase activity. Lanes 6 and 7 in Figure 4.6 have the most intense bands which show the 16 s and 23s RNA of $B$. licheniformis with minimal degradation. They also show contamination with genomic DNA. This contamination will need to be addressed before a proper gene expression assay can commence. Concentration of RNA was estimated using the $A_{260}$ of the RNA samples and the extinction coefficient $\varepsilon=25(\mu \mathrm{l} / \mu \mathrm{g}) \mathrm{cm}^{-1}$ and listed in Table 4.4. 


\subsubsection{Reverse Transcription}

In order to conduct the qPCR assay, mRNA in the total RNA samples needed to be translated into cDNA. This process of reverse transcription was completed using the QuantiTect Reverse Transcription Kit (Qiagen). This kit was selected because it contained a step to eliminate genomic DNA, which was shown as a contaminant in the RNA samples in Figure 4.6. Once gDNA was eliminated and reverse transcription was complete, amplification of the cDNA was performed using the primer set corresponding to the reference gene (rrnE-16s) to confirm that the primers and PCR conditions work for cDNA as well as the gDNA that was used in previous experiments. The results of this amplification are shown in Figure 4.7. Concentrations of the cDNA samples were estimated assuming $100 \%$ efficiency of the QuantiTect Reverse Transcription Kit (Table 4.4).

Table 4.4 Concentration of RNA calculated from the $A_{260}$ readings given by the NanoDrop 2000c UV-Vis Spectrophotometer using $\varepsilon=25(\mu \mathrm{L} / \mu \mathrm{g}) \mathrm{cm}^{-1}$. Concentrations of cDNA were estimated assuming $100 \%$ efficiency of the RTase. Varying amounts of the RNA depending on the starting concentration, hence the incongruity between [RNA] and [cDNA].

\begin{tabular}{|c|c|c|c|}
\hline Sample & $\mathbf{A}_{\mathbf{2 6 0}}$ & {$[\mathrm{RNA}](\mathbf{n g} / \mathbf{\mu L})$} & [cDNA] $(\mathbf{n g} / \mathbf{\mu L})$ \\
\hline B. subtilis 0min & 0.576 & 23.04 & 13.82 \\
\hline B. subtilis 30min & 2.681 & 107.24 & 42.90 \\
\hline B. subtilis 60min & 0.104 & 4.16 & 2.50 \\
\hline B. subtilis 120min & 0.619 & 24.76 & 14.86 \\
\hline B. licheniformis 0min & 0.653 & 26.12 & 15.67 \\
\hline B. licheniformis 30min & 1.800 & 72.0 & 43.2 \\
\hline B. licheniformis 60min & 0.146 & 5.84 & 3.5 \\
\hline B. licheniformis 120min & 1.500 & 60.0 & 18.0 \\
\hline B. subtilis No RT & ${ }^{*}$ & 23.88 & 0 \\
\hline B. licheniformis No RT & $*$ & 24.59 & 0 \\
\hline
\end{tabular}

*No RT samples were made using pooled RNA samples of each species, and only the gDNA wipeout. 
Amplification of the cDNA samples with the reference gene primer set was successful; bands at 197bp are seen for each sample of template (Fig. 4.7). The "No RT" samples for each species fill the role of negative control in the qPCR assay to ensure that gDNA contamination does not impact the amplification, and consequently, gene expression assay.

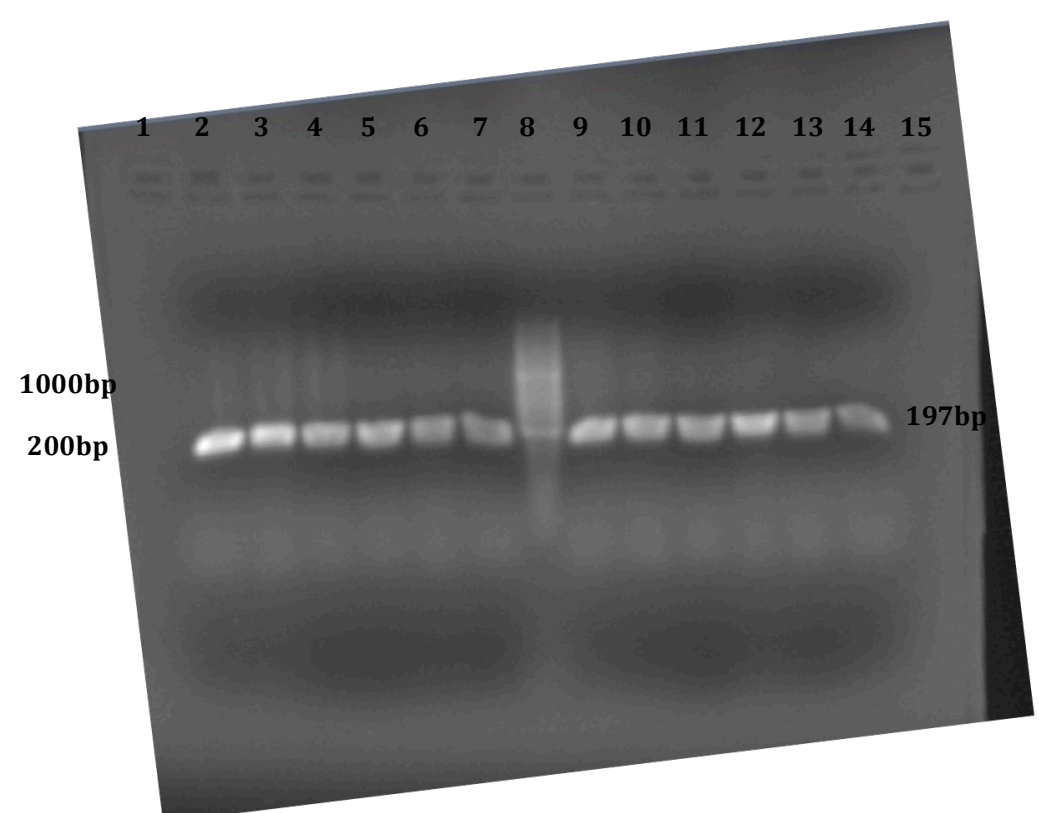

Figure 4.7 PCR amplification using the primer set for the $16 \mathrm{~s}$ gene (reference gene). $1.5 \%$ w/v agarose gel in $0.5 \mathrm{x}$ TBE with $3 \mu \mathrm{L}$ ethidium bromide run at $90 \mathrm{v}$ for $20 \mathrm{~min}$. Lanes 1 and 9 contain cDNA from $B$. licheniformis incubated for $30 \mathrm{~min}$; lanes 3 and 10 contain cDNA from $B$. licheniformis incubated for $60 \mathrm{~min}$; lanes 4 and 11 contain cDNA of $B$. licheniformis incubated for $120 \mathrm{~min}$; lanes 5 and 12 contain gDNA from $B$. licheniformis; lanes 6 and 13 contain gDNA from $B$. subtilis; lanes 7 and 14 contain cDNA from $B$. subtilis incubated for $120 \mathrm{~min}$; and lane 8 contains EZ Load ${ }^{\text {TM }}$ 20bp Molecular Ruler (BioRad). 
Only the primers for the $r r n E$ gene were used because they were the positive control. Therefore, amplification should occur whether or not germination related genes were expressing. The other primers target sequences within genes that may or may not be expressed in these cDNA samples. If the amplification was unsuccessful for these primers, it would be uncertain whether it was due to an error in the design of the primers, or if that particular gene was not expressed in that sample.

\subsubsection{Validation Assay}

From the validation assay, completed according to the Materials and Methods, dissociation curves were created and the efficiency of the reactions were calculated. If the designed primers were specific to the target gene, only one product would result. The dissociation curves will confirm this by having one peak if this specificity is achieved. Figure 4.8 shows the dissociation curve for the primers designed to target the $r n E-16$ s gene. The single peak corresponds to the melting temperature of the product or amplicon created by these primers. One PCR product results in one melting temperature that will show up as one peak on the dissociation curve. 


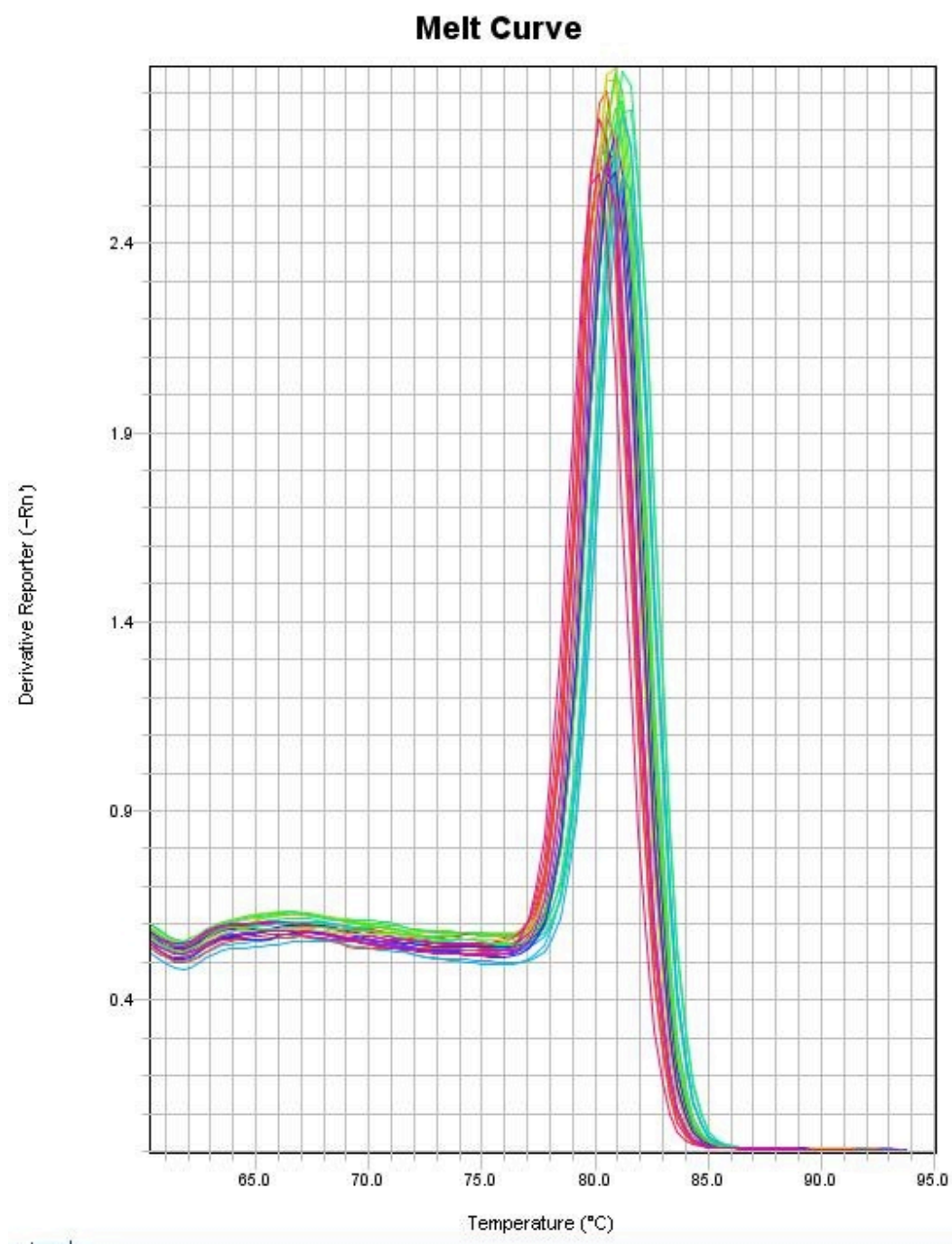

Figure 4.8 Dissociation curve of 16s Primers (HKG) on template cDNA for both species. Each line in the figure corresponds to a triplicate of the 4 different initial template concentrations for both $B$. subtilis and $B$. licheniformis. $-\mathrm{RN}$ is the negative first derivative of reporter molecule(fluorescence).

If the dissociation curve had 2 or more peaks, the primers were not specific enough and not used in the experimental assay. Figure 4.9 shows the dissociation curve for the primers that targeted the SleB gene on the $B$. subtilis species. The 2 peaks in Figure 4.9 correspond with 2 melting temperatureseach belonging to a different PCR product. Specificity of primers is required for 
an optimized assay, so the primers for this particular target gene were not used in the experimental assay.

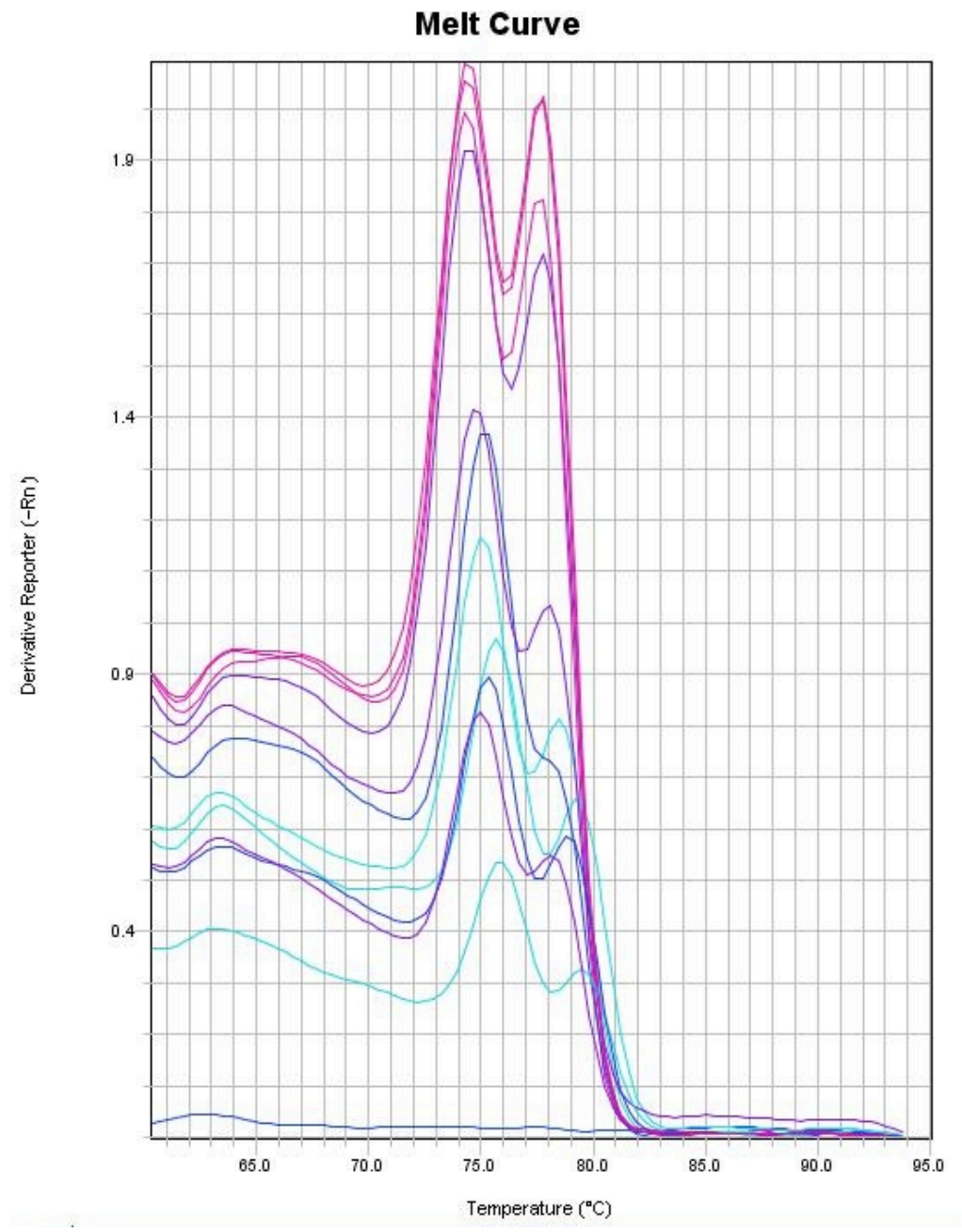

Figure 4.9 Dissociation curve of SleB primers for $B$. subtilis template cDNA. Each line in the figure corresponds to a triplicate of the 4 different initial template concentrations for both $B$. subtilis. $-\mathrm{RN}$ is the negative first derivative of reporter molecule(fluorescence).

The primers that target the gpr gene on $B$. subtilis were also excluded from the experimental assay due to nonspecific priming. For optimization of future experimental runs, new primers for those target genes-B. subtilis gpr and SleB — would need to be designed so that only one peak appeared on the dissociation curve. 
The primers with dissociation curves that corresponded with specific binding were analyzed for efficiency (E). Ideal efficiency, or an E of $100 \%$, corresponds to a PCR reaction in which the amount of product doubles with the completion of each cycle. For an optimized assay, E should be $90-110 \%$. To calculate efficiency, the following equation was used:

$$
E=10^{-\frac{1}{S L O P E}}-1
$$

The slope is calculated from the plot of log(initial template concentration) v. $\mathrm{C}_{\mathrm{T}}$, and referred to as the standard curve (Figure 4.10). The E values for each reaction set are shown in Table 4.5 .

Table 4.5 E values for rrnE and GerAC (B.subtilis and B.licheniformis), and gpr and SleB (B.licheniformis). E values for the primers to amplify the gpr and SleB gene on $B$. subtilis were not calculated as the corresponding dissociation curves displayed non-specificity of the primers.

\begin{tabular}{|c|c|c|c|}
\hline Target Species & Target Gene & Slope & Efficiency (\%) \\
\hline B. licheniformis & 16 s (Ref) & -3.2693 & 102.257 \\
\hline B. licheniformis & GerAC & -3.014 & 114.895 \\
\hline B. licheniformis & GPR & -2.0698 & 204.153 \\
\hline B. licheniformis & SleB & -2.5531 & 146.43 \\
\hline B. subtilis & 16 s (Ref) & -3.5494 & 91.324 \\
\hline B. subtilis & GerAC & -2.4515 & 155.759 \\
\hline
\end{tabular}




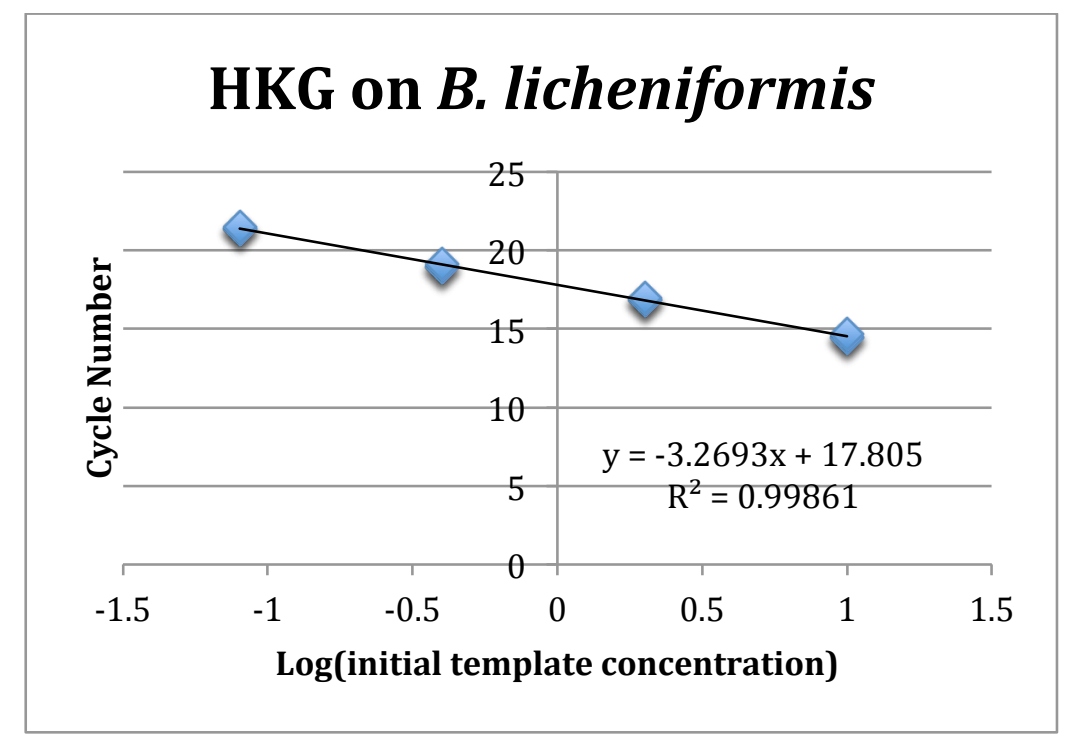

Fig 4.10 Standard Curve using B. licheniformis template cDNA and rrnE primers. Each point on the graph corresponds to the average $\mathrm{C}_{\mathrm{T}}$ value for the different concentrations of starting template.

Excluding the reference, the primers in this validation assay have sub-optimal efficiency values, as they do not fall between $90-110 \%$. As a preliminary investigation, this assay provides information for the optimization of future experiments. One explanation for the less than ideal efficiency may have to do with the initial template concentration. The mean $\mathrm{C}_{\mathrm{T}}$ values are higher then those for the HKG (rrnE), which suggests the amount of expressed target gene, is in relatively low concentrations. The concentrations at this low of a level produce high $\mathrm{C}_{\mathrm{T}}$ values. Higher $\mathrm{C}_{\mathrm{T}}$ values can give efficiencies above 100\% (a practical impossibility) when the reaction begins the linear phase. Outside of the exponential phase, the output cannot be correlated to input (Pfaffl, 2006). Higher initial concentrations will lower $\mathrm{C}_{\mathrm{T}}$ values and keep quantitation in the exponential phase where results are more reliable. 


\subsubsection{Experimental Assay}

With the completion of the validation assay, an experimental assay was run on the different treatments of each species of heat shocked spore solutions. Using the cDNA synthesized from the mRNA of heat-shocked spores that had been incubated for $0,30,60$, and $120 \mathrm{~min}$; qPCR was completed following the protocol listed in the Materials and Methods. The resulting cycle threshold values were used in the analysis of gene expression. Cycle threshold $\left(\mathrm{C}_{\mathrm{T}}\right)$ is the number of cycles in which the amount of fluorescence generated by the reaction exceeds the threshold of fluorescence set by the manufacturer.

Figure 4.11 shows the amplification plot for all the reactions; that is each triplicate of the 5 sets of primers on each treatment for each corresponding species. The orange and yellow curves grouped on the left side of the graph are the reference gene amplified for each treatment of each species. The curves grouped on the right side of the graph are the germination genes amplified for each treatment of each species. This separation suggests that the expression of the reference gene was much higher than that of the germination genes targeted, and as mentioned earlier, the higher $\mathrm{C}_{\mathrm{T}}$ values can lead to decreased accuracy in relative expression, especially if the reference gene has a $\mathrm{C}_{T}$ value half that of the corresponding target gene. If an alternate reference gene has a similar level of expression to the target (germination) genes, it would be beneficial to apply it to this assay. 


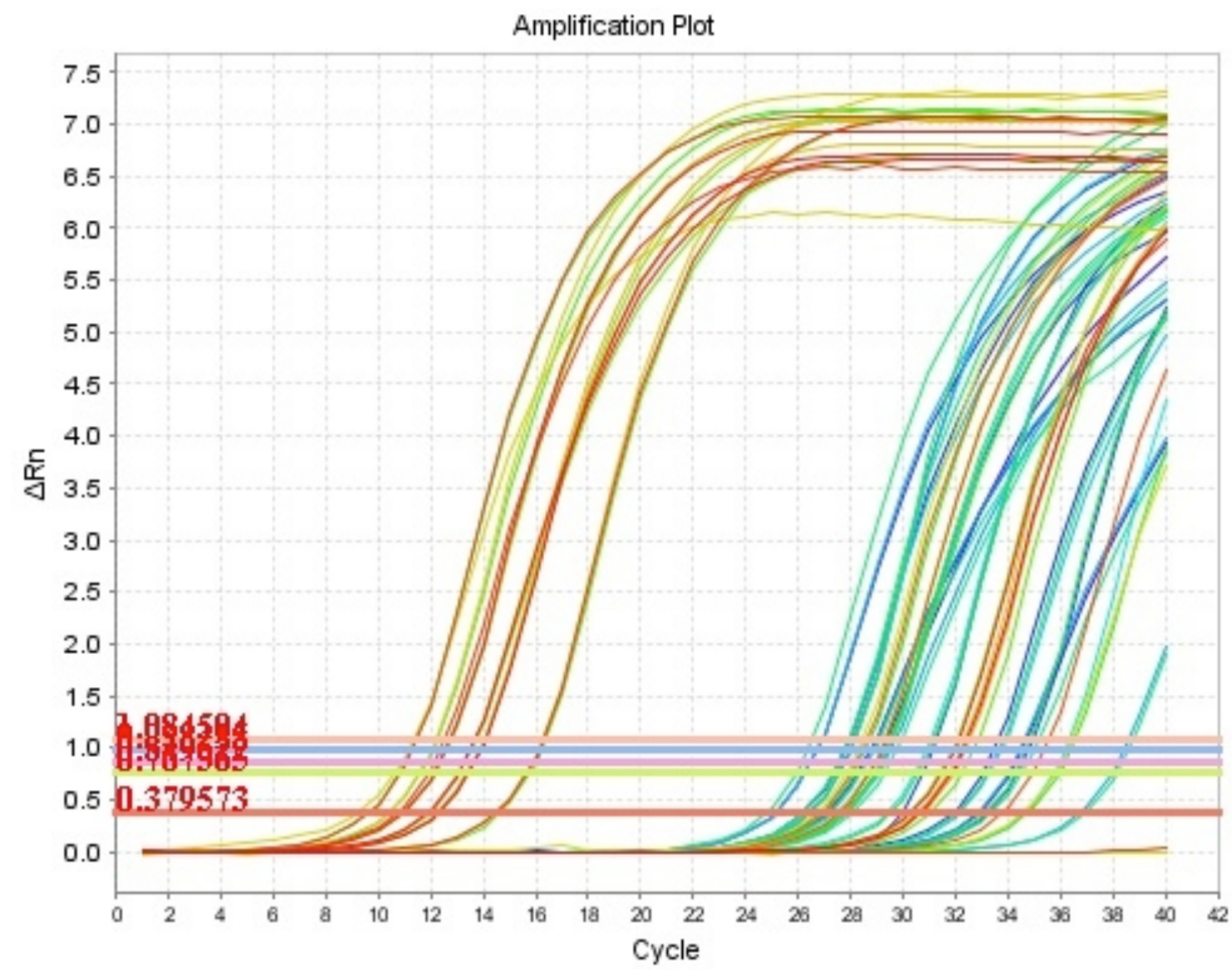

Figure 4.11 Amplification plot showing all 5 PCR reactions-Reference gene and GerAC for both B. licheniformis and B. subtilis, and gpr and SleB for B. licheniformis. The horizontal lines correspond to threshold values determined by the manufacturer's program, and each curve represents one individual PCR reaction. $\mathrm{Rn}$ is the normalized fluorescence of the reporter; $\Delta \mathrm{Rn}$ is the $\mathrm{Rn}$ minus the baseline.

The typical method for analyzing relative gene expression is the Livak Method, which calculates an expression ratio with this equation (Bio-Rad Laboratories, 2005):

$$
2^{-\Delta \Delta C_{T}}=\text { Normalized expression ratio }
$$

However, this method assumes not only that the efficiencies of the PCR reactions are within the optimal $90-110 \%$ range, but also that they are similar to each other. As shown in Table 4.5, that is not applicable to this experiment. Even 
small differences in efficiencies between target and reference give false difference in relative gene expression (Pfaffl, 2006). To remedy this, the Pfaffl Method was used (Pfaffl, 2001). This method takes into account the difference in amplification efficiencies and is as follows:

$$
\text { Ratio }=\frac{\left(E_{\text {target }}\right)^{\Delta C_{t}, \text { target }(\text { control-target })}}{\left(E_{\text {ref }}\right)^{\left.\Delta C_{t}, \text { ref (control-test }\right)}}
$$

In this equation, 'target' refers to the target genes, or the germination genes in the case of this experiment, and 'reference' refers to the reference gene, or rrnE$16 \mathrm{~s}$ in this experiment. The 'control' refers to the control treatment: the heat shocked spores incubated for $120 \mathrm{~min}$. The results are shown in Table 4.6 and Figure 4.12. Of particular note, are the ratios calculated for the relative expression of the GerAC gene on B. subtilis and for SleB on B. licheniformis at the 0 min treatment. These values show an expression that is hundreds of times higher than the control treatment, while having $\mathrm{C}_{\mathrm{T}}$ values which are considerably larger than the control treatment. This incongruity would need to corrected with repetitive experiments; preferably, with higher template concentrations that would yield lower $\mathrm{C}_{T}$ values and a more accurate representation of relative gene expression at this treatment level. The ratio values for the different treatments are shown relative to the control group $(R=1)$ in Figure 4.12--excluding those for the GerAC gene on $B$. subtilis and for SleB on $B$. licheniformis at the Omin treatment, since their accuracy is questionable. 
Table 4.6 Mean $\mathrm{C}_{\mathrm{T}}$ values and calculated Ratios for relative gene expression of the treatments of $B$. subtilis and $B$. licheniformis. The ratio is a comparison to the control $(120 \mathrm{~min})$ treatment.

\begin{tabular}{|c|c|c|c|}
\hline Sample Name & Target Name & $\mathbf{C}_{\boldsymbol{T}}$ Mean & Ratio* $^{*}$ \\
\hline B.subtilis 0min & rnnE-16s (ref) & 32.19521713 & -- \\
\hline B.subtilis 30min & rnnE-16s (ref) & 13.88511181 & -- \\
\hline B.subtilis 60min & rnnE-16s (ref) & 13.50222301 & -- \\
\hline B.subtilis 120min & rnnE-16s (ref) & 12.59861469 & -- \\
\hline B. licheniformis 0min & rnnE-16s (ref) & 32.27990723 & -- \\
\hline B. licheniformis 30min & rnnE-16s (ref) & 16.11261177 & -- \\
\hline B. licheniformis 60min & rnnE-16s (ref) & 12.12410355 & -- \\
\hline B. licheniformis 120min & rnnE-16s (ref) & 11.24506474 & -- \\
\hline B.subtilis 0min & GerAC & 35.00172043 & 372.135702 \\
\hline B.subtilis 30min & GerAC & 30.80378151 & 0.132899182 \\
\hline B.subtilis 60min & GerAC & 29.10375404 & 0.511634374 \\
\hline B.subtilis 120min & GerAC & 27.76582336 & 1 \\
\hline B. licheniformis 0min & GerAC & Undetermined & -- \\
\hline B. licheniformis 30min & GerAC & 33.79566574 & 0.14102034 \\
\hline B. licheniformis 60min & GerAC & 27.92178917 & 0.759694933 \\
\hline B. licheniformis 120min & GerAC & 26.75312233 & 1 \\
\hline B. licheniformis 0min & SleB & 36.90638733 & 421.7508144 \\
\hline B. licheniformis 30min & SleB & 33.08751297 & 0.149710145 \\
\hline B. licheniformis 60min & SleB & 27.85214233 & 1.013475873 \\
\hline B. licheniformis 120min & SleB & 27.18047523 & 1 \\
\hline B. licheniformis 0min & GPR & Undetermined & -- \\
\hline B. licheniformis 30min & GPR & 35.57197189 & 0.006729986 \\
\hline B. licheniformis 60min & GPR & 28.79077721 & 0.765344416 \\
\hline B. licheniformis 120min & GPR & 27.99373627 & 1 \\
\hline
\end{tabular}

${ }^{*}$ Calculated using the Pfaffl Method (Pfaffl, 2001) 


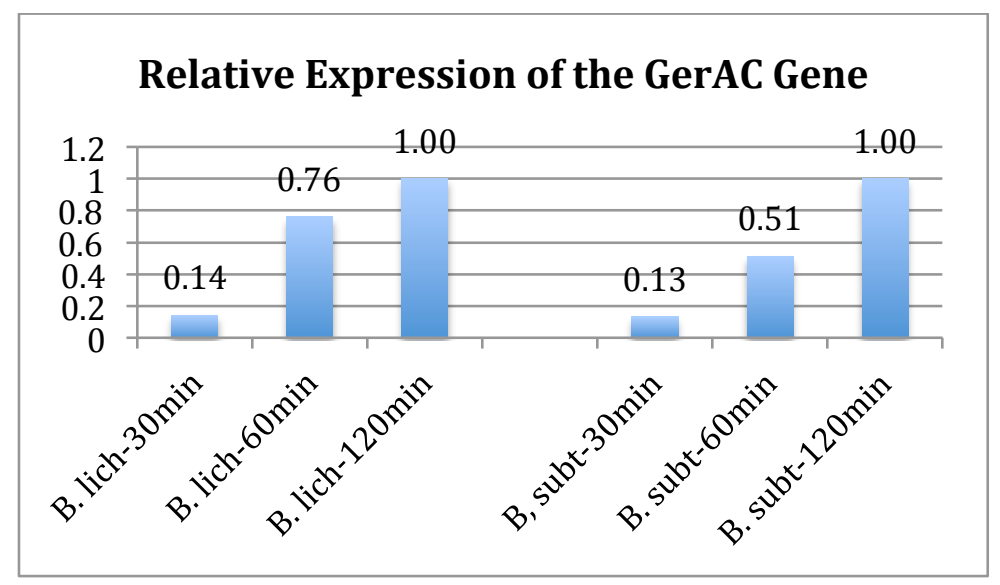

(A)

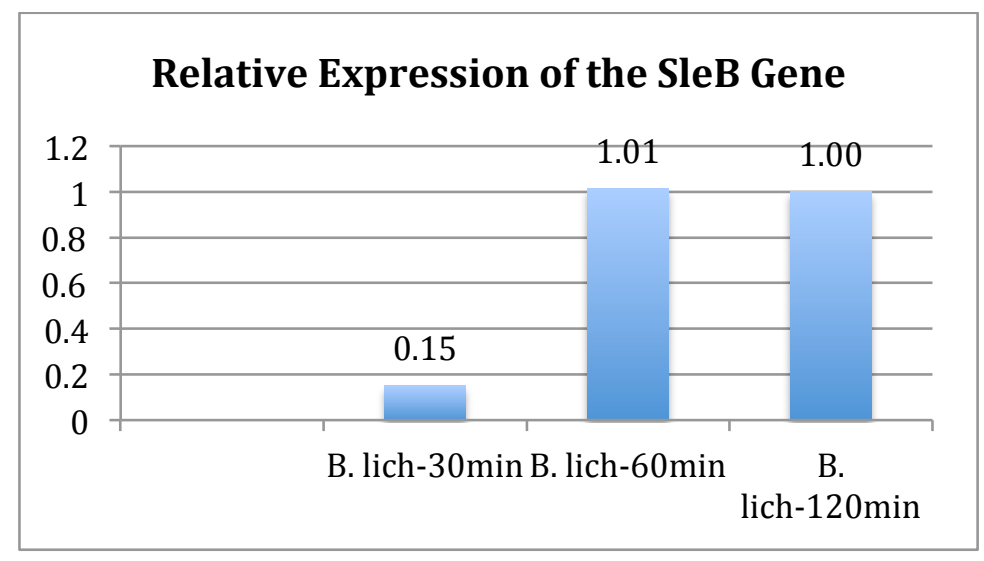

(B)

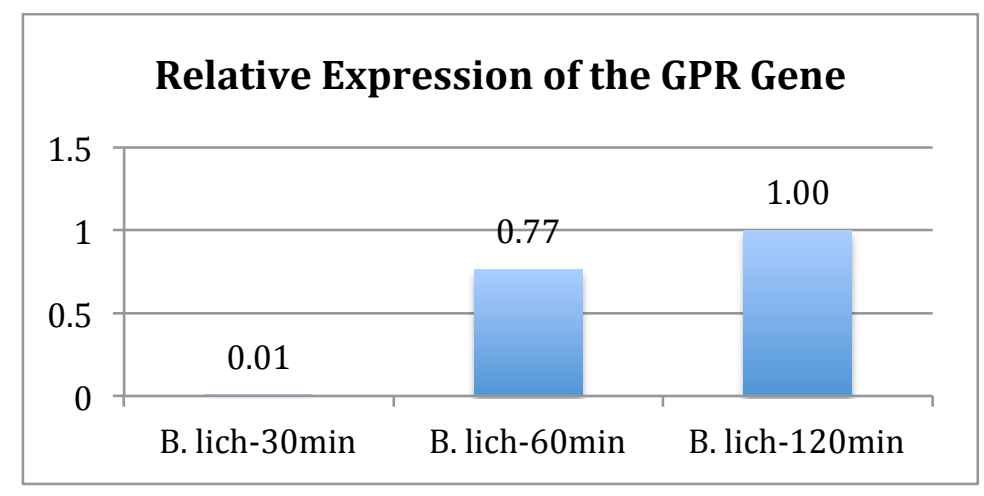

(C)

Figure 4.12 Ratio of the gene expression of the test treatment to the control treatment plotted according to test treatment. Values less than one correlate to a relative expression that is lower than the control $(R=1)$, while values greater than one correlate to a higher relative expression. (A) The relative of expression of the GerAC gene over the different test treatments; $(B)$ the relative expression of SleB; and (C) the relative expression of GPR 


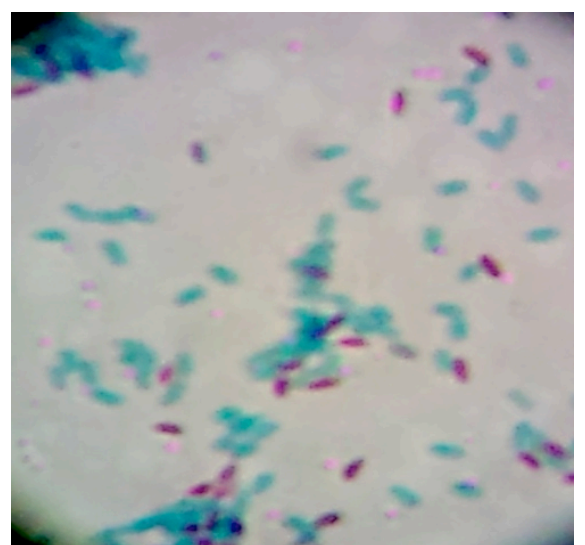

(A)

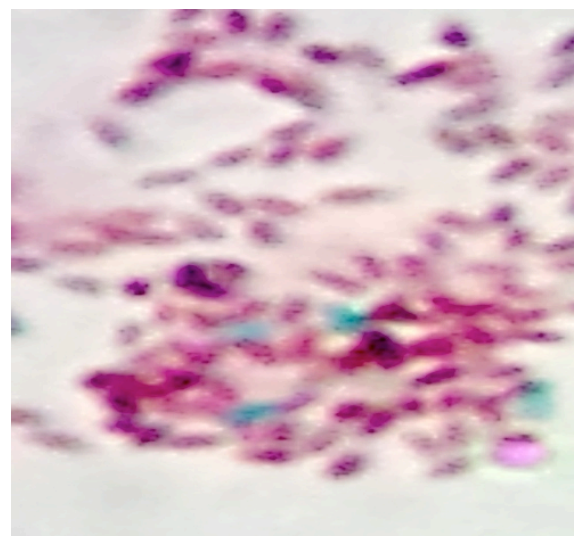

(C)

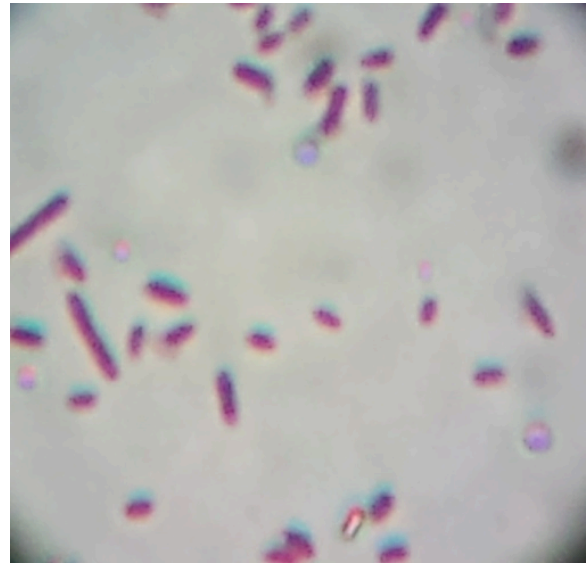

$(\mathrm{E})$

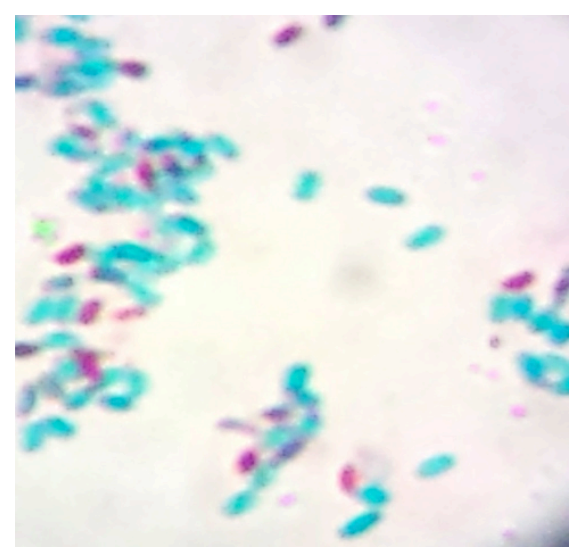

(B)

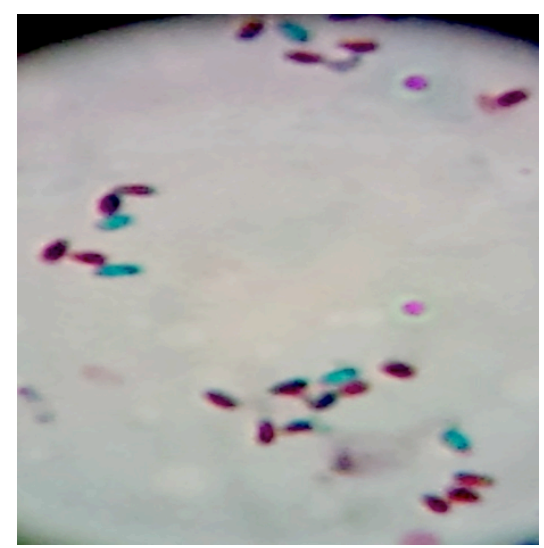

(D)

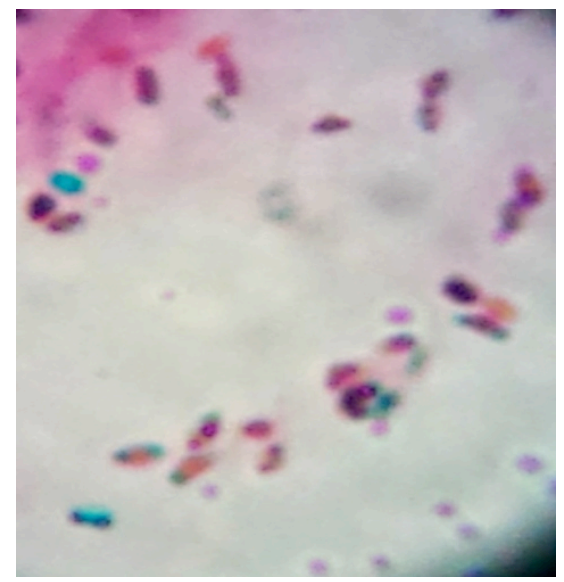

$(\mathrm{F})$

Figure $4.13100 x--S p o r e$ differential staining using a $5 \% \mathrm{w} / \mathrm{v}$ malachite green solution. Spores are stained green, while the vegetative cells are stained red/pink. (A), (C), and (E) are $B$. licheniformis; (B), (D), and (F) are B. subitlis; $(A)$ and $(B)$ are heat shocked and incubated for $30 \mathrm{~min} ;(C)$ and $(D)$ are heat shocked and incubated for $60 \mathrm{~min}$; and $(E)$ and $(F)$ are incubated for 120 min. 
For each gene, the level of expression appears to be increasing with an increase in incubation time. Although the trend is similar across the different genes, the level of expression for each treatment between genes varies. This difference is visibly noticeable at the $60 \mathrm{~min}$ treatment, and would be an interesting place to investigate the variability in expression level between these different germination genes.

The expression of these genes reflects the visual observation of these two Bacillus species. Especially in the case of $B$. subtilis, the treatments were all within the lag phase; however, viable cells were seen as early as $30 \mathrm{~min}$ into incubation, and germination genes were already expressing. Also of note, the GerAC gene of both $B$. subtilis and $B$. licheniformis showed similar relative gene expression although they had significantly different lengths of lag phase. The suggestion that GerAC is involved in the first steps of phase I of germination, or initiation, could explain why is it already equally expressed in both species, even though the rates at which the rest of the germination takes place may differ between the two.

Not all of the spores will commit to germination at the same time; the act of initiation (in which the involvement of GerAC is crucial) may have several minutes of lag for each individual spore. A population of spores will take many minutes to go through the germination phase (Setlow, 2003). This would result in the increase in relative gene expression to be attributed to the increase in the 
number of spores committing to germination rather than an increase in expression in the organism as incubation time increases. This theory could be investigated with repeated qPCR assays of different times within the lag phase along with the ratio of spores to vegetative cells at those times. With these values, a statistical approach could identify whether a significant interaction between the two factors exists.

The SleB gene on $B$. licheniformis exhibits the most change between the $30 \mathrm{~min}$ and 60min treatment (a 0.85 point increase in relative gene expression)-a change that is also visually significant. Figure 4.13 (C) and (D) show the $60 \mathrm{~min}$ treatment for both species; and a majority of the spores have completed germination, or at least lost their spore coat. Loss of the spore coat means a gain in vulnerability and ideally, mortality when subjected to high heat or UV. If the 60 min time limit is the maximum amount of time to wait in a processing application for germination of a majority of the spores, the SleB may be worth looking at more closely since is seems to match the dramatic increase in sporecoat loss shown in Figure 4.13. 


\section{CHAPTER 5 CONCLUSION AND FUTURE RESEARCH}

Utilization of qPCR in the enumeration and identification of endospore formers is not a novel technique. Rueckert et al (2006) carried out successful amplification using the spoOA gene. This assay was rapid ( $\leq 1 \mathrm{hr}$ of lab time) and able to enumerate thermophilic endospore formers; however, it was not specific enough to the individual species of thermophilic endospore formers and so could not be successfully used to profile the different species that would be found in milk powder.

This study focused on the germination of mesophilic endospore formers and relative expression of the genes associated with germination. First came the observation and comparison of the growth curves of Bacillus licheniformis and Bacillus subtilis. The significant difference in lag time of these two organisms has implications for the milk powder process, as they represent a majority of spore formers found in milk. Rate of germination of these two species would provide a great deal of relevant information about the life cycle of these two spores if compared in conjunction. Further attempts to create a functional germination assay for these specific organisms will provide a lot more insight when coupled with relative gene expression.

The results of this study demonstrate increasing levels of expression of the GerAC, SleB, and gpr genes as the lag phase progresses. It would be beneficial to optimize this assay in order to validate such a hypothesis. Steps for 
optimization would include: re-designing primers that are specific and do not give two dissociation curves, increasing the mRNA and subsequent cDNA concentrations through higher population numbers of the organisms themselves or by a RNA purification protocol that isolates more RNA. As seen in Figure 4.5, some of the primer sets work for both species. The primers that were originally designed for $B$. licheniformis can be applied to $B$. subtilis cDNA in a verification assay to assess reaction efficiency as well as the dissociation curve.

It may also be important to verify that the ratio of relative expression is increasing over the course of the lag phase because of an increase in expression rather than an increase in organisms beginning expression. Evaluating the results of the reference gene should do this, as the expression should be the same if the population stays the same. However, if the reference gene expresses the same in spores as viable cells, than the latter situation is a possibility and the dormancy and resistance of spores with low levels of relative gene expression should be tested. If resistance to wet-heat has decreased enough to terminate the germinating spores, then an increase in relative expression due to an increase in the population that is expressing is an important piece of information to know. By optimizing and verifying this assay for a pure solution of only two species of spores, an investigation into the applications of such a technique become practical next steps. The milk powder process increases the complexity due to a change in the environmental factors the spores experience, as well the diversity in spore-former population that exists in a processing plant. This research 
provides a foundation to not only develop an optimized assay for quantifying relative expression of germination genes, but also to applying it to the milk powder process in a way that decreases counts in the final product. Including a heat "pulse" to initiate germination followed by a secondary "kill step" similar to pasteurization when the spores are viable cells would be a possible implementation. This increase in product quality will provide economic benefits to the United States Dairy Industry, and even improve food safety if the assay can be reapplied to pathogenic spore-formers and other (food and non-food processing) environments. 


\section{BIBLIOGRAPHY}

Applied Biosystems. 2011. Real Time PCR: Understanding Ct. Application Note

Behravan, J., H. Chirakkal, A. Masson, and A. Moir. 2000. Mutations in the gerP locus of Bacillus subtilis and Bacillus cereus affect access of germinants to their targets in spores. Journal of bacteriology 182.7: 1987-1994. doi: 10.1128/JB.182.7.1987-1994.2000

Burgess, S. A., J.D. Brooks, J, Rakonjac, K. M. Walker, and S. H. Flint. 2009. The formation of spores in biofilms of Anoxybacillus flavithermus. Journal of applied microbiology 107.3: 1012-1018. doi: 10.1111/j.13652672.2009.04282.x

Burgess, S. A., D. Lindsay, and S. H. Flint. 2010. Thermophilic bacilli and their importance in dairy processing. Int. J. Food Microbiol. 144.2: 215-225.

Christiansson, A., J. Bertilsson, and B. Svensson. 1999. Bacillus cereus Spores in Raw Milk: Factors Affecting the Contamination of Milk During the Grazing Period. J. Dairy Sci. 82.2: 305-314.

Cowan, A. E., D. E. Koppel, B. Setlow, and P. Setlow. 2003. A soluble protein is immobile in dormant spores of Bacillus subtilis but is mobile in germinated spores: implications for spore dormancy. Proc. Natl. Acad. Sci.

USA 100.7: 4209-4214. doi: 10.1073/pnas.0636762100

Corfe, B. M., R. L. Sammons, D. A. Smith, and C. Mauel. 1994. The gerB region of the Bacillus subtilis 168 chromosome encodes a homologue of the gerA spore germination operon. Microbiology 140.3: 471-478.

Faille, C., F. Fontaine, and T. Bénézech. 2001. Potential occurrence of adhering living Bacillus spores in milk product processing lines. Journal of Applied Microbiology 90.6: 892-900.

Feavers, I. M., J. S. Miles, and A. Moir. 1985. The nucleotide sequence of a spore germination gene (gerA) of Bacillus subtilis 168. Gene 38.1: 95-102

Flint, S., J. L. Drocourt, K. Walker, B. Stevenson, M. Dwyer, I. Clarke, and D. McGill. 2006. A rapid, two-hour method for the enumeration of total viable bacteria in samples from commercial milk powder and whey protein concentrate powder manufacturing plants. Int. Dairy J. 16.4: 379-384.

Flint, S., K. Walker, B. Waters, and R. Crawford. 2007. Description and validation of a rapid $(1 \mathrm{~h})$ flow cytometry test for enumerating thermophilic bacteria in milk powders. Journal of applied microbiology. 102.4: 909-915. 
Foster, S. J., and K. Johnstone. 1990. Pulling the trigger: the mechanism of bacterial spore germination. Molecular microbiology 4.1: 137-141.

Gould, G. W. 2006. History of science-spores. Journal of applied microbiology 101.3: 507-513.

Hong, H. A., E. To, S. Fakhry, L. Baccigalupi, E. Ricca, and S. M. Cutting. 2009. Defining the natural habitat of Bacillus spore-formers. Research in microbiology 160.6: 375-379. Doi: 10.1016/j.resmic.2009.06.006

Jordan, S., A. Junker, J.D. Helmann and T, Mascher. 2006. Regulation of LiarRS-dependent gene expression in Bacillus subtilis: Identification of inhibitor proteins, regulator binding sites, and target genes of a conserved cell envelope stress-sensing two-component system. J. Bacteriol.188.14: 5153-5166. Doi: 10.1128/JB.00310-06

Hudson, K. D., B. M. Corfe, E. H. Kemp, I. M. Feavers, P. J. Coote, and A. Moir. 2001. Localization of GerAA and GerAC germination proteins in the Bacillus subtilis spore. Journal of bacteriology 183.14: 4317-4322. Doi: 10.1128/JB.183.14.4317-4322.2001

Kunst, F., N. Ogasawara, I. Moszer, A. M. Albertini, G. Alloni, V. Azevedo, M. G., Bertero, P. Bessieres, A. Bolotin, S. Borchert, R. Borriss, and et al. 1997. The complete genome sequence of the gram-positive bacterium Bacillus subtilis. Nature 390.6657: 249-256.

Leggett, M. J., G. Mcdonnell, S. P. Denyer, P. Setlow, and J. Maillard. 2012. Bacterial spore structures and their protective role in biocide resistance. Journal of applied microbiology 113.3: 485-498.

Moir, A., E. Lafferty, and D. A. Smith. 1979. Genetic analysis of spore germination mutants of Bacillus subtilis 168: the correlation of phenotype with map location. J. Gen. Microbiol. 111.1: 165-180.

Moir, A. 1981. Germination properties of a spore coat-defective mutant of Bacillus subtilis. Journal of bacteriology 146.3: 1106-1116.

Moir, A., and D. A. Smith. 1990. The genetics of bacterial spore germination. Annual Reviews in Microbiology 44.1: 531-553.

Moir, A., B. M. Corfe, and J. Behravan. 2002. Spore germination. Cellular and Molecular Life Sciences CMLS 59.3: 403-409.

Moir, A. 2006. How do spores germinate? Journal of applied microbiology 101.3: 526-530.

Nicholson, W. L., N. Munakata, G. Horneck, H. J. Melosh and P. Setlow. 2000. 
Resistance of Bacillus endospores to extreme terrestrial and extraterrestrial environments. Microbiology and Molecular Biology Reviews 64.3: 548-572.

Nicholson, W. L., A. C. Schuerger, and P. Setlow. 2005. The solar UV environment and bacterial spore UV resistance: considerations for Earthto-Mars transport by natural processes and human spaceflight. Mutation Research/Fundamental and Molecular Mechanisms of Mutagenesis 571.1: 249-264.

Paidhungat, M. and P. Setlow. 2000. Role of Ger proteins in nutrient and nonnutrient triggering of spore germination in Bacillus subtilis. Journal of Bacteriology 182.9: 2513-2519.

Paidhungat, M., and P. Setlow. 2002. Spore germination and outgrowth. Bacillus subtilis and its relatives: from genes to cells. American Society for Microbiology, Washington, DC: 537-548.

Pfaffl, M. W. 2001. A new mathematical model for relative quantification in real time RT-PCR. Nucleic acids research 29.9: e45-e45.

Postollec, F., A-G. Mathot, M. Bernard, M-L. Divanac'h, S. Pavan, and D. Sohier. 2012. Tracking spore-forming bacteria in food: from natural biodiversity to selection by processes." Int. J. Food Microbiol. 158.1: 1-8.

Rode, L.J. and J. W. Foster. 1961. Germination of bacterial spores with alkyl primary amines. Journal of Bacteriology 81, 768-779.

Rueckert, A., R.S. Rominus, and H.W. Morgan. 2004. A RAPD-based survey of thermophilic bacilli in milk powders from different countries. Int. J. Food Microbiol. 96: 263-272.

Rueckert, A., R. S. Ronimus, and H. W. Morgan. 2005a. Rapid differentiation and enumeration of the total, viable vegetative cell and spore content of thermophilic bacilli in milk powders with reference to Anoxybacillus flavithermus. Journal of applied microbiology 99.5: 1246-1255.

Rueckert, A., R. S. Ronimus, and H. W. Morgan. 2005b. Development of a rapid detection and enumeration method for thermophilic bacilli in milk powders. Journal of microbiological methods 60.2: 155-167.

Rueckert, A., R. S. Ronimus, and H. W. Morgan. 2006. Development of a real time PCR assay targeting the sporulation gene, spo0A, for the enumeration of thermophilic bacilli in milk powder. Food microbiology 23.3: 220-230. 
Sammons, R. L., A. Moir, and D. A. Smith. 1981. Isolation and properties of spore germination mutants of Bacillus subtilis 168 deficient in the initiation of germination. J. Gen. Microbiol. 124.2: 229-241.

Setlow, B., E. Melly, and P. Setlow. 2001. Properties of spores of Bacillus subtilis blocked at an intermediate stage in spore germination. Journal of bacteriology 183.16: 4894-4899.

Setlow, P. 1995. Mechanisms for the prevention of damage to DNA in spores of Bacillus species. Annual Reviews in Microbiology 49.1: 29-54.

Setlow, P. 2003. Spore germination. Current opinion in microbiology 6.6: 550 556.

Setlow, P. 2006. Spores of Bacillus subtilis: their resistance to and killing by radiation, heat and chemicals. Journal of applied microbiology 101.3: 514525.

Setlow, P. 2012. Resistance of bacterial spores to chemical agents. Pages 121 130 in Russel, Hugo and Ayliffe's Principles and Practices of Disinfection, Preservation and Sterilization. $5^{\text {th }}$ ed. A. Fraise, J. Maillard and S. Sattar, ed. John Wiley \& Sons Ltd. West Sussex, UK.

Stoodley, P, K. Sauer, D. G. Davies, and J. W. Costerton. 2002. Biofilms as complex differentiated communities. Annual Reviews in Microbiology 56.1: 187-209.

Thackray, P. D., J. Behravan, T. W. Southworth and A. Moir. 2001. GerN, an antiporter homologue important in germination of Bacillus cereus endospores. Journal of bacteriology 183.2: 476-482.

Tovar-Rojo, F., M. Chander, B. Setlow, and P. Setlow. 2002. The products of the spoVA operon are involved in dipicolinic acid uptake into developing spores of Bacillus subtilis. Journal of bacteriology 184.2: 584-587.

Vaerewijck, M. J. M., P. De Vos, L. Lebbe, P. Scheldeman, B. Hoste, and M. Heyndrickx. 2001. Occurrence of Bacillus sporothermodurans and other aerobic spore-forming species in feed concentrate for dairy cattle. Journal of applied microbiology 91.6: 1074-1084.

Warth, A. D. 1980. Heat stability of Bacillus cereus enzymes within spores and in extracts. Journal of bacteriology 143.1: 27-34.

Weller, G. R., B. Kysela, R. Roy, L. M. Tonkin, E. Scanlan, M. Della, S. K. Devine, J. P. Day, A. Wilkinson, K. M. Devine, R. P. Bowater, P. A. Jeggo, S. P. Jackson, and A. J. Doherty. 2002. Identification of a DNA 
nonhomologous end-joining complex in bacteria. Science 297.5587: 16861689.

Zuberi, A. R., A. Moir, and I. M. Feavers. 1987. The nucleotide sequence and gene organization of the gerA spore germination operon of Bacillus subtilis 168. Gene 51.1: 1-11. 


\section{APPENDIX A \\ STATISTICAL ANALYSIS OF LAG PHASE}

Lag Time as the Response Variable with Species and Dilution as Effects

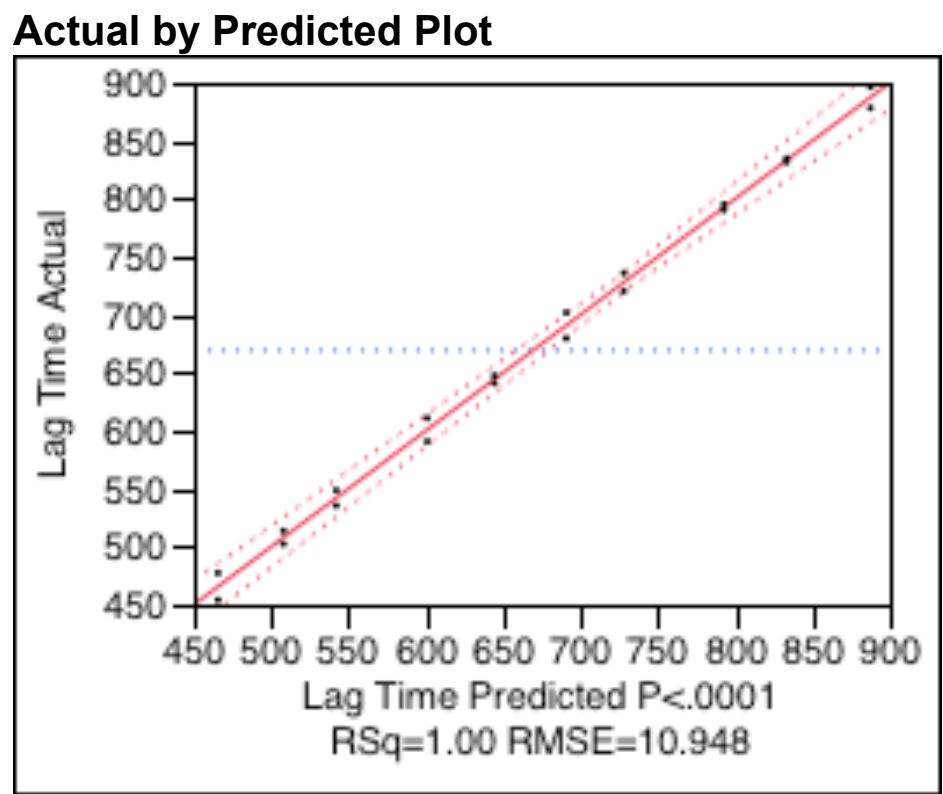

\section{Summary of Fit}

RSquare

RSquare Adj

Root Mean Square Error

Mean of Response

Observations (or Sum Wgts)
0.99673

0.993787

10.94797

669.3055

20

\section{Analysis of Variance}

Source DF

$\begin{array}{lrr} & & \begin{array}{r}\text { Squares } \\ \text { Model }\end{array} \\ \text { Error } & 10 & 365330.88 \\ \text { C. Total } & 19 & 366529.46\end{array}$

$\begin{array}{rr}\text { Mean Square } & \text { F Ratio } \\ 40592.3 & 338.6703 \\ 119.9 & \begin{array}{r}\text { Prob }>\text { F } \\ <.0001^{*}\end{array}\end{array}$

\section{Parameter Estimates}

Term

Intercept

Dilution[0]

Dilution[1]

Dilution[2]

Dilution[3]

Species[Blich]

Dilution[0] ${ }^{*}$ Species[Blich]

$\begin{array}{rrrr}\text { Estimate } & \text { Std Error } & \mathbf{t} \text { Ratio } & \text { Prob }>|\mathbf{t}| \\ 669.3055 & 2.448039 & 273.40 & <.0001^{*} \\ 191.067 & 4.896079 & 39.02 & <.0001^{*} \\ 91.0795 & 4.896079 & 18.60 & <.0001^{*} \\ -1.7605 & 4.896079 & -0.36 & 0.7266 \\ -97.848 & 4.896079 & -19.98 & <.0001^{*} \\ -26.6525 & 2.448039 & -10.89 & <.0001^{*} \\ -0.48 & 4.896079 & -0.10 & 0.9238\end{array}$


Term

Dilution[1] ${ }^{*}$ Species[Blich]

Dilution[2] ${ }^{*}$ Species[Blich]

Dilution[3] ${ }^{*}$ Species[Blich]
Estimate Std Error $\mathbf{t}$ Ratio Prob $>|\mathbf{t}|$

$\begin{array}{llll}-5.6425 & 4.896079 & -1.15 & 0.2759\end{array}$

$\begin{array}{llll}3.4125 & 4.896079 & 0.70 & 0.5017\end{array}$

$\begin{array}{llll}-2.77 & 4.896079 & -0.57 & 0.5840\end{array}$

Effect Tests

Source

$\begin{array}{rrrrr}\text { Nparm } & \text { DF } & \begin{array}{r}\text { Sum of } \\ \text { Squares }\end{array} & \text { F Ratio } & \text { Prob > F } \\ 4 & 4 & 350798.10 & 731.6956 & <.0001^{*} \\ 1 & 1 & 14207.12 & 118.5329 & <.0001^{*} \\ 4 & 4 & 325.67 & 0.6793 & 0.6218\end{array}$

Dilution

Species

Dilution*Species

\section{Residual by Predicted Plot}

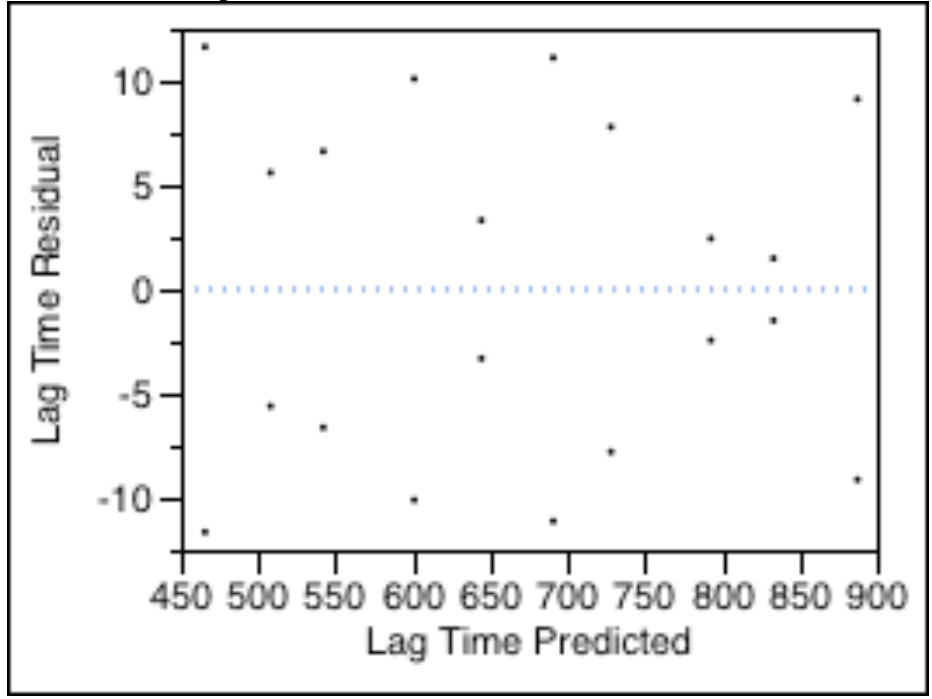


Lag time ratios as the response with species and dilutions as the effects (no interactions)

\section{Actual by Predicted Plot}

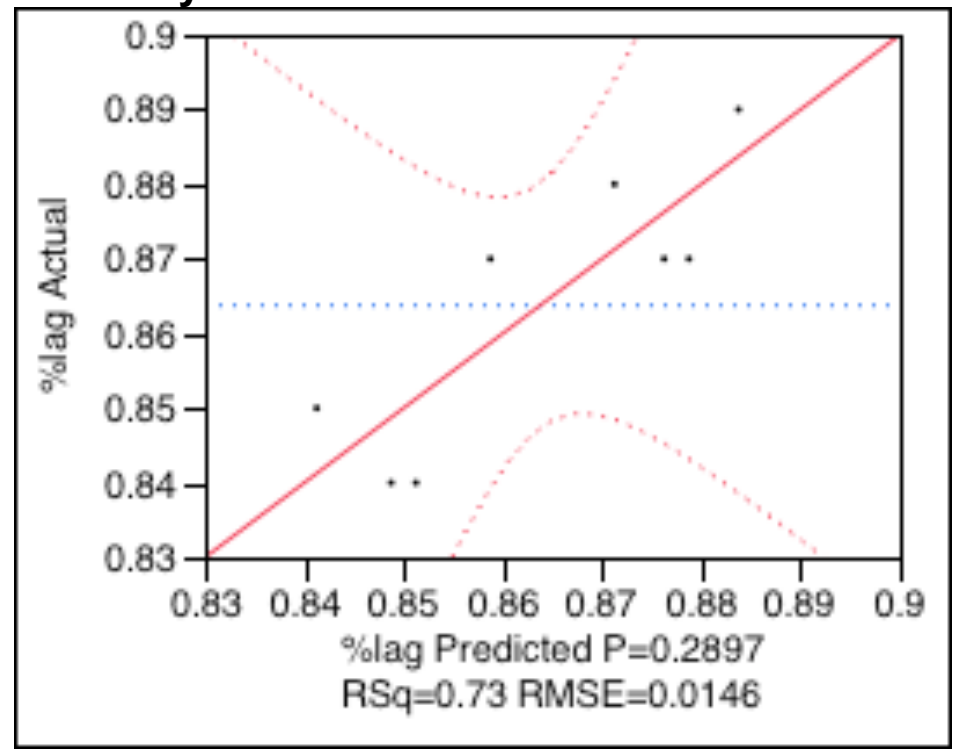

\section{Summary of Fit}

RSquare

RSquare Adj

Root Mean Square Error

Mean of Response

Observations (or Sum Wgts)
0.732984

0.376963

0.014577

0.86375

8

\section{Analysis of Variance}

$\begin{array}{lrrrr}\text { Source } & \text { DF } & \begin{array}{r}\text { Sum of } \\ \text { Squares }\end{array} & \text { Mean Square } & \text { F Ratio } \\ \text { Model } & 4 & 0.00175000 & 0.000438 & 2.0588 \\ \text { Error } & 3 & 0.00063750 & 0.000213 & \text { Prob > F } \\ \text { C. Total } & 7 & 0.00238750 & & 0.2897\end{array}$

\section{Parameter Estimates}

Term

Intercept

Species[Blicheniformis]

Dilution[1:0]

Dilution[2:1]

Dilution[3:2]

\section{Estimate}

0.86375

0.00375

0.01625

0.01125

$-0.00875$

Effect Tests

Source Nparm DF

Sum of
Std Error

0.005154

0.005154

0.008927

0.008927

0.008927 t Ratio

167.59

0.73

1.82

1.26

$-0.98$
Prob $>|\mathbf{t}|$

$<.0001^{*}$

0.5195

0.1663

0.2967

0.3993

F Ratio Prob > F Squares 
Source Nparm DF Sum of F Ratio Prob $>$ F

$\begin{array}{lllrll} & & & \text { Squares } & & \\ \text { Species } & 1 & 1 & 0.00011250 & 0.5294 & 0.5195\end{array}$

$\begin{array}{llllll}\text { Dilution } & 3 & 3 & 0.00163750 & 2.5686 & 0.2295\end{array}$

\section{Residual by Predicted Plot}

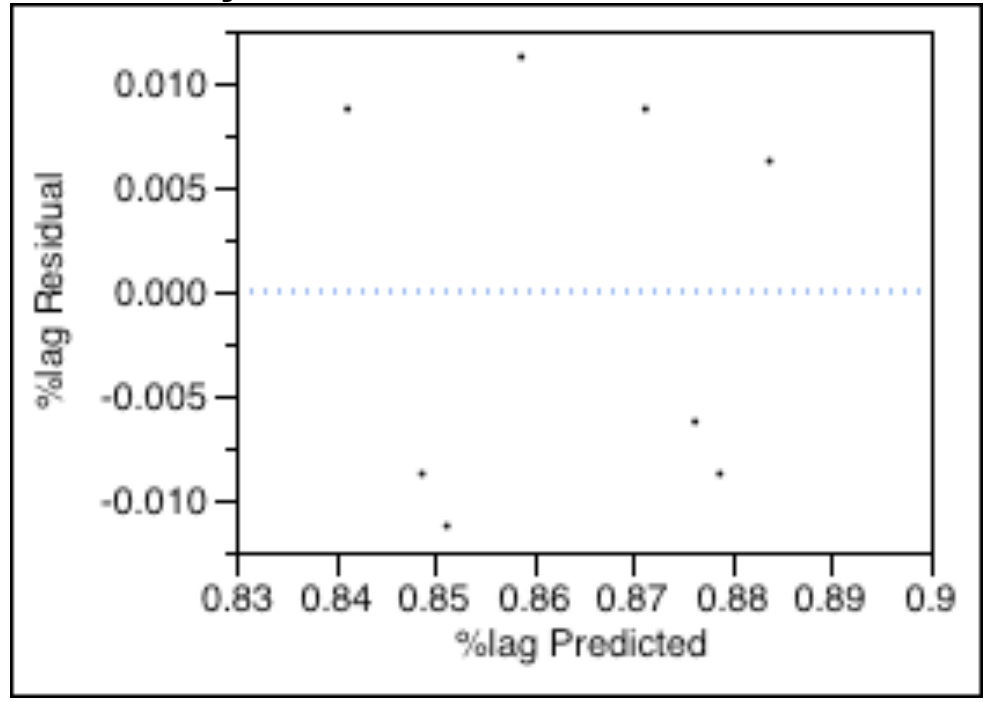

\section{Species}

Leverage Plot

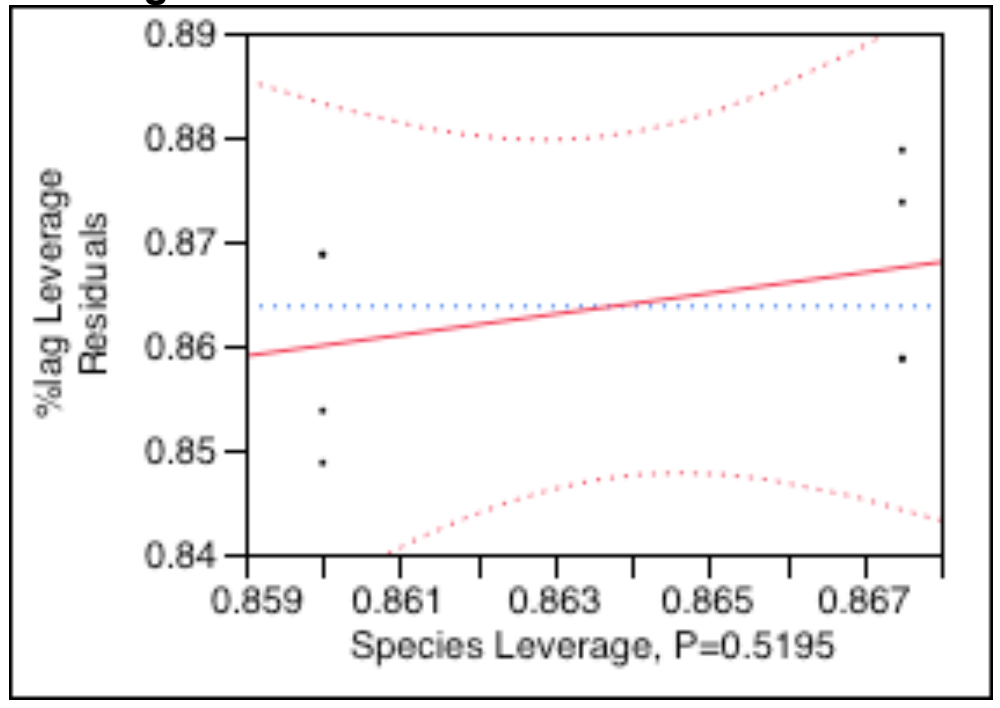

\section{Least Squares Means Table} Level

Std Error Mean

Blicheniformis Mean

Bsubtilis 0.86750000

0.00728869

0.867500

0.007288690 .860000




\section{Dilution}

Leverage Plot

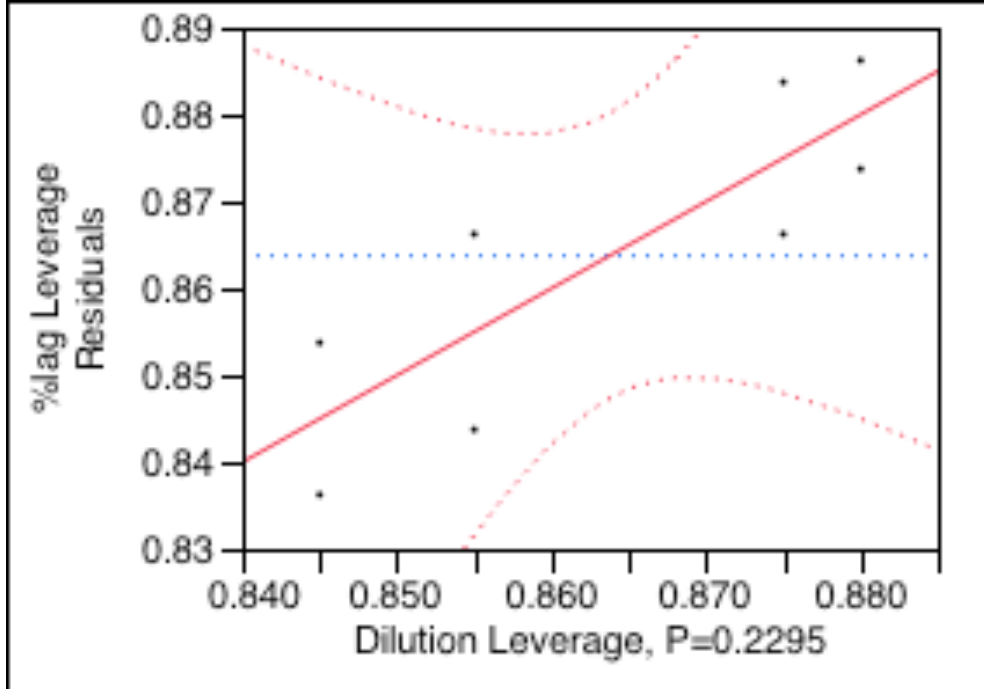

Least Squares Means Table

$\begin{array}{lrrr}\text { Level } & \begin{array}{r}\text { Least Sq } \\ \text { Mean }\end{array} & \text { Std Error } & \text { Mean } \\ & & \\ 1: 0 & 0.88000000 & 0.01030776 & 0.880000 \\ 2: 1 & 0.87500000 & 0.01030776 & 0.875000 \\ 3: 2 & 0.85500000 & 0.01030776 & 0.855000 \\ 4: 3 & 0.84500000 & 0.01030776 & 0.845000\end{array}$




\section{APPENDIX B \\ ADDITIONAL STANDARD CURVES AND DISSOCIATION CURVES FOR \\ EACH PRIMER SET \\ Melt Curve}

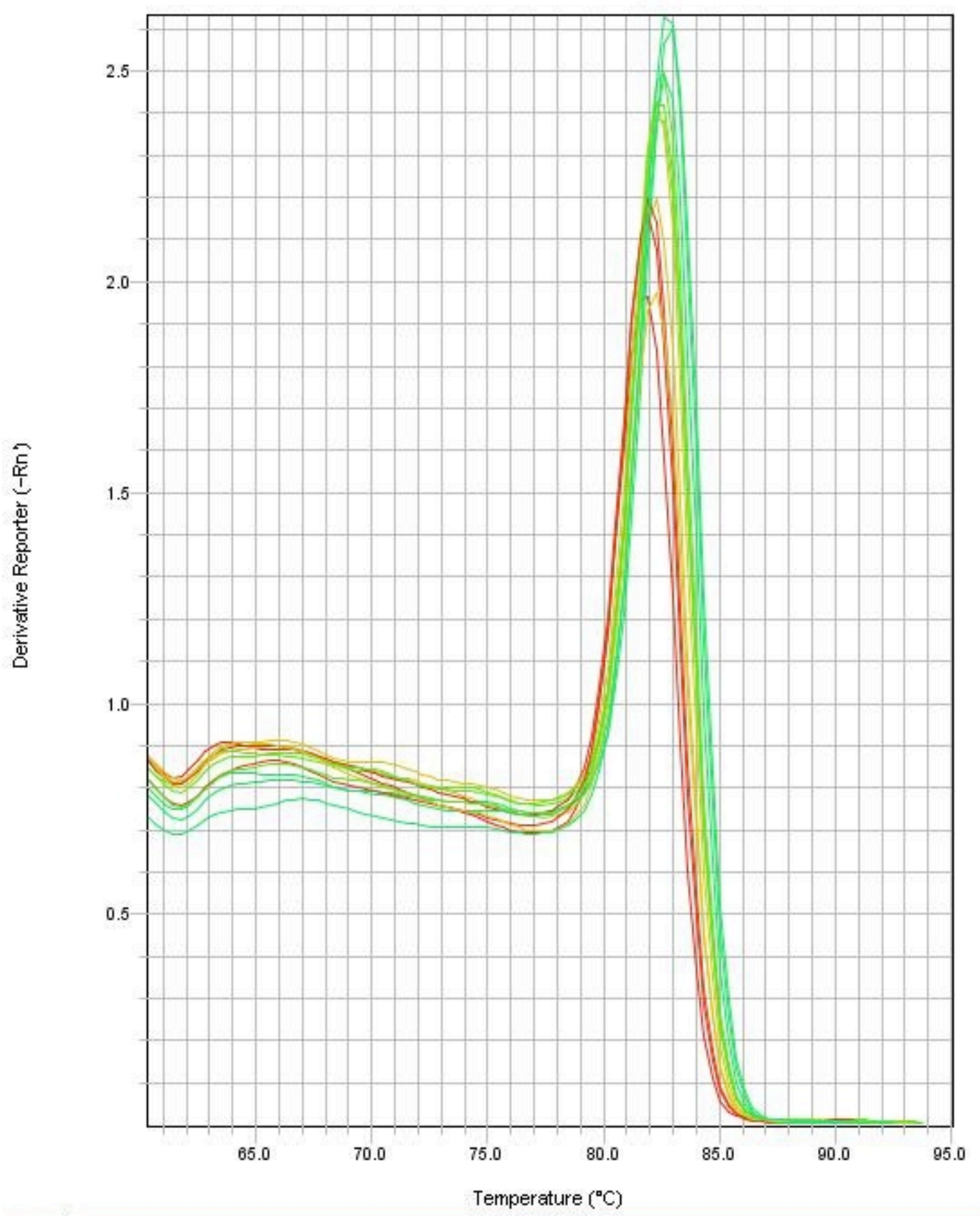

Figure A. Dissociation curve for primers targeting the gpr gene on B. licheniformis 


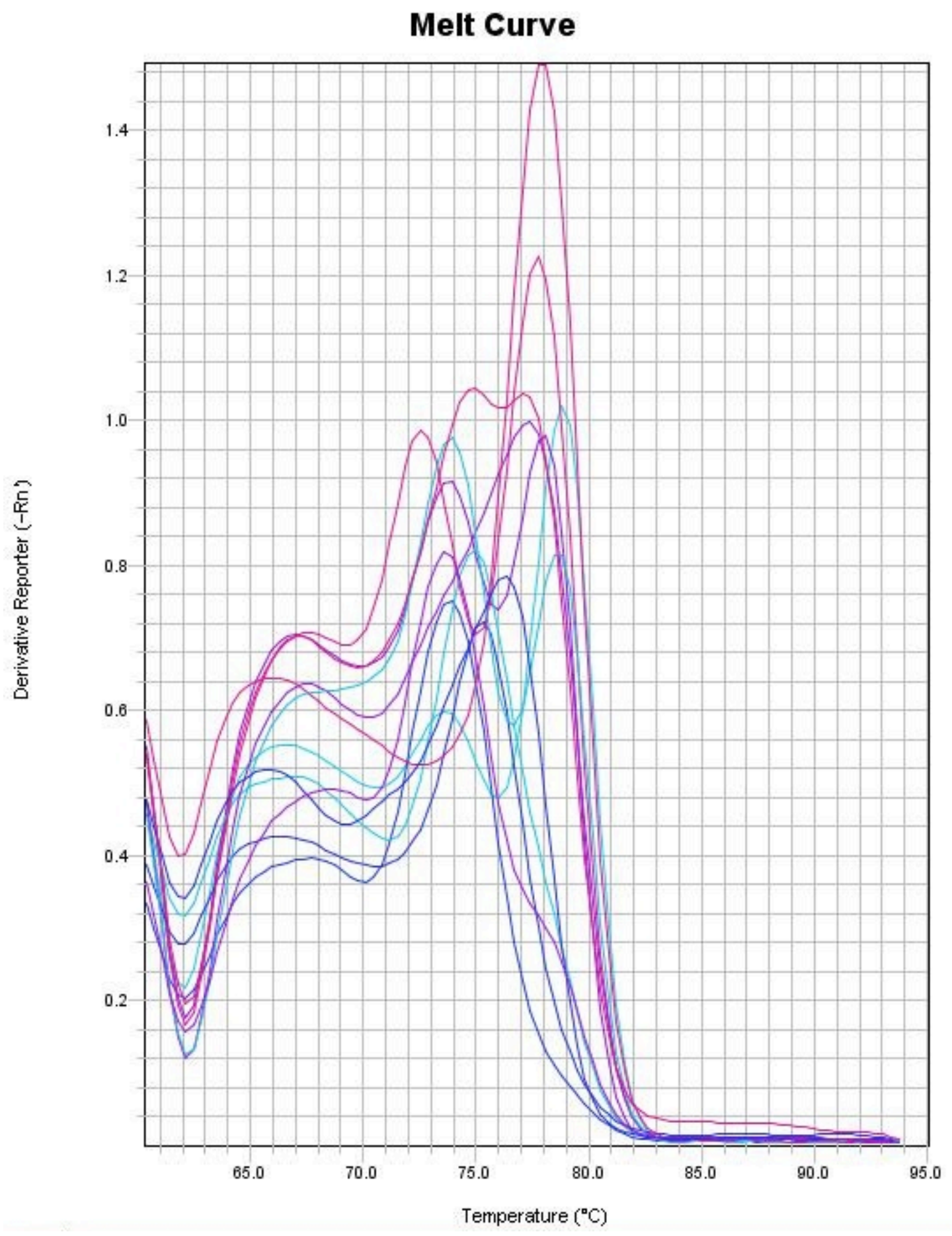

Figure B. Dissociation Curve for primers targeting the gpr gene on B. subtilis 


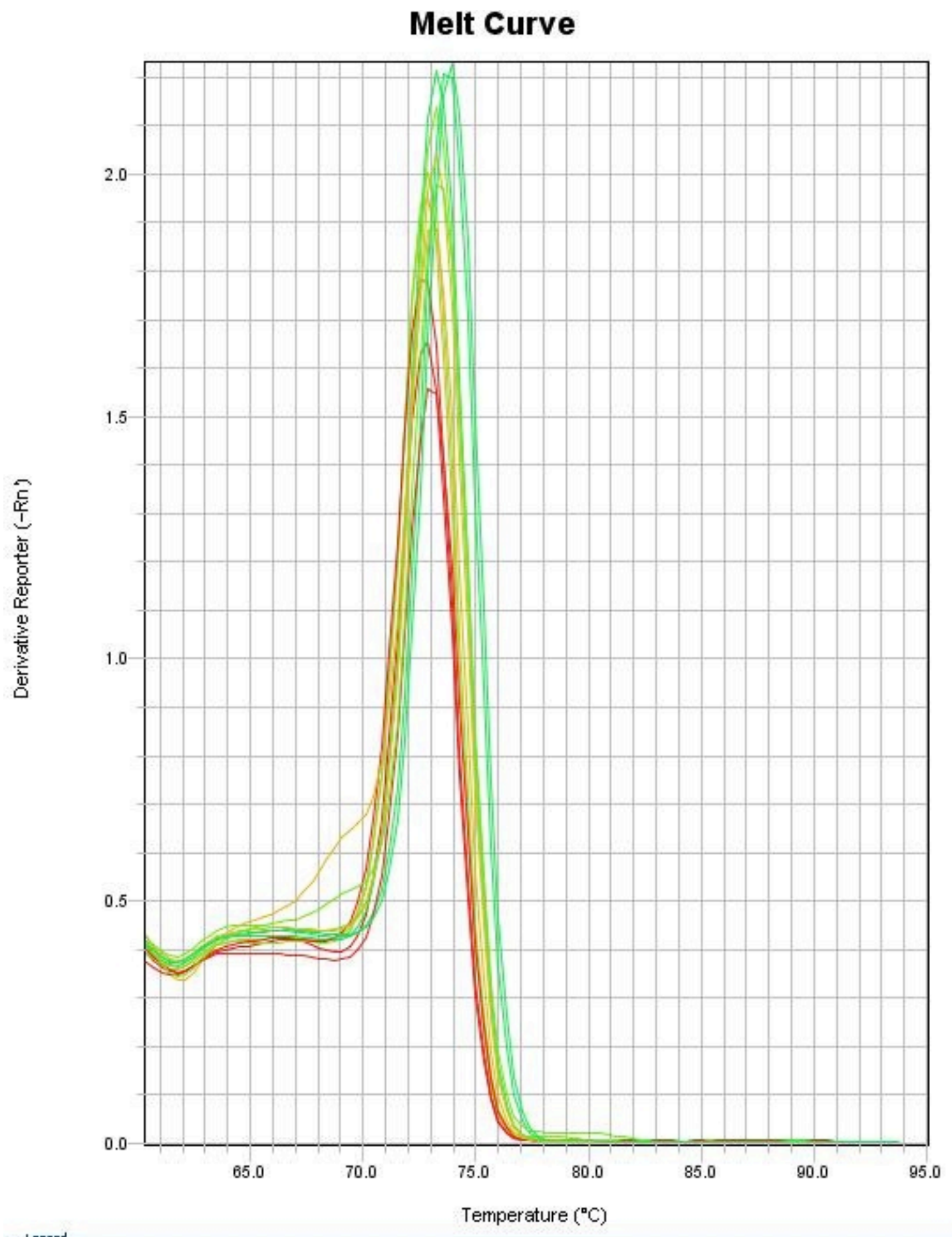

Figure C. Dissociation curve for primers targeting the SleB gene on $B$. licheniformis 


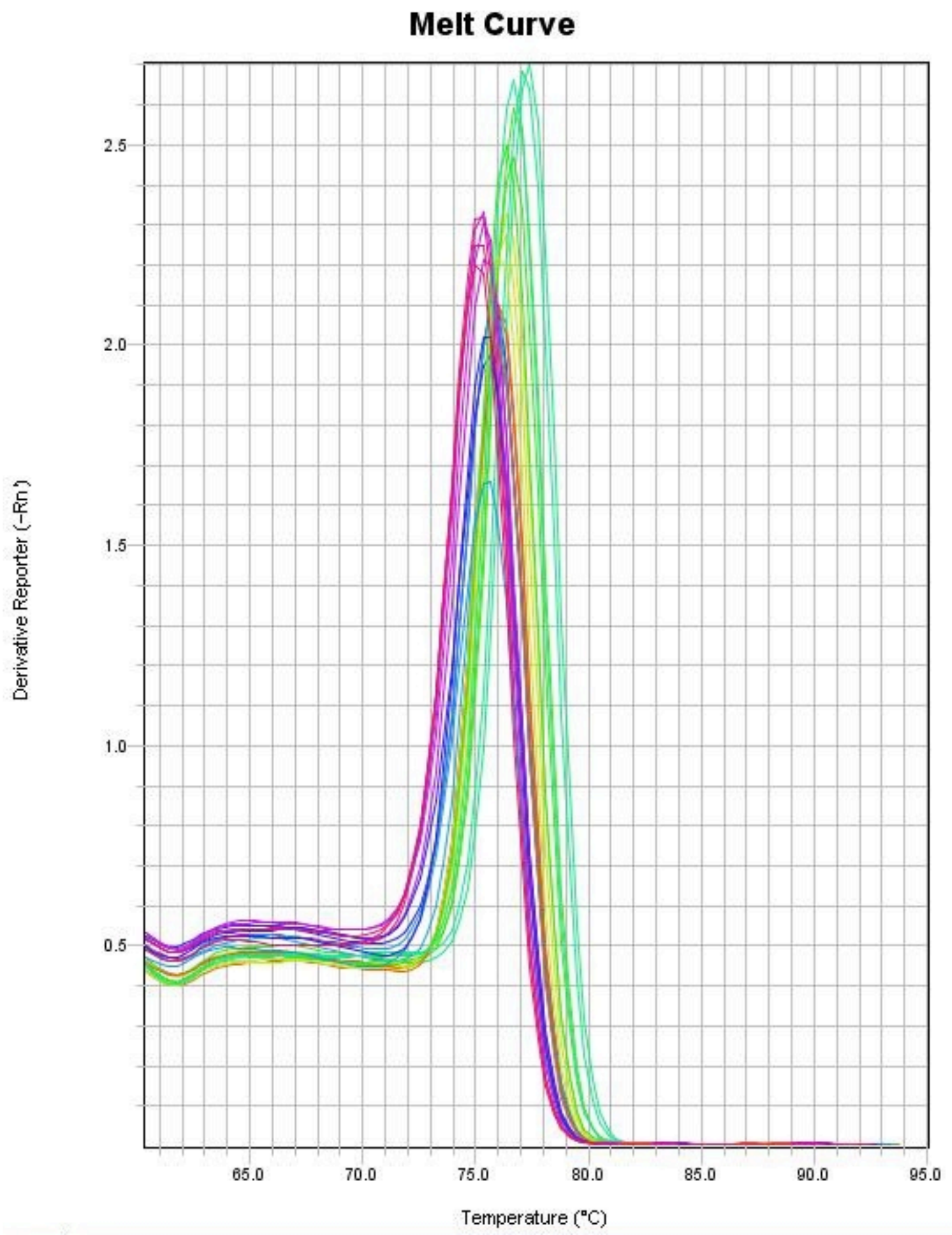

Figure D. Dissociation curve for primers targeting the GerAC gene on $B$. licheniformis (green and yellow curves) and on $B$. subtilis (blue and purple curves). 


\section{APPENDIX C AMPLIFICATION PLOTS}

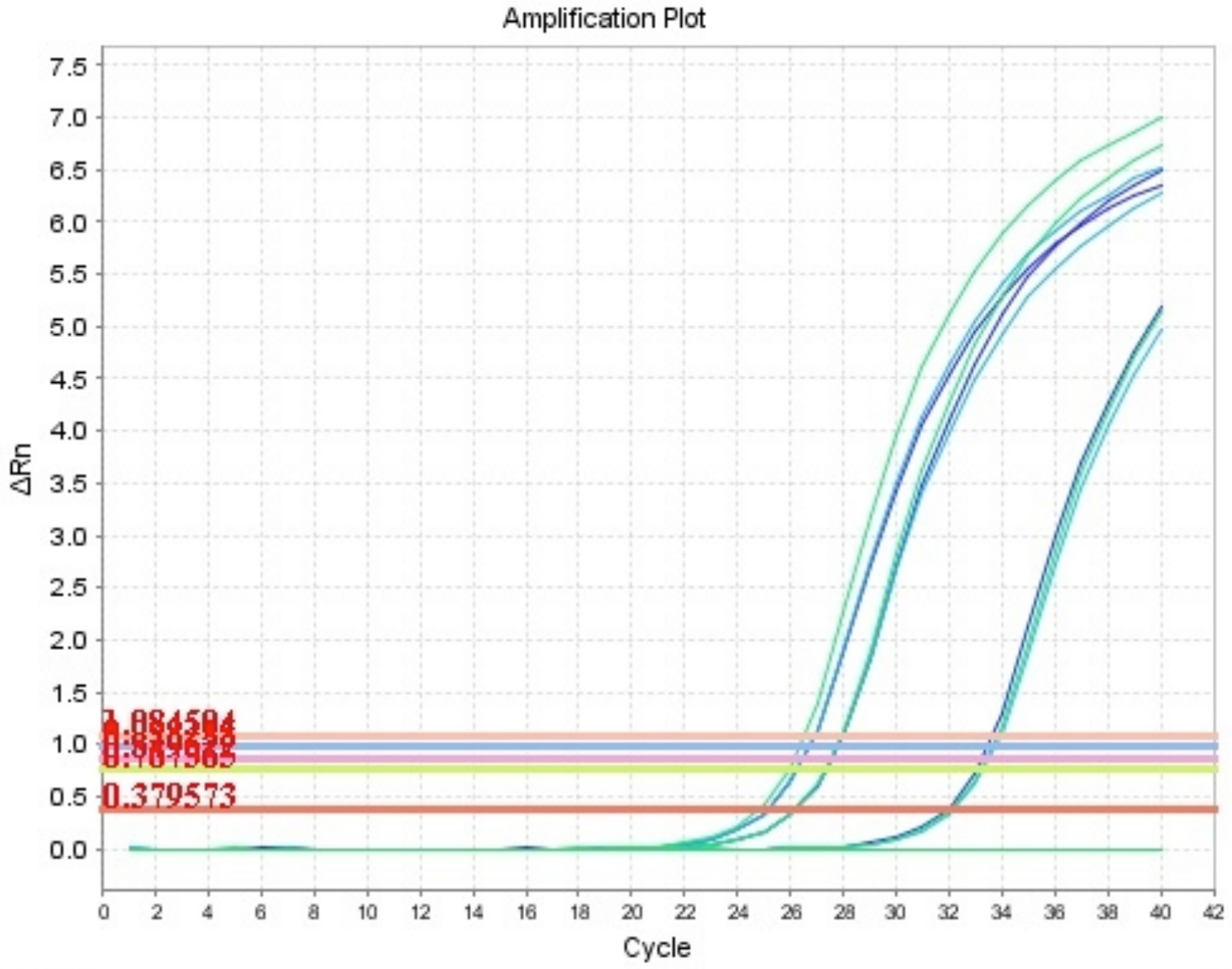

Figure E. Amplification plot for primers targeting the GerAC gene on B. licheniformis. Each line represents a triplicate of the 4 different treatments. 


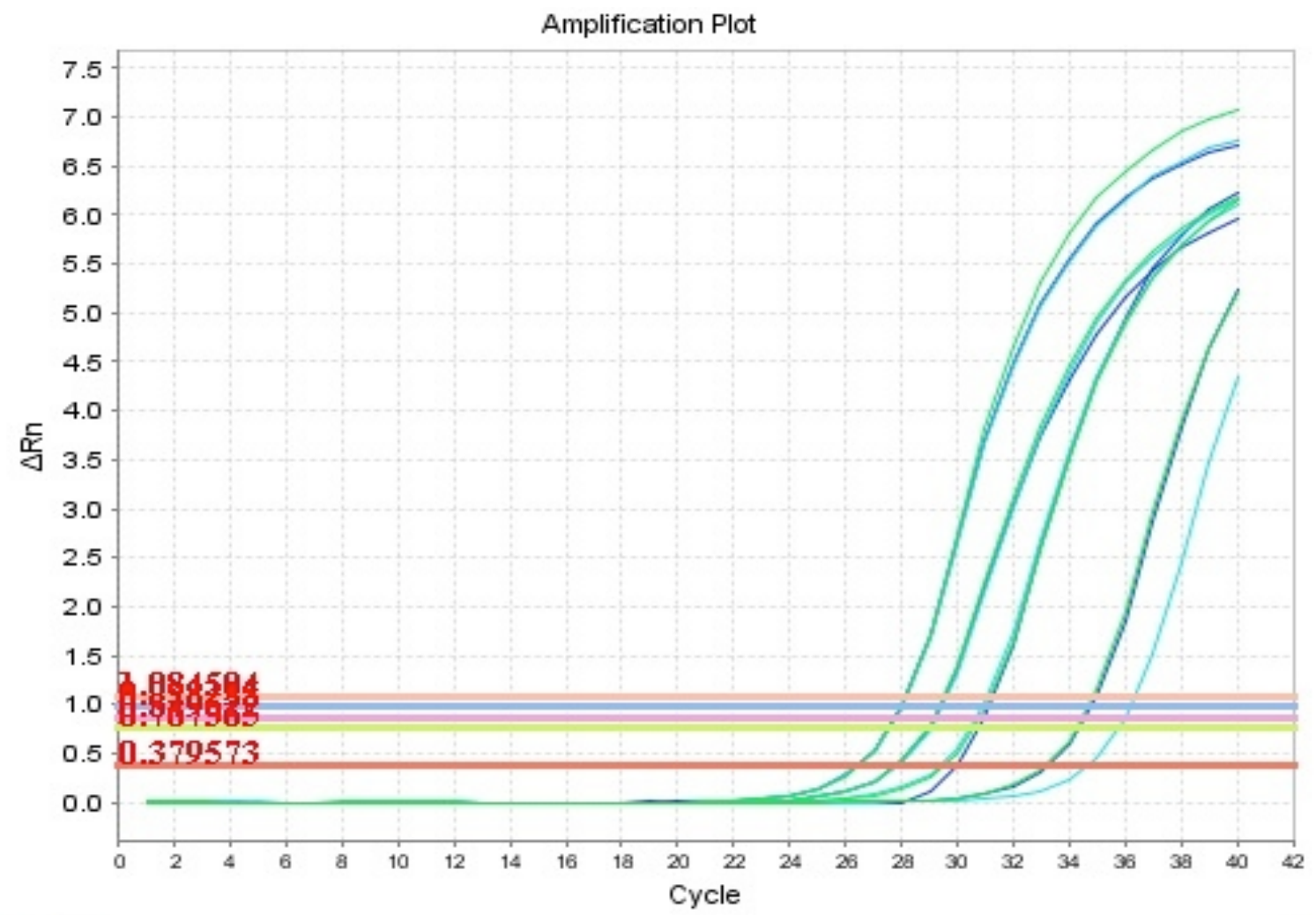

Figure F. Amplification plot for primers targeting the GerAC gene on B. subtilis. Each line represents a triplicate of the 4 different treatments. 